الاغتراب الزواجى كما تدركه الزوجة وعلاقته بكلٍ من كفاءتها الإنتاجية فى أداء المهام المنزلية والرهاب

\title{
الاجتماعى لأبنائها
}

حنان حنا عزيز '

والرهاب الاجتماعى لأبنائهن المراهقين. عدم وجود فروق بين

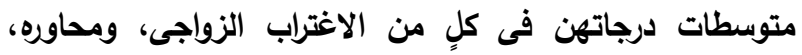
والإجمالى، وكفاءتهن الإتتاجية، ومحاورها، والإجمالى تبعاً لمكان

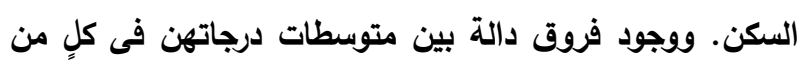

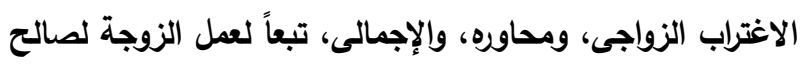

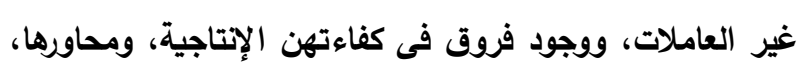

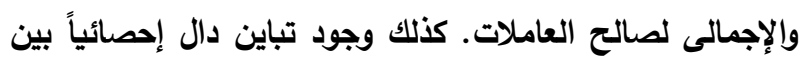
متوسطات درجاتهن فى الاغتراب الزواجى بحداوره، والإجمالى

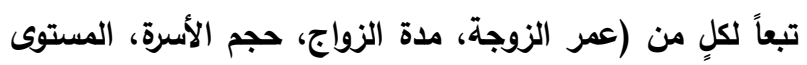

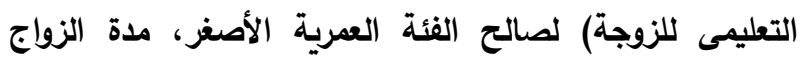
الأقل، حجم الأسرة الأكبر، المستوى التعليمى المنذفض للزئل للزوجة.

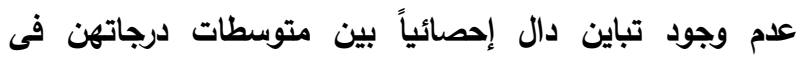

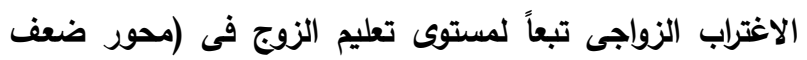

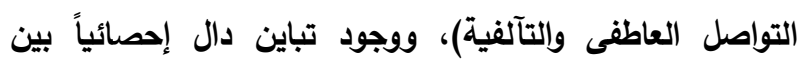
متوسطات درجاتهن فى الكفاءة الإتاجية في أداء التهاء المهام

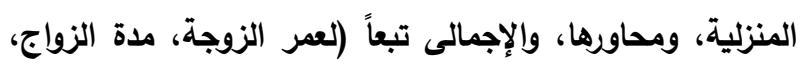

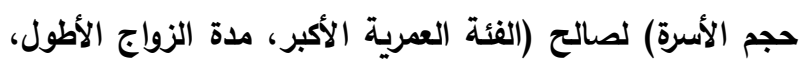

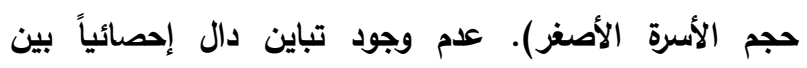
متوسطات درجاتهن فى محور (الرضا عن أداء المهام المنزلية)

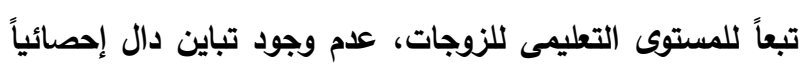
بين متوسطات درجاتهن فى محورى (الرغبة، الرضا) في ألداء

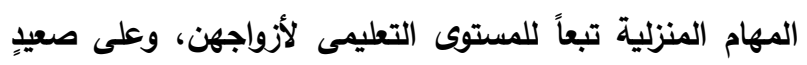

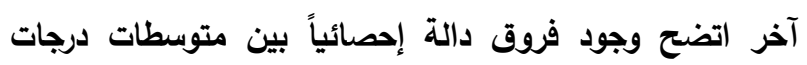

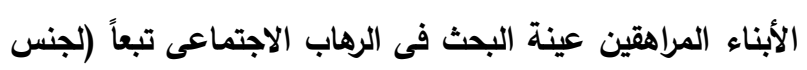

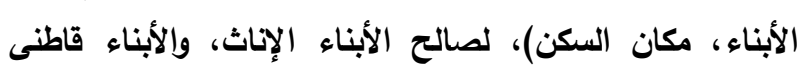

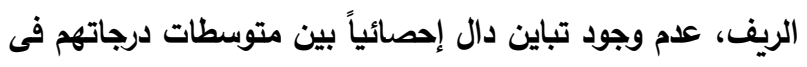

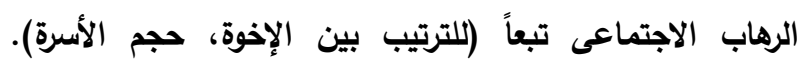
ووجود تباين دال إحصائياً بين متوسطات درجاتهم فى الرهاب

الملخص العربى

استهاف البحث الحالى الكثف عن العلاقة بين الاغتراب

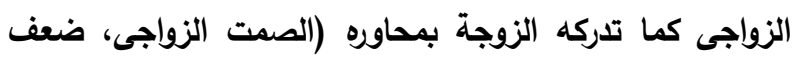

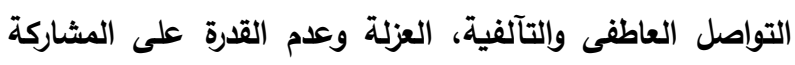

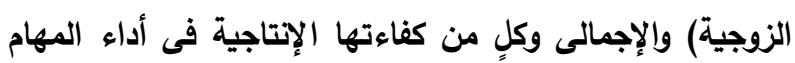

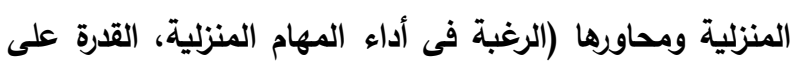

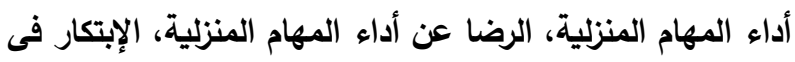

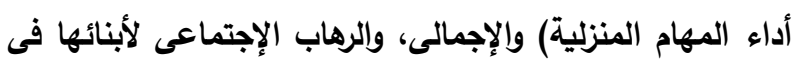

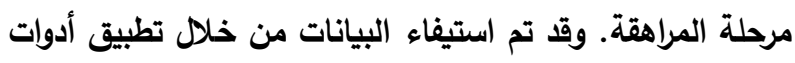
البحث (من إعاد الباحثة) والمتمثلة فى (إستمارة البيانات

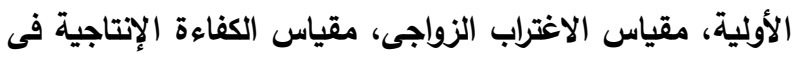

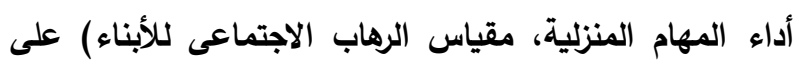

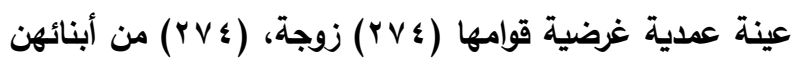
المراهقين ممن ينتمون إلى مستويات اجتماعية واقتصادية

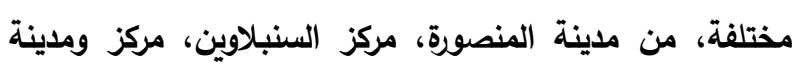

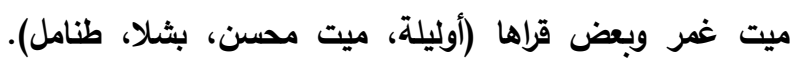

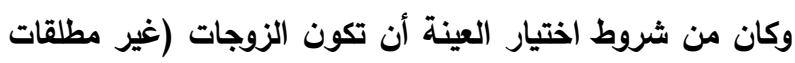

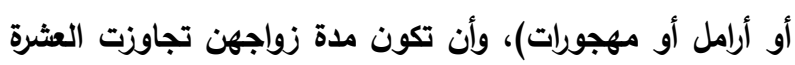

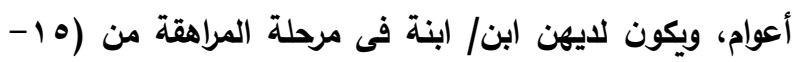

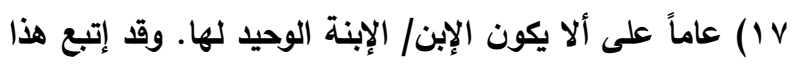

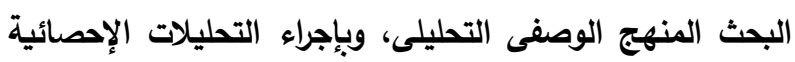
المناسبة باستخام برنامج SPSS لاستخلاص النتائج. أسفر النجاء

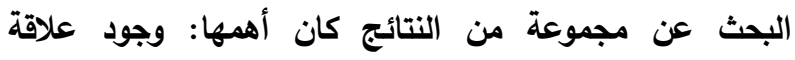

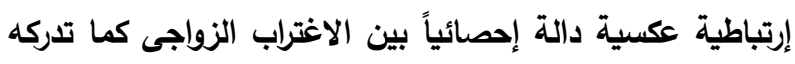
الزوجات عينة البحث بحداوره، والإجمالى، وكفاءتهن الإنتاجية

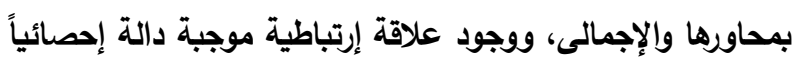
بين الاغتراب الزواجى بمحاوره والإجمالى للزوجات عينة البحث

\footnotetext{
'أستاذ مساعد تخصص إدارة منزل - قسم الاقتصاد المنزلى - كلية التربية النوعية - جامعة المنصورة 


$$
\text { مجلة الإسكندرية للتبادل العلمى - (مجلد \& العدد () يناير - مارس IY.r }
$$

وإنسجام كلٍ منهما مع الآخر لحل المشكلات الأسرية التى

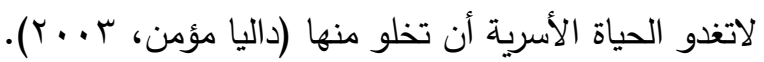
كما يُعد الزواج من أهم ركائز الصحة النفسية للزوجين؛ وذلك لإثباعه العديد من الحاجات والدوافع التى يصعب

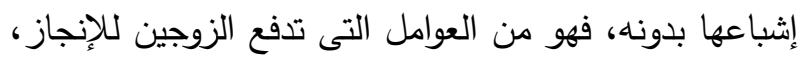
والقدرة على التجديد والإبتكار فى مجالات العمل المختلفة (عبد الله محمود، ج + . ب). وبقدر وجود التوافق الزواجى بين الزوجين بقدر قوتهم وصلابتهم وزيادة إنتاجهم فى المجتمع، والعكس صحيح كلما غاب التوافق بين الزوجين يظهر التباعد ولردي والاغتراب، ويصبح عدم التواصل هو السائد (فاتتة ديبه،

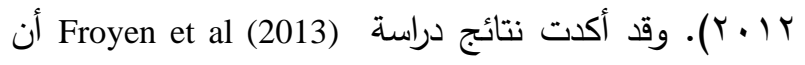
التواصل العاطفى يلعب دوراً هاما فى استقرار الحياة الزوجية، وتحقيق الإنسجام بين الزوجين. وذلك كونه يُمثل الدعم والحافز لكلٍ من الزوجين على استمرار العلاقة بينهما ونجاحها، وبدونه يحدث جفاء وإغتراب بين الزوجين (أسماء

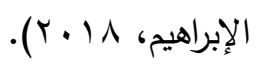

وتعتبر مشكلة الاغتراب الزواجى من المشكلات المهمة

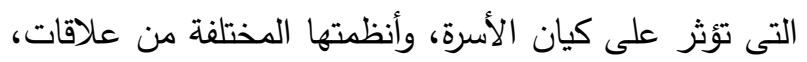
وتقاعلات، وإتصالات، وتعاون، ومشاركة، وإنتماء ويُمكن القول أن الاغتراب الزواجى يجعل الأسرة كالقوقعة الفارغة

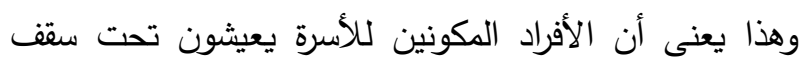
واحد لكنهم يفشلون فى علاقاتهم، وتفاعلاتهم معاً ( ممدوح

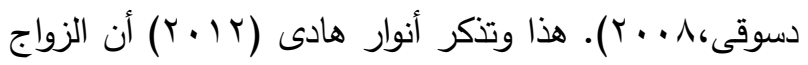
لاينهار بين ليلة وضحاها، فالاغتراب الزواجى لا يحدث بسبب حادثة أو خطأ لأحد الزوجين وإنما تمتد المشاكل والخلافات على مدار عدة سنوات تؤدى إلى هذه الظاهرة فى لى النهاية. وقد أشار محمد خطاب (1) (1) أن الاغتراب الزواجى ما هو إلا مرحلة متقدمة من الطلاق العاطفى، وهو يُمثل المظلة الرئيسية التى تحوى بداخلها مجموعة من الأعراض التى تتبئ بوجوده كإنعدام التفاعل والتحاور، والمشاركة
الاجتماعى تبعاً (للمستوى التعليمى للأم، المستوى التعليمى للأب، مستوى الاخل الثهرى للأسرة) لصالح الأبناء المراهقين

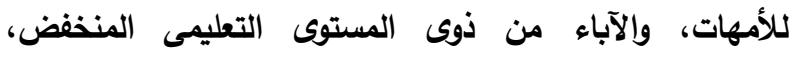
ومستوى الاخل الثهرى المنخفض. وفى ضوء النتائج السابقة اقترحت الباحثة عدداً من التوصيات: - مساهمة وسائل الإعلام فى تقديم برامج حوارية تثقيفية، وذلك بإستضافة أساتذة متخصصين فى مجال علم النفس، والإرشاد الأسرى؛ لتبصير الأزواج بماهية كلٍ من من الأن الاغتراب الزواجى، واضطراب الرهاب الاجتماعى والآثار السلبية لكلٍ منهما.- إعداد برامج إرشادية من قِبل الجهات المابط المعنية بالمرأة (كالمجلس القومى للمرأة، ومكاتب التوجيه والإستشارات الأسرية) لتوعية الأزواج، والمقبلين على الزواج بأسس ومقومات الحياة الزوجية السليمة الناجحة، وكيفية إدارة المشاكل. إطلاق قوافل إرشادية من قِبل الجمعيات الأهلية، والحكومية الخاصة بالمرأة تقوم من خلالها رائدات الجمعية، والمساعدات بتبصير الزوجات، والمقبلات على الزواج بسبل تحقيق الكفاءة الإنتاجية فى أداء الأعمال المنزلية وذلك للنهوض بكات بكفاءتهن (كماً، وكيفاً) مما يكون له عظيم الأثر على الأسرة وبالتالى لأله

\section{المجتمع.}

الكلمات المفتاحية: الاغتراب الزواجى - الكفاءة الإنتاجية -

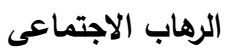

\section{المقدمة والمشكلة البحثية}

يُعد الزواج من أقدس العلاقات الإنسانية فى حياة البشر ؛ إذ به يرتبط الرجل بالمرأة برباط مشروع مقدس لبناء

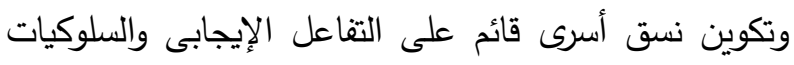
المتوافقة (كلثوم بلميهوب، • r)، كذلك قائم على التواصل الثرى الفعال على كافة المستويات الفكرية، والعاطفية، والنغسية، والجسدية (محمد طعبلى، سميرة عمامرة، ع ( ب). وعليه فإن نجاح أى علاقة زوجية ومايناط بها من أدوار ومسؤليات يتوقف بالدرجة الأولى على مستوى التقاعل والمشاركة بين الزوجين، وحصول كل منهما على مطالبه، وتوفير الظروف التى تساعد الطرف الآخر على تحقيق ذاته، 
ضعف التواصل العاطفى، والمشاعر السلبية، والنزاعات الأمر الذى يؤثر على أدائهم وإنتاجيتهم فى مختلف الدجالات، وتتحول المسؤليات المتعلقة بالزوج والزوجة إلى مسؤليات فردية مما يجعل الأسرة فى حالة اضطراب وعدم توازن.

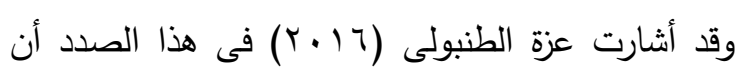

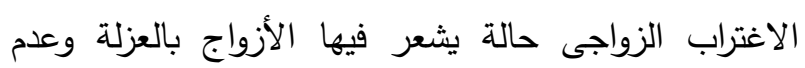

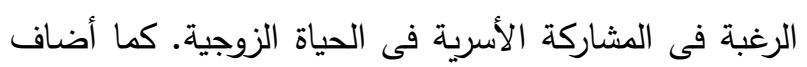

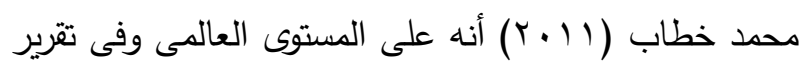

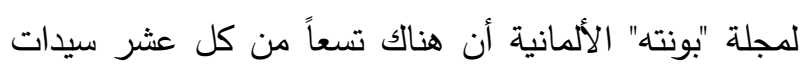

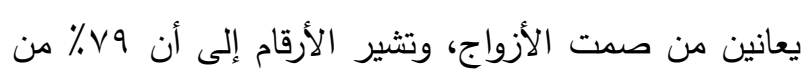

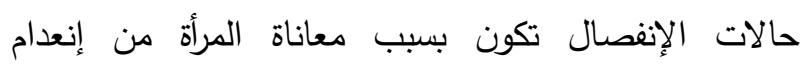

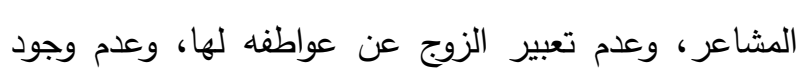

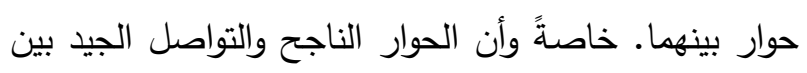
الزوجين يُشكل الحبل السرى الذى تتغذى منه السعادة الزوجية؛ لأنه يمنع الوقوع فى الكثير من المشاكل التى يخلفها

$$
\text { الصمت (عبد الكريم بكار ، 9. ج ب). }
$$

وقد أظهرت نتائج دراسة(2015) Miley تأثير المشاكل والخلافات الزوجية على إنتاجية الزوج والزوجة، حيث تلتعكس

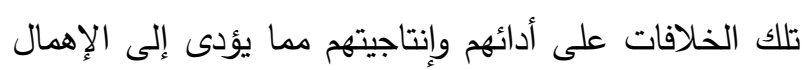

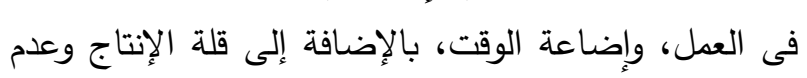

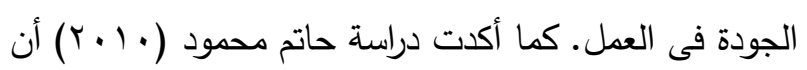

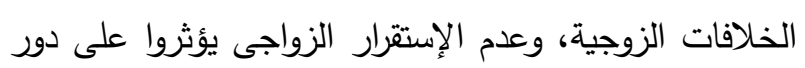

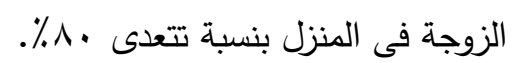

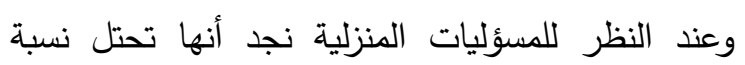

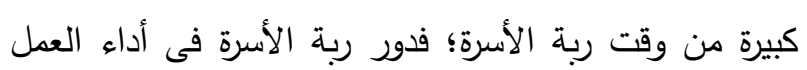

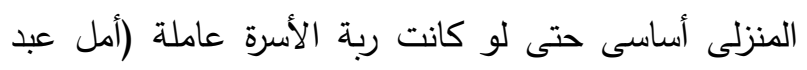

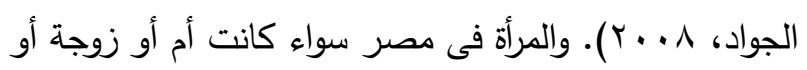

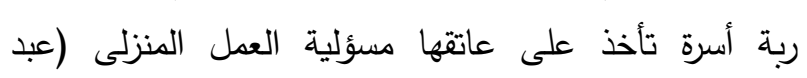

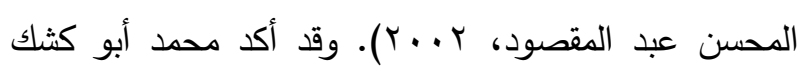

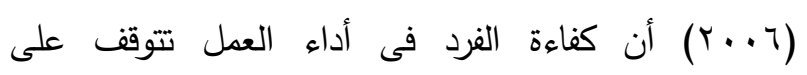
عنصرين أساسيين هما: المقدرة على العمل، والرغبة فيه، ألى العكل
السلبية، وسوء التواصل بأشكاله المختلفة. ومن الأعراض

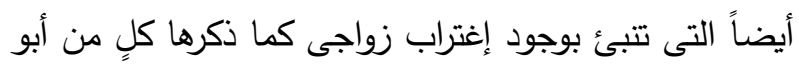

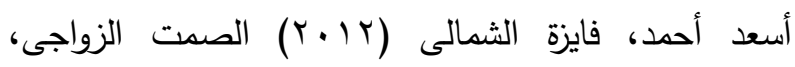
وغياب مشاعر الحب بين الزوجين، وفقدان التقدير بينهما.

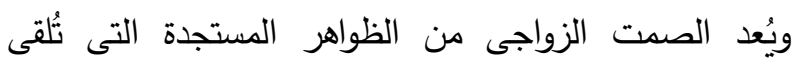
بظلالها السلبية على مناخ العلاقات الزوجية بين الأزواج،

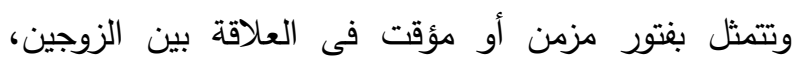

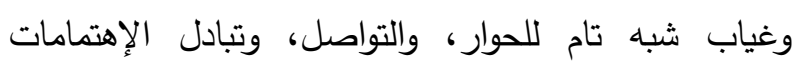

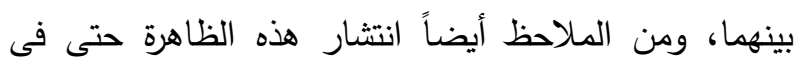

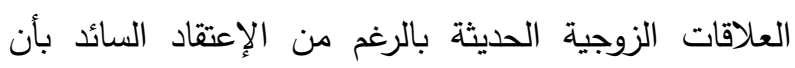

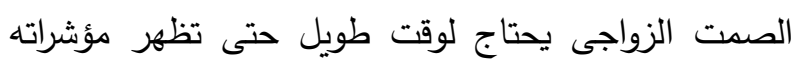

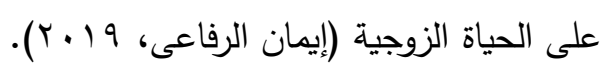

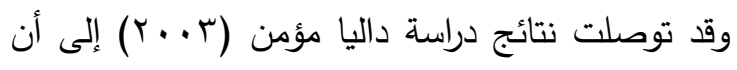

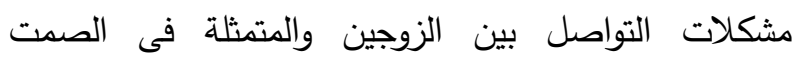

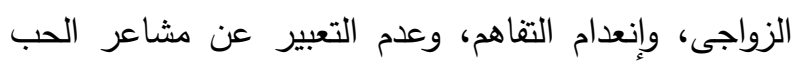

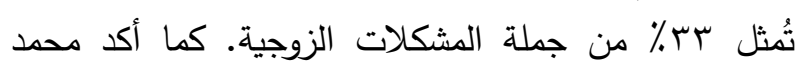

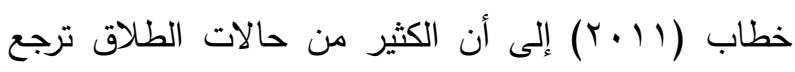

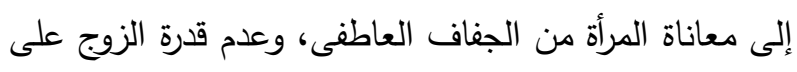

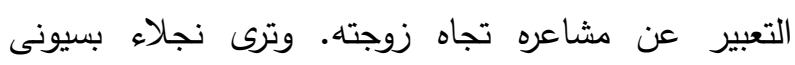

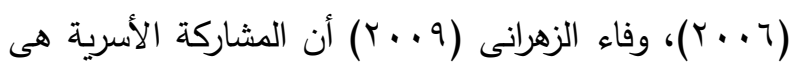
تقبل الزوجين كل ماتحمله الحياة من مصاعب ومشاكل الزيل

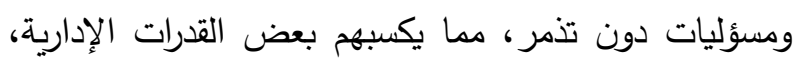

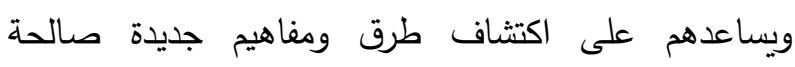

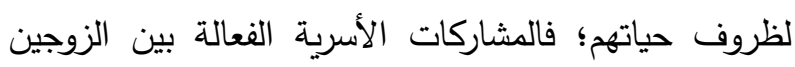

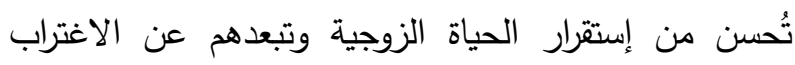

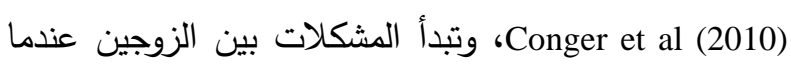

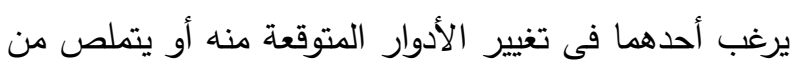

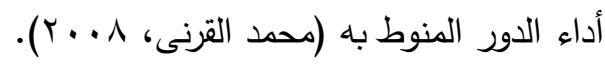

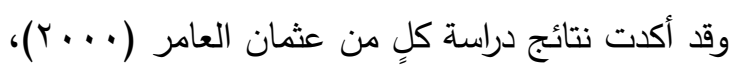
إبراهيم الحسن (r . . r) أن الاغتراب الزواجى من المشكلات

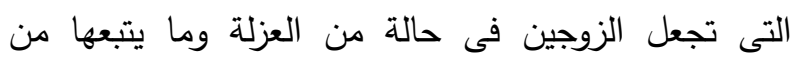




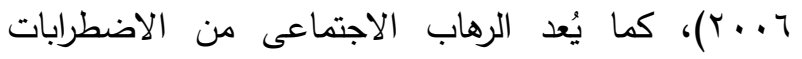
الإنفعالية الاجتماعية، يظهر فى الخوف الدائم والفزع الثديد من مواقف اجتماعية (لا تسبب الخوف فى حد ذاتها) والتى الإنى يكون فيها الفرد محط أنظار الآخرين، وتظهر لديه مخاوف غير مبررة من تقييم الآخرين السلبى، مما يؤدى إلى مشاعر

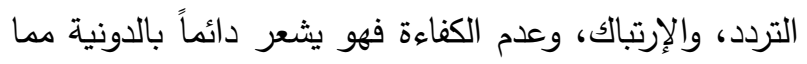

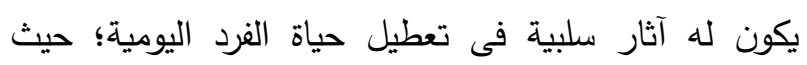
يتجنب المواقف الاجتماعية، وينسحب ويبتعد عن الأداء

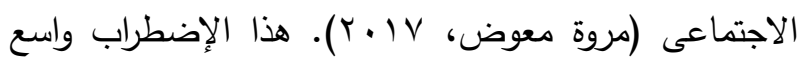
الإنتشار فى مجتمعاتتا العربية؛ حيث تصل نسبة المصابين باه من مرضى العيادات النفسية إلى (س (1\%) من عموم

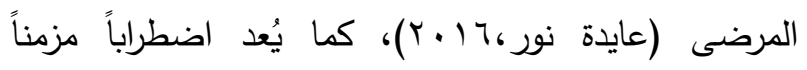

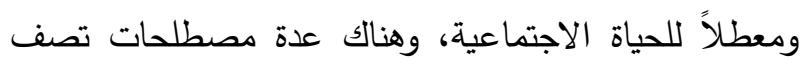
هذا الإضطراب منها القلق الاجتماعى، والخوف والإرتباك فى ومى وهن

المواقف الاجتماعية المختلفة (2014) Pilling, et al. والاغتراب الزواجى لايمتد تأثثره على الزوجين فقط بل

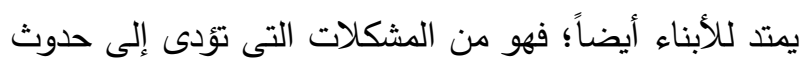
التوتر بين أفراد الأسرة، وفتور العلاقات بين الزوجين والأبناء

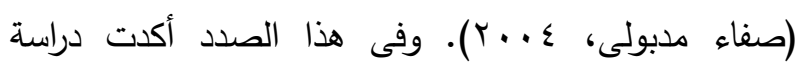

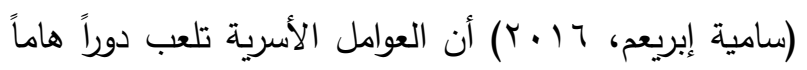
فى نشوء حالات الرهاب الاجتماعى؛ فالمرضى المصابين به ذكروا فى تاريخ شخصيتهم أن طفولتهم كانت غير سعيدة،

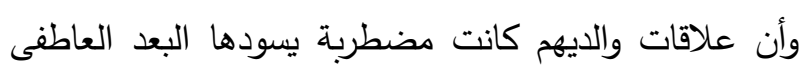
والبرود وعدم التقبل مثل هذه المشاعر ساهمت فى تكوين

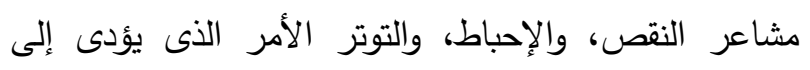

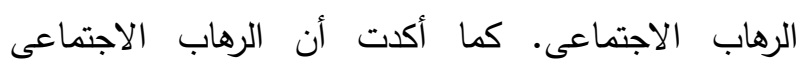
إضطراب عادةً يظهر فى مرحلة المراهقة بسبب الأبى الجواء الأسرية المضطربة. بناءً على ذلك نجد أن الإهتمام بدراسة الاغتراب الزواجى إتجاه عالمى فرضته التغيرات الاجتماعية، والثقافية،

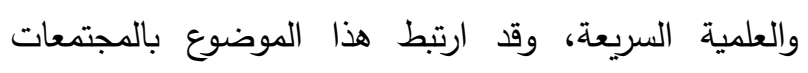

وتتمثل المقدرة على العمل فيما يمتلكه الفرد من مهارات ومعارف وقدرات يكتسبها بالتعلم، والتدريب، والخبرة العملية

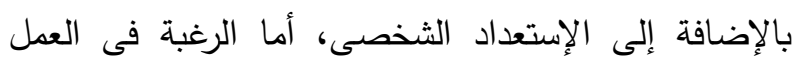

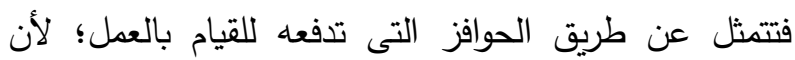
المقدرة وحدها غير كافية لكى يعمل بأقصى كفاءة ممكنة. حيث تمثل الكفاءة الأدائية والإنتاجية إحدى القضايا الحيوية التى تؤثر على معدلات النمو الاقتصادى فى أى مجتمع

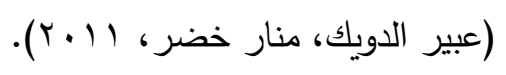

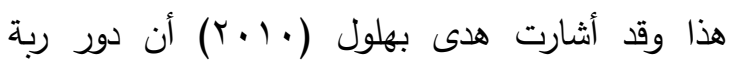
الأسرة فى أداء أعمالها، ومهامها المنزلية يأتى فى صدارة الأعمال التى تقوم بها الزوجة من حيث الحجم، والأهمية، والمقصود بأداء المهام المنزلية الكفاءة فى أدائها بتقليل الوقت والجهد مع إخراج العمل فى أحسن صورة. لذلك كلما كان الزواج ناجحاً كلما دفع الزوجين للإنجاز ، والقدرة على التجديد (Chiung, et al, والإبداع، ومقاومة مشاكل الحياة والعمل (2005، وكثيراً ما تتوقف قدرة المرأة على الأداء الفعال للعمل على علاقتها بشريك حياتها، فكلما كانت العلاقة إيجابية كلما

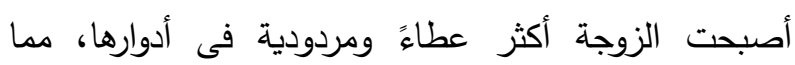
ينعكس إيجابياً على أبنائها وعلى أسرتها (فطيمة ونوغى، $\cdot(r.) \varepsilon$

ويُعد إضطراب الرهاب الإجتماعى أحد الأنواع الرئيسية والثائعة للرهاب فى مرحلة المراهقة، الوقت الذى يحاول فيه

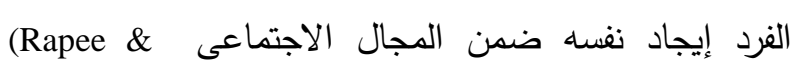
Hudson,2000) حرجة فى حياة الفرد؛ حيث يسيطر عليه الإرتباك؛ لعدم تحديد أدواره التى يجب عليه القيام بها، كما أنها تُوصف الإنب بأنها مرحلة المشكلات، سواء الاجتماعية أو الدراسية أو لوائ النفسية ومن بين المشكلات النفسية فى هذه المرحلة نذكر تحديداً اضطراب الرهاب الاجتماعى، هذا الأخير الذى يحتل

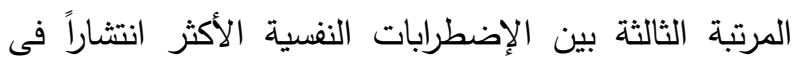
العالم بعد الإكتئاب وإدمان الكحوليات (حياة البناء وآخرون، 
القدرة على أداء المهام المنزلية، الرضا عن أداء المهام المنزلية، الإبتكار فى أداء المهام الدنزلية) والإجمالى، الدهاء الدهاء والرهاب الإجتماعى لأبنائها فى مرحلة المراهقة؟

\section{والذى ينبثق منه الأسئلة الفرعية التالية:} - ما مستوى كلٍ من الاغتراب الزواجى كما تدركه الزوجات

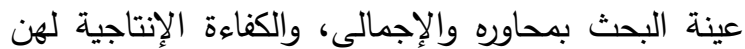

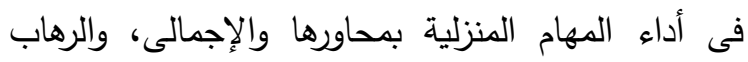

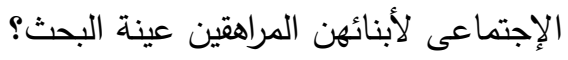
- ما العلاقة بين الاغتراب الزواجى كما تدركه الزوجات عينة البحث بمحاوره والإجمالى، وكلٍ من كفاءتهن الإنتاجية فى أداء المهام المنزلية بمحاورها والإجمالى، والرهاب الإجتماعى لأبنائهن المراهقين عينة البحث؟ - ما الفروق بين متوسطات درجات الزوجات عينة البحث فى كلٍ من الاغتراب الزواجى كما تدركه بدحاوره والإجمالى، و كفاءتهن الإنتاجية فى أداء المهام المنزلية بمحاورها والإجمالى تبعاً لمتغيرات البحث (مكان السكن،

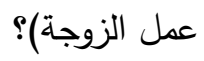

- ما التباين بين متوسطات درجات الزوجات عينة البحث فى الاغتراب الزواجى بمحاوره والإجمالى، تبعاً لمتغيرات

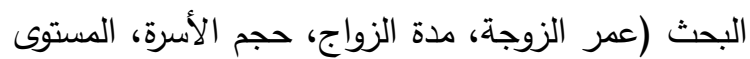
التعليمى للزوجة، المستوى التعليمى للزوج، متوسط الدخل

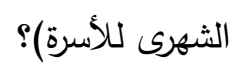

- ما التباين بين متوسطات درجات الزوجات عينة البحث فى كفاءتهن الإتتاجية فى أداء المهام المنزلية بدحاورها والإجمالى، تبعاً لمتغيرات البحث (عمر الزوجة، مدة الإناه

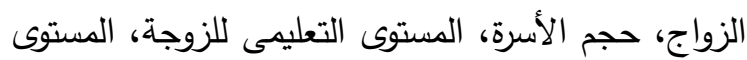

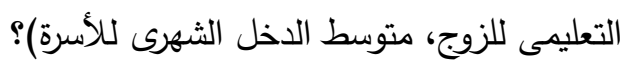
- ما الفروق بين متوسطات درجات الأبناء عينة البحث فى الرهاب الاجتماعى تبعاً لمتغيرات البحث (جنس الأبناء،

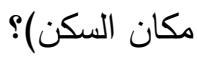

المعاصرة التى أخذت بأسباب التتمية والتحديث (روان أبو

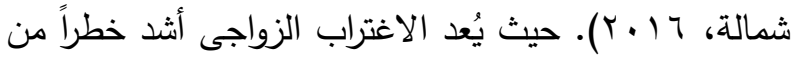
الطلاق الفعلى؛ لأن آثاره المدمرة على نفسية الزوج والزوجة والأبناء بمنزلة المسرحية الدرامية الوغلة فى السوداوية التى التى التئي يستمر عرضها يومياً دون أن تكون لها نهاية يسدل بعدها

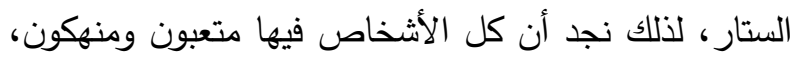

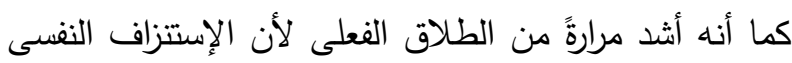
والجسدى فيه مؤلم وموجع بسبب ما يصاحبه من الإحساس

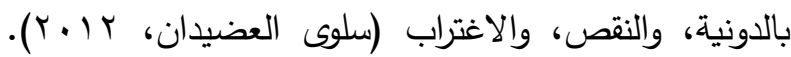
مما قد يؤثر ذلك على الكفاءة الإنتاجية للزوجة فى أداء المهام المنزلية، فالفرد الذى يعيش فى وسط التوتر والمشاكل

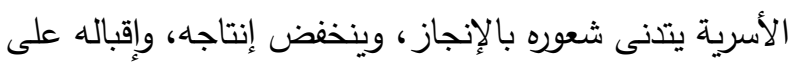

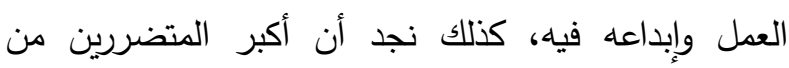
الاغتراب الزواجى هم الأبناء؛ إذ ترتفع لديهم نسبة الإصابة

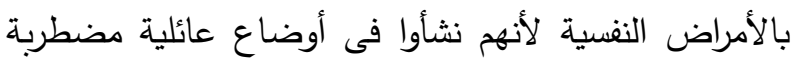

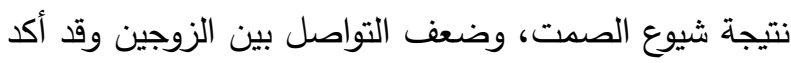

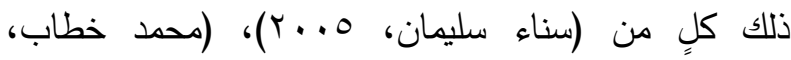

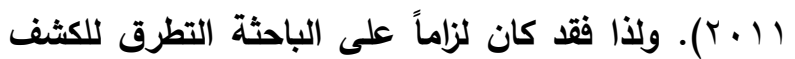
عن العلاقة بين الاغتراب الزواجى (خاصةً وأنه أشد خطراً ومرارةً من الطلاق الفعلى) كما تدركه الزوجات (خاصةً

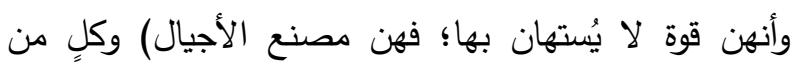
كفاءتهن الإنتاجية فى أداء الأعمال المنزلية (خاصةً وأن الأن العمل الهنزلى فى صدارة أعمالهن) والرهاب الاجتماعى الاعى الإنية

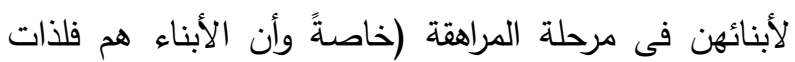
أكبادنا، وعماد ظهورنا، وطبيعة العلاقة بين الزوجين تلعب فالتباء دوراً هاماً فى تثكيل شخصية الأبناء وبنائهم النفسى). وعليه فإن البحث الحالى ماهو إلا محاولة للكثف عن هذأه

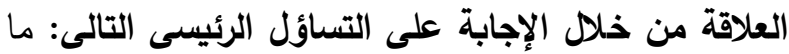
العلاقة بين الاغتراب الزواجى كما تدركه الزوجة بمحاوره (الصدت الزواجى، ضعف التواصل العاطفى والتآلفية، العزلة

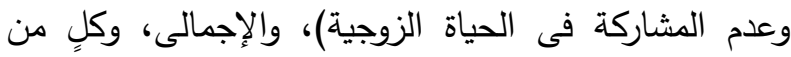
كفاءتها الإنتاجية بدحاورها (الرغبة فى أداء المهام الدنزلية، 


$$
\text { مجلة الإسكندرية للتبادل العلمى - (مجلد بع العدد () يناير - مارس اY.r }
$$

0- تحديد التباين بين متوسطات درجات الزوجات عينة البحث فى كفاءتهن الإنتاجية فى أداء المهام المنزلية

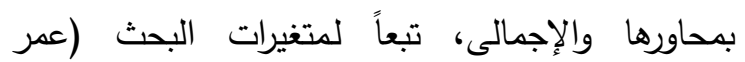

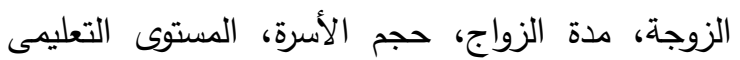

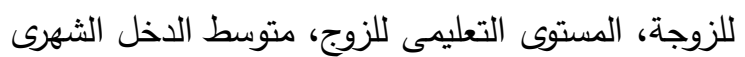
ل نلأسرة). 7- تحديد الفروق بين متوسطات درجات الأبناء عينة البحث

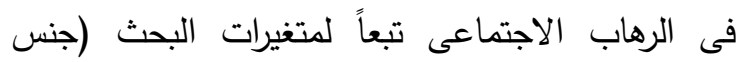

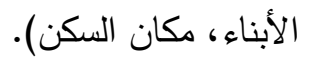

- تحديد التباين بين متوسطات درجات الأبناء عينة البحث فى الرهاب الاجتماعى تبعاً لمتغيرات البحث (الترتيب

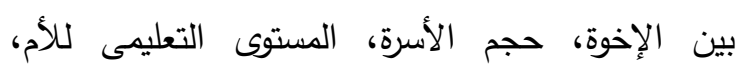
المستوى التعليمى للأب، متوسط الدخل الثهرى للأسرة).

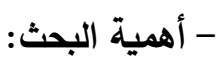
- الأهمية النظربة: 1- محاولة تسليط مزيد من الضوء على ظاهرة الاغتراب الزواجى؛ كونها تهدد كيان مجتمع بأكمله، فهى تشير إلى وجود خلل يُمارس خلف أبواب مغلقة وينعكس أثرها على الأبناء، وذلك للحد منها حتى لا نحصل على جيل مغترب لا يجيد إلا لغة اليأس، والعنف. r- تبدو أهمية البحث فى محاولة النهوض بالكفاءة الإنتاجية للزوجة فى أداء المهام المنزلية، وأهمية العمل بله على تتمية قدراتها ومهاراتها نحو المهام المنزلية والإبداع والإبتكار فيها، مما يكون لله عظيم الأثر على طاقة لهن الزوجة الإيجابية تجاه المهام المنزلية.

r- تتبع أهمية البحث من ارتباطه بطبيعة العلاقة بين الزوجين والتى تُعد من أهم ركائز الصحة النفية لهنية للزوجين، بالإضافة للدور الذى تلعبه فى تشى تشكيل شخصية الأبناء، وبنائهم النفسى. بالهُ
- ما التباين بين متوسطات درجات الأبناء عينة البحث فى الرهاب الاجتماعى تبعاً لمتغيرات البحث (الترتيب بين

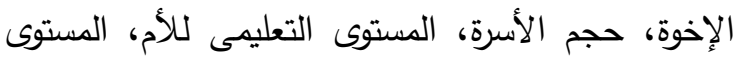
التعليمى للأب، متوسط الدخل الثهرى للأسرة)؟ - أهداف البحث: يهدف البحث الحالى بصفة رئيسية إلى الكثف عن العلاقة بين الاغتراب الزواجى كما تدركه الزوجات بمحاوره (الصمت الزواجى، ضعف التواصل العاطفى والتآلفية، العزلة وعدم المشاركة فى الحياة الزوجية) والإجمالى، وكلٍ من كفاءتهن الإنتاجية فى أداء المهام المنزلية بمحاورها (الرغبة فى أداء المهام المنزلية، القدرة على ليى أداء المهام المنزلية، الرضا عن أداء المهام المنزلية، الإبتكار

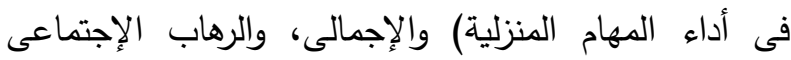
لأبنائهن المراهقين. وذلك من خلال التعرف على: 1- مستوى كلٍ من الاغتراب الزواجى كما تدركه الزوجات عينة البحث بمحاوره والإجمالى، والكفاءة الإنتاجية لهن فى أداء المهام المنزلية بمحاورها والإجمالى، والرهاب الإجتماعى لأبنائهن المراهقين عينة البحث. r- تحديد العلاقة بين الاغتراب الزواجى بمحاوره والإجمالى لعينة البحث من الزوجات، وكلٍ من كفاءتهن الإنتاجية فى أداء المهام المنزلية بمحاورها والإجمالى، والرهاب الإجتماعى لأبنائهن المراهقين عينة البحث. r- تحديد الفروق بين متوسطات درجات الزوجات عينة البحث فى كلٍ من الاغتراب الزواجى بمحاوره والإجمالى، وكفاءتهن الإنتاجية فى أداء المهام المنزلية بمحاورها والإجمالى تبعاً لمتغيرات البحث (مكان

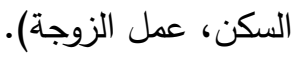
ع- تحديد التباين بين متوسطات درجات الزوجات عينة البحث فى الاغتراب الزواجى بمحاوره والإجمالى، تبعاً لمتغيرات البحث (عمر الزوجة، مدة الزواج، حجم الأسرة، المستوى التعليمى للزوجة، المستوى التعليمى للزوج، متوسط الدخل الثهرى للأسرة). 


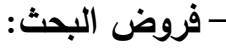

1- توجد علاقة إرتباطية دالة إحصائياً بين الاغتراب

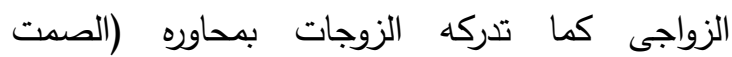
الزواجى، ضعف التواصل العاطفى والتآلغية، العزلة وعدم المشاركة فى الحياة الزوجية) والإجمالى، وكلٍ من التها كفاءتهن الإنتاجية فى أداء المهام المنزلية بمحاورها (الرغبة فى أداء المهام المنزلية، القدرة على أداء المهام

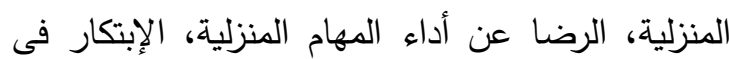
أداء المهام المنزلية) والإجمالى، والرهاب الإجتماعى الإنى لأبنائهن المراهين عينة البحث.

ץ- توجد فروق دالة إحصائياً بين متوسطات درجات الزوجات عينة البحث فى كلٍ من الاغتراب الزواجى

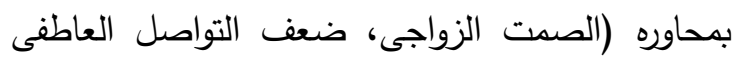
والتآلفية، العزلة وعدم المشاركة فى الحياة الزوجية) والإجمالى، وكفاءتهن الإنتاجية فى أداء المهام المنزلية بمحاورها (الرغبة فى أداء المهام المنزلية، القدرة على الإنى

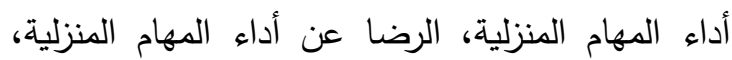

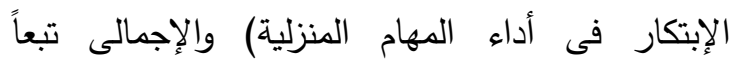
لمتغيرات البحث (مكان السكن، عمل الزوجة). ץ- يوجد تباين دال إحصائياً بين متوسطات درجات الزوجات عينة البحث فى الاغتراب الزواجى بدحاوره (الصمت الزواجى، ضعف التواصل العاطفى والتآلفية،

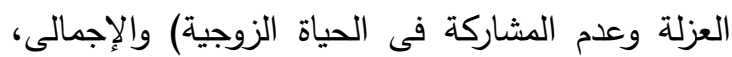

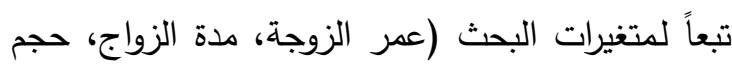

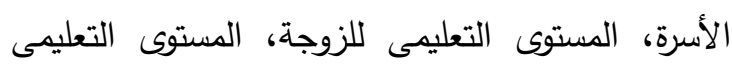
للزوج، متوسط الدخل الثهرى للأسرة). ع- يوجد تباين دال إحصائياً بين متوسطات درجات الزوجات عينة البحث فى كفاءتهن الإنتاجية فى أداء المهام المنزلية، بمحاورها (الرغبة فى أداء المهام

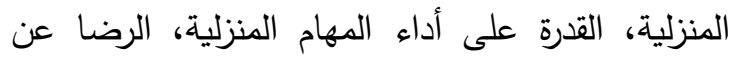
أداء المهام المنزلية، الإبتكار فى أداء المهام المنزلية)
ع- تكمن أهمية البحث الحالى فى العينة، فعينة البحث

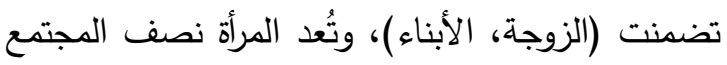

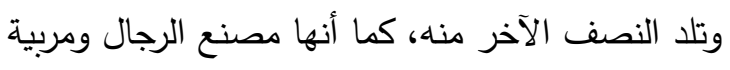
الأجيال، والإهتمام بها إهتمام بالدجتمع بأسره. والأبناء الأباء

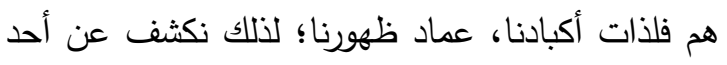
المشاكل النفسية التى قد تصيبهم فى مرحلة المراهقة

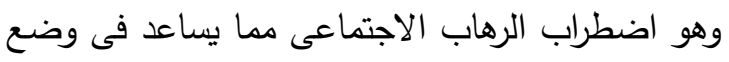
حلول للتصدى لهذا الاضطراب، وكيفية التعامل معه. - الأهمية التطبيقية: 1- قد تفيد نتائج البحث الجهات المعنية بالمرأة لإعداد

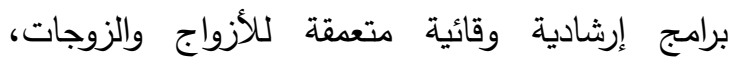

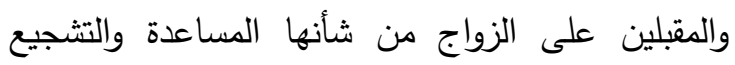
على الحوار الأسرى الفعال فى الأسرة، المشاركة

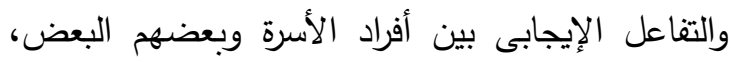

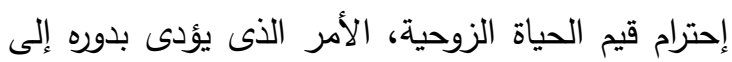

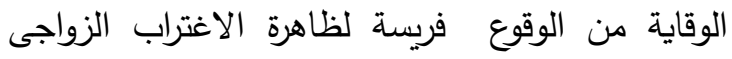
كأحد أهم وأصعب القضايا الأسرية الثائكة التى تهدد كيان الأسرة بأكملها ومن ثم المجتمع بأسره. ץ- يُكن الإستفادة من نتائج البحث فى مجال الإرشاد

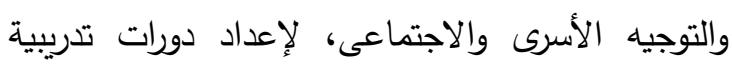

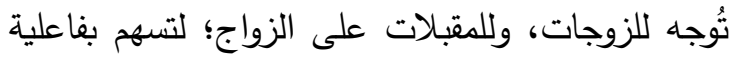
فى النهوض بمستوى كفاءتهن الإنتاجية فى أداء الدهام

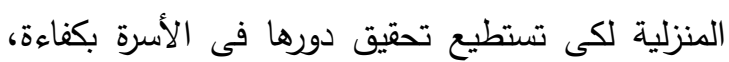

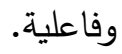

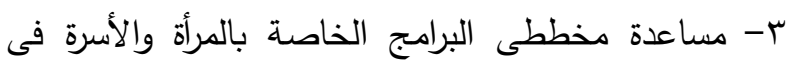
وسائل الإعلام المختلفة بالتركيز على ظاهرة الإغتراب

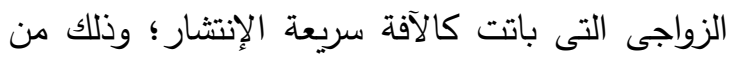

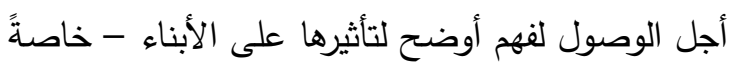

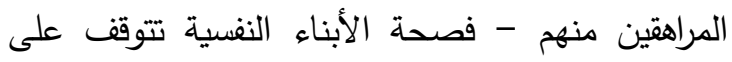
إجتياز تلك المرحلة بنجاح؛ حتى يصبحوا فعاليين، ومؤهلين للنهوض بمسؤوليات بناء مجتمعهم. 
الاجتماعى، فهى لا تشعر بوجوده أو أهميته فى حياتها،

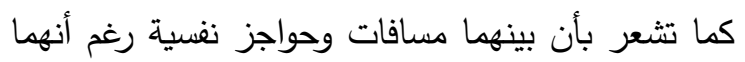
يعيشان تحت سقف واحد، ويتضمن الاغتراب الزواجى

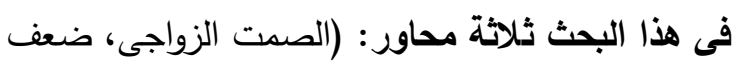

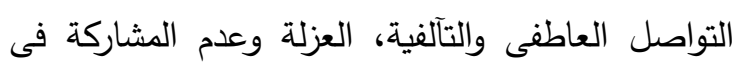

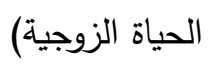
- الصمت الزواجى: هو من الظواهر المستجدة التى تُلقى بظلالها السلبية على مناخ العلاقات الزوجية بين الأزواج، وتتمثل بفتور مزمن أو مؤقت فى العلاقة بين الزوجين، وغياب شبه تام للحوار والتواصل وتبادل

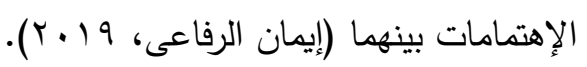
- ويُعرف إجرائياً على أنه: أحد أوجه الجمود فى العلاقة الزوجية؛ لغياب لغة الحوار بين الزوجين - إلا ما ندر -

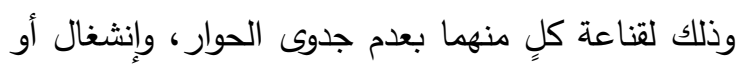

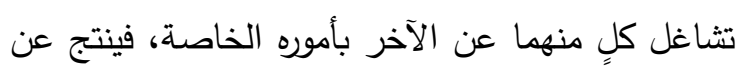
ذلك زيادة الفجوة بينهما.

- ضعف التواصل العاطفى: هو فقدان تدريجى للمشاركة الوجدانية، والفكرية الإيجابية بين الزوجين والتى تتم من خلا إرسال واستقبال الرسائل اللفظية، وغير اللفظية التى لتى لإلى

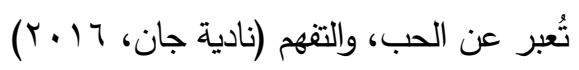
- ضعف التواصل العاطفى والتآلفية يُعرف إجرائياً على أنه: فقدان تدريجى للشعور بالمودة والمحبة والإهتمام بين الزوجين، حيث يكون بينهما تراخى عاطفى، وجفاف مشاعر فى علاقتهم الزوجية، فلم يعد كل منهما منجذباً نحو الآخر بل صار منصرفاً عنه، الأمر الذى يجعلهما

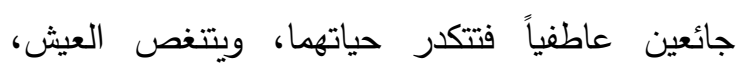
ويفقدان تدريجياً الحياة السليمة. - - العزلة النفسية: تُعد من الأعراض الواضحة للإغتراب

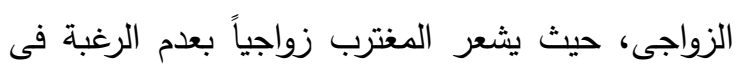

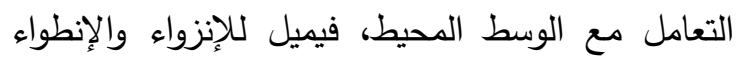

والإجمالى، تبعاً لمتغيرات البحث (عمر الزوجة، مدة

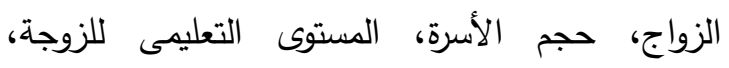

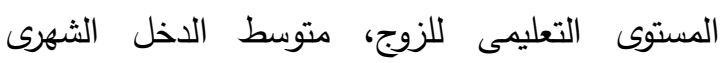

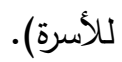
0- توجد فروق دالة إحصائياً بين متوسطات درجات الأبناء المراهقين عينة البحث فى الرهاب الاجتماعى تبعاً لمتغيرات البحث (الجنس، مكان السكن). 7- يوجد تباين دال إحصائياً بين متوسطات درجات الأبناء عينة البحث فى الرهاب الاجتماعى تبعاً لمتغيرات البحث (الترتيب بين الإخوة، حجم الأسرة، المستوى

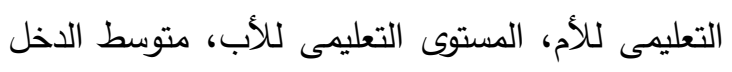
- الثهرى للأسرة). التحليلى، الذى يهتم بجمع البيانات عن الظاهرة موضع الدراسة وتصنيفها ثم تحليلها إحصائياً للوصول إلى نتائج خاصة بالظاهرة، مع بيان العلاقة بين المتغيرات البحثية

$$
\text { (عبد المرضى عزام، } 0 \text {. . ب). }
$$

- انياً: المصطلحات العلمية والمفاهيم الإجرائية للبحث:

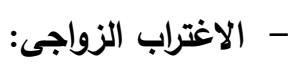

هو حالة تصيب أحد الزوجين أو كلاهما، وتُولا لديهم شعوراً بالبعد والإنفصال العاطفى عن شريك حياته بحيث لا لأهيل يشعر بوجوده أو أهميته فى حياته الوجدانية، فينظر إليه على بلى لئى أنه غريب، ويصبحان مرتبطين إسمياً، وظاهرياً دون طلاق

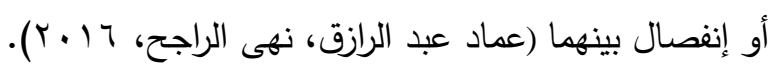
- ويعرف الاغتراب الزواجى كما تُركه الزوجة إجرائياً على أنه: حالة تُصيب الزوجة يتخلف عنها آثار ونتائج

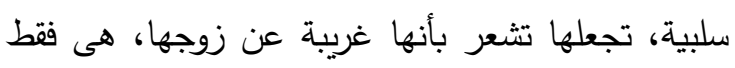

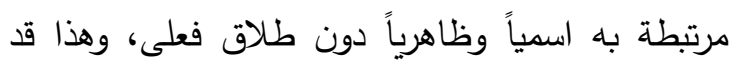
يكون لأسباب خارجية منها مراعاة الأطفال أو الثكل 
- القدرة على أداء المهام المنزلية: هى قدرة الزوجة على

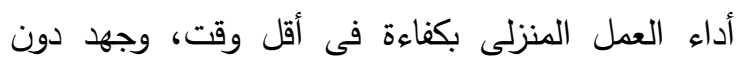
الثعور بالتعب، والإرهاق (إيمان قطب، 17 • ب).

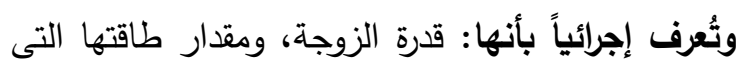
تملكها لأداء المهام المنزلية، يساعدها فى ذلك معارفها، ومهاراتها حول المهام المطلوبة، واختيارها أفضل الطرق

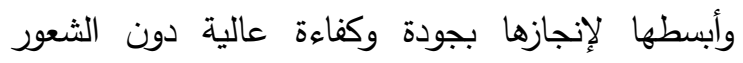

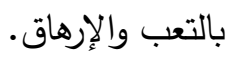
- الرضا عن أداء المهام المنزلية: هو درجة إثباع حاجات الفرد نتيجة ما يقوم به من أعمال، ويتحقق هذا

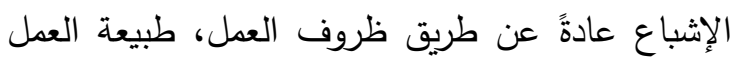
نفسه، الإعتراف بواسطة الآخرين (صلاح الدين عبد الإندان

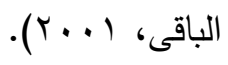

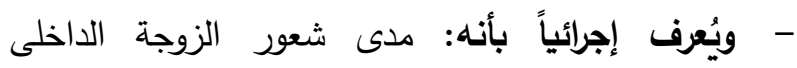
بالرضا، والإرتياح نحو ما تقوم به من مهام منزلية، فهو بمثابة المردود المعنوى للزوجة الذى تحصل عليه من أداء مهامها ومسؤولياتها، فيكون لديها إتجاهات إيجابية نحو هذه المهام والمسؤوليات المنزلية؛ مما يحفزها على لئى إنجازها بأقل جهد وأسرع وقت وبأعلى كفاءة.

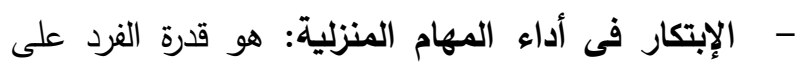
إعادة ترتيب الخبرات السابقة فى إنتاج نماذج أصلية جديدة من معلومات، وعناصر سابقة (مايسة الحبشى، . ( r... - ويُعرف إجرائياً بأنه: قدرة الزوجة على الإستفادة من المعارف والمهارات والخبرات السابقة التى اكتسبتها أثناء تأدية المهام المنزلية لإنتاج أفكار مبتكرة تثيد بها أسرتها وتجعل الحياة أكثر بهجة.

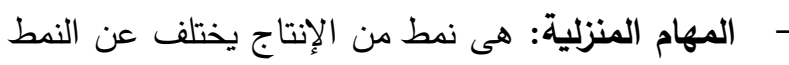
الرأسمالى المتعارف عليه، والذى يهدف إلى القياج التيام بوظائف معينة من خلال مجموعة من الأدوار، والمهام

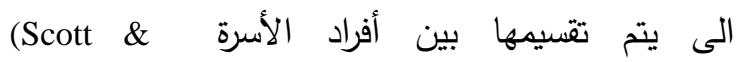

وينصرف عما يشغل من حوله (عبد الرحمن عثمان، . (r..r - - العزلة وعدم المشاركة فى الحياة الزوجية تُعرف إجرائياً على أنها: عدم رغبة أى من الزوجين فى التعامل أو الو التيات

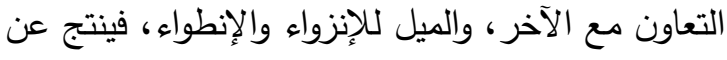
ذلك حدوث خلل وتضارب فى أداء الأدوار التى يتوقعها

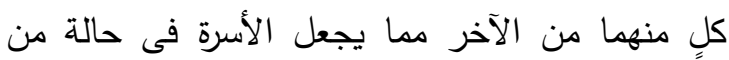

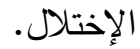

- - الكفاءة الإتتاجية للزوجة: هى قيام الزوجة بالأعمال

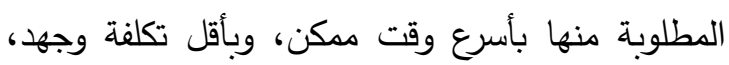

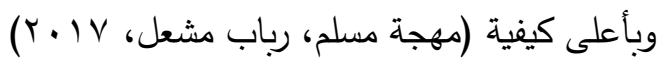

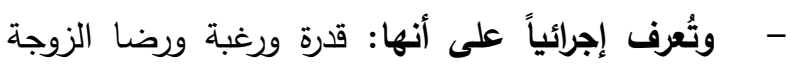
عن أداء المهام المنزلية المطلوبة، وتحقيق أقصى إنتاج أنها: ممكن بجودة عالية، وبأقل تكلفة، مع مراعاة الاستخدام الأمثل للموارد المتاحة للأسرة، والإستفادة من خبراتها

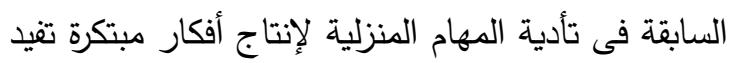
بها أسرتها. وتتضمن الكفاءة الإنتاجية فى هذا البحث

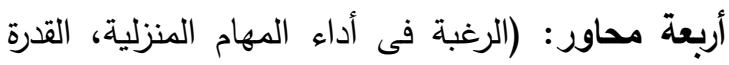
على أداء المهام المنزلية، الرضا عن أداء الدهاء الدهام الدهاء المنزلية، الإبتكار فى أداء المهام المنزلية) - - الرغبة فى أداء المهام المنزلية: هى الميل نحو الأداء

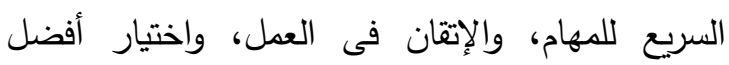
الطرق لإنجازه (صلاح مراد، أحمد عبد الخالق،

$$
\text { (r.... }
$$

- متُعرف إجرائياً بأنها: الدافع، والعامل المحرك النابع من

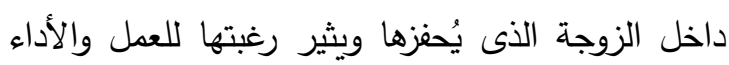
السريع للمهام المنزلية المطلوبة دون تأجيل أو كسل، ولأل متخطية جميع الصعوبات التى تواجهها أثناء تأدية هذه الهن

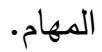


- - وتُعرف إجرائياً بأنها: مرحلة حرجة من بين المراحل التى يمر بها الفرد؛ نظراً للتغيرات العديدة التى تحدث فيها،

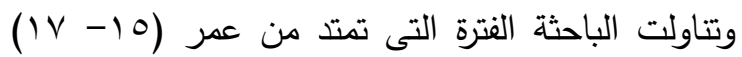
عاماً وتُعرف بالمراهقة المتوسطة. ثاثثاً: حدود البحث: تمثلت حدود البحث فى الآتى:

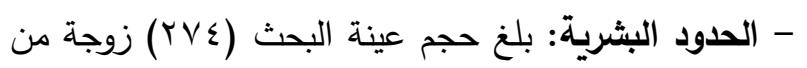
الزوجات المنتميات إلى مستويات اجتماعية واقتصادية مختلفة، وقد تم اختيار العينة بطريقة عمدية غرضية.

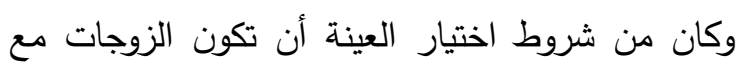

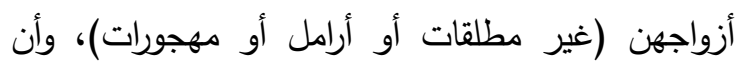

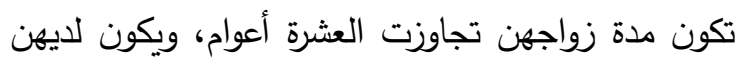

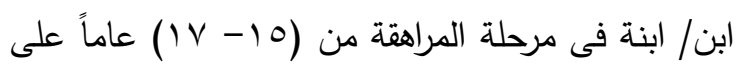

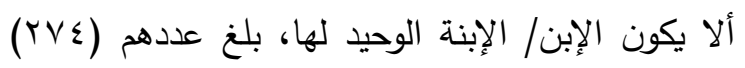

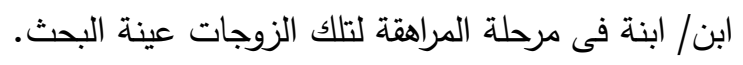

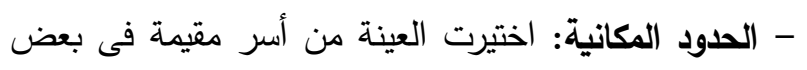
مدن وقرى محافظة الدقهلية، حيث تم تجميع أفراد العينة من مدينة المنصورة، مركز السنبلاوين، مركز ومدينة ميت غمر وبعض قراها (أوليلة، ميت محسن، بثلا،

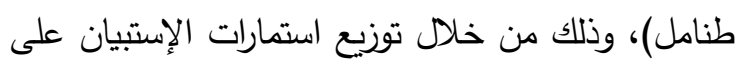

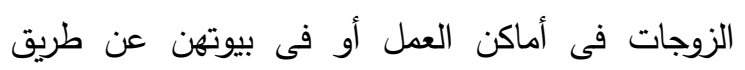
الأهل، والمعارف، والأصدقاء.

- الحدود الزمنية: تم التطبيق الميدانى لأدوات البحث فى والهئ.

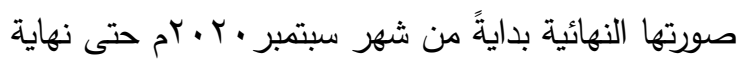

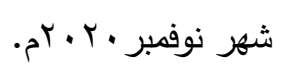

رابعاً: إعداد وبناء أدوات البحث وتقنينها: (إعداد الباحثة) الشتملت الأدوات المستخدمة فى هذا البحث وفى ضوات ضواء الأهداف البحثية على ما يلى: - استمارة البيانات العامة تم إعداد استمارة البيانات العامة

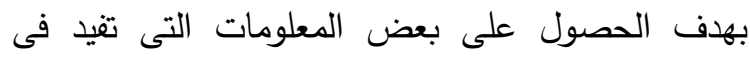
إمكانية تحديد بعض الخصائص الاجتماعية والاقتصادية

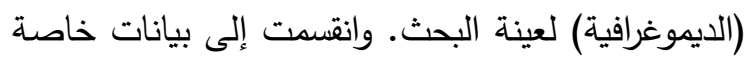

Marshall,2009) كما تُعرف بأنها مجمل المهام والوظائف والأنشطة العضلية والفكرية التى تقوم بها الزوجة فى بيتها مثل التظظيف، وكى الملابس...إلخ

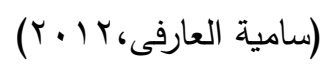
- متُعرف إجرائياً بأنها: مجمل الأعمال والمهام التى تقوم

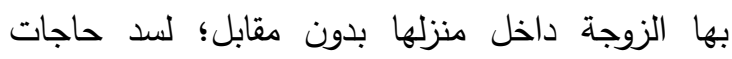

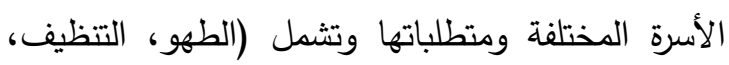
الغسيل، رعاية الأبناء...إلخ).

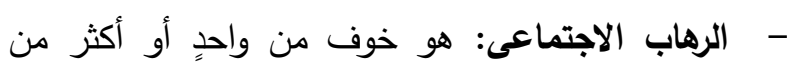

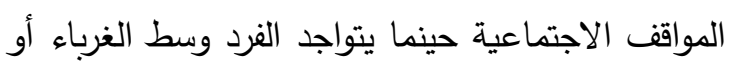

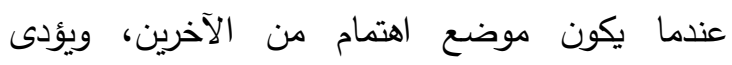
التعرض لكثل هذه المواقف - غالباً - إلى إثارة القلق

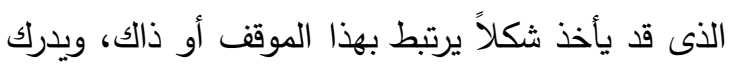

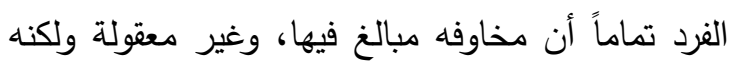
مع ذلك يخاف من المواقف الاجتماعية ويتجنبها (عادل محمد، (Y... (Y). - ميُعرف إجرائياً بأنه: خوف مرضى غير مبرر يشعر به المراهق فى معظم المواقف الاجتماعية، يجعله يتجنب

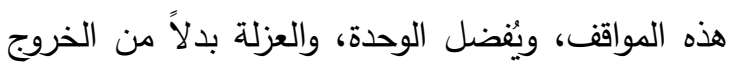

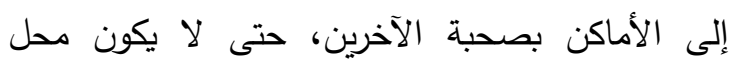

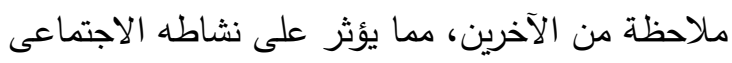

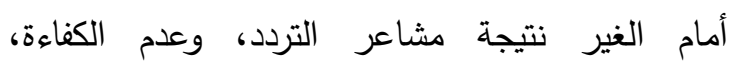

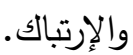
- مرحلة المراهقة: هى مرحلة أساسية فى حياة الإنسان،

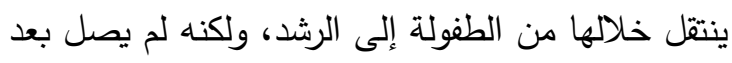

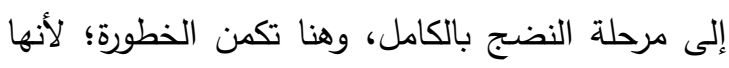

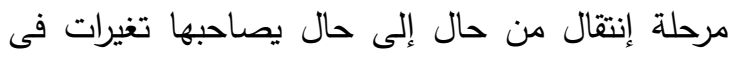
جوانب الثخصية، هذه التغيرات تكون سريعة ومتلاحقة تفاجئ المراهق كما تفاجئ من حوله، وتتقسم إلى مراهقة مبكرة، مراهقة متوسطة، مراهقة متأخرة (خولة السبتى، كماهي . ( r. . 纟 
المنصورة، وبلغت نسبة إتفاق المحكمين ما بين ه1\%

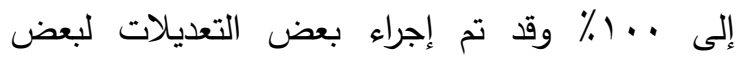
العبارات، وظل المجموع الكلى للعبارات كما هو، وبذلك يكون قد خضع لصدق المحتوى.

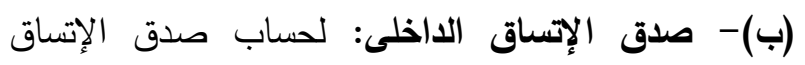
الداخلى للمقاييس الثلاثة (الاغتراب الزواجى، الكفاءة الإدات

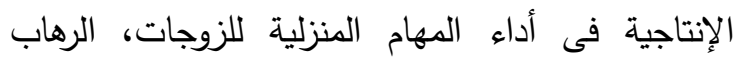
الاجتماعى)، قد تم تطبيق (مقياسى الاغتراب الزواجى،

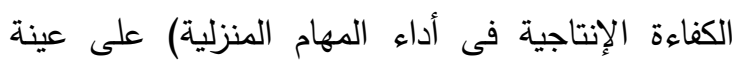

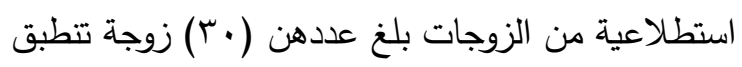
عليهم شروط اختيار العينة، وكذلك تطبيق (استبيان

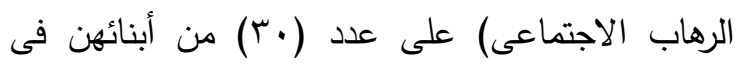

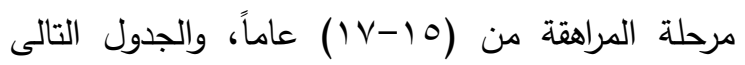
يوضح ذلك مرحة
بالزوجة (مكان السكن، عمل الزوجة، عمر الزوجة، مدة

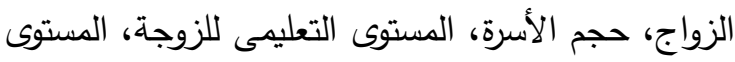

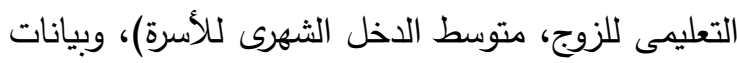
خاصة بالأبناء المراهتين (الجنس، الترتيب بين الإخوة).

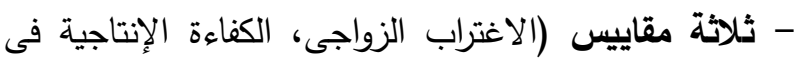

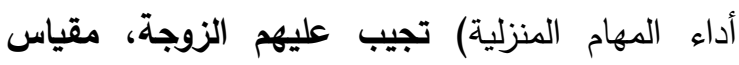
(الرهاب الاجتماعى للأبناء) يجيب عليه الأبناء. - تقنين المقاييس: أولاً: حساب صدق المقاييس: اعتد البحث الحالى فى التحقق من صدق المقاييس على ثلاث طرق: (أ)- صدق المحتوى: للتأكد من صدق محتوى المقاييس تم

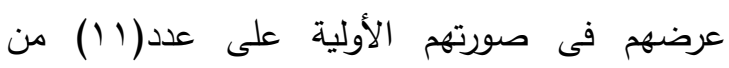
الأساتذة المحكمين فى مجال (إدارة مؤسسات الأسرة والطفولة، وإدارة المنزل، علم النفس) كلية الاقتصاد

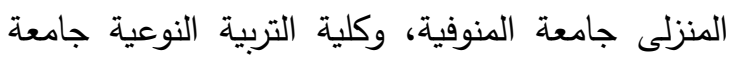

جدول اــ معاملات الإرتباط بين كل عبارة والارجة الكلية للمقاييس الثلاثة الاغتراب الزواجى كما تدركه الزوجات عينة البحث، والكفاءة

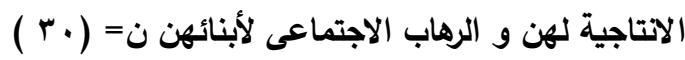

\begin{tabular}{|c|c|c|c|c|c|c|c|c|}
\hline \multirow[b]{2}{*}{ الاجتماعى الرهاب } & \multicolumn{4}{|c|}{ مقياس الكفاءة الانتاجية } & \multicolumn{3}{|c|}{ مقياس الاغتراب الزواجى } & \\
\hline & 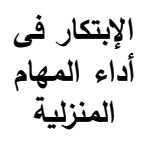 & 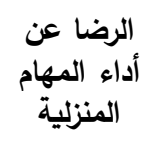 & أداء المدرة على المهام & أداء المهام المنية & المشياة الزوكة فيّلة & ضعف التواصل & الزواجى & \\
\hline$* *, 7,1$ & $* *, \leqslant 9 V$ & $* *, \vee, q$ & $* *, 7 \wedge 0$ & $* *, V \backslash V$ & $* *, \pi / r$ & **, O & $* *,, \vee \circ\{$ & 1 \\
\hline$* *, 0 \wedge 4$ & $* *, \quad Y V$ & $* *, \quad T \leq r$ & $* *, \quad \vee \wedge \vee$ & $* *$, , V৭ & $* *, O V Y$ & $* *, \vee \vee १ \wedge$ & דro, ס ט & r \\
\hline$* *, 0.1$ & **, , VAr & $* *, \vee \vee \wedge r$ & $* *, Y \backslash 1$ & $* *, \quad T \leqslant 1$ & $* *$, , ० V & $*, \varepsilon r V$ & \& & r \\
\hline$* *, 09$ & $* *,, V V r$ & $* *, \Lambda K r$ & $* *, 01 \mathrm{~V}$ & $* *, 101$ & $* * .0 V \varepsilon$ & $* *, 790$ & $* *,, \uparrow \Lambda$. & $\varepsilon$ \\
\hline$* *$, V04 & $* *, 799$ & $* *, \quad \leq \nearrow \leq$ & $* *,,\rceil \wedge \varepsilon$ & $* *, V Y \leq$ & $* *,, \vee \neg \leq$ & $* *, \uparrow \wedge$. & $* *, \quad, \tau$ & 0 \\
\hline$* *, 000$ & $* *, V \backslash V$ & $* *, V Y Y$ & $*,, \leqslant \leqslant 0$ & ***, , VY & $* *, T 0 \mathrm{~V}$ & $* *, \wedge 9 \varepsilon$ & $* * ., 099$ & 7 \\
\hline$* *, \leqslant 9 Y$ & $* *, \quad, Y Y \leq$ & **\%, ד . & **, Or r & **, , & $* *,, T \leq \varepsilon$ & $* *, O V Y$ & $* *, 0 . r$ & v \\
\hline$* * 077$ & $* *, \vee \wedge \wedge$ & ***. . Nor & $* *, \quad V Y Y$ & 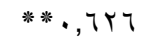 & **., ONY & **,人ץ. & $* *,, Y Y O$ & $\wedge$ \\
\hline$* *, \Upsilon 4 \wedge$ & $* *, 001$ & $* *,, \vee q r$ & $* *,, V \vee$ & **, & $* *, 0 \leq \varepsilon$ & $* *,, V \Gamma$. & $* *, \vee \vee q \mu$ & 9 \\
\hline$* *, 0 . V$ & ***, Ar & $* *, \quad, V \leqslant r$ & $* *, \vee \vee 90$ & $* *, \pi T V$ & $* *, T r \leq$ & $* *,, T \leq r$ & $* *, \quad T \leqslant r$ & 1. \\
\hline$* *, 799$ & & & & & & 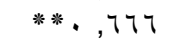 & & 11 \\
\hline$* *, V \Gamma \leq$ & & & & & & * & & ir \\
\hline$* *, \vee \Gamma q$ & & & & & & & & Ir \\
\hline$* *, \vee \vee \top$ & & & & & & & & $1 \varepsilon$ \\
\hline
\end{tabular}


على الإتساق الداخلى لعبارات المقاييس الثلاثة، مما يسمح

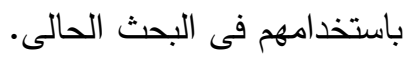

(ج)- الصدق البنائى: يتم فيه التأكد من صدق أداة البحث بإستخدام طريقة حساب معامل الإرتباط بين الدرجة الكلية للمقياس والمحاور المكونة له.

يتضح من نتائج جدول (Y) أن معاملات الإرتباط

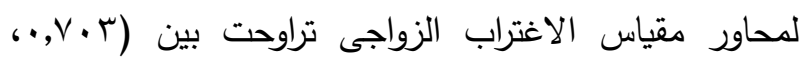

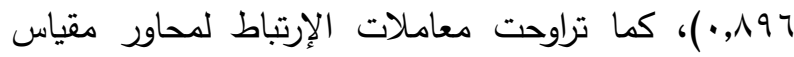

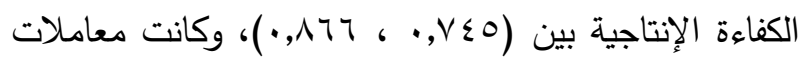

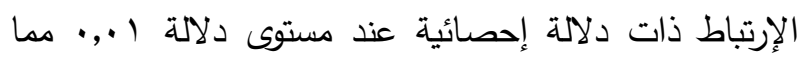

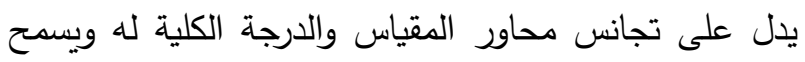
للباحثة بإستخدامهما فى بحثها الحالى. ثانياً: حساب ثبات المقاييس: قامت الباحثة باستخدام معامل Split - ألفا كرونباخ Alpha-Cronbach ، والتجزئة النصفية

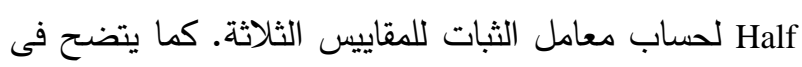

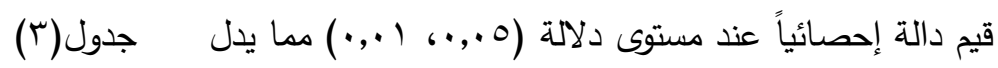

يتضح من نتائج جدول (1) أن قيم معامل الإرتباط بين درجة كل عبارة من عبارات مقياس الاغتراب الزواجى

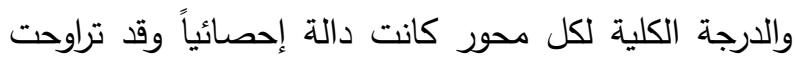

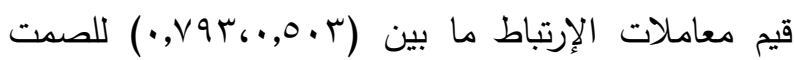

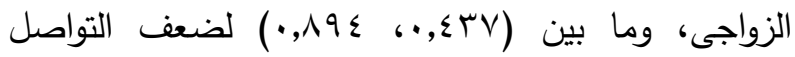

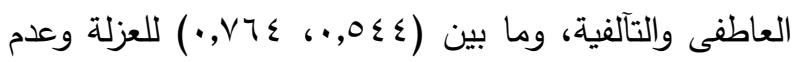
المشاركة فى الحياة الزوجية، وبالنسبة لقيم معامل الإرتباط بين درجة كل عبارة من عبارات مقياس الكفاءة الانتاجية

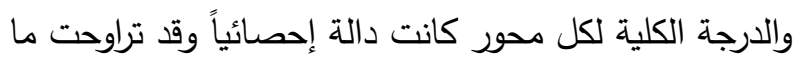

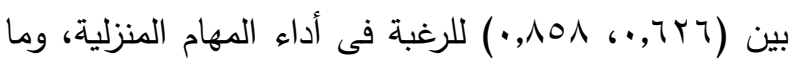

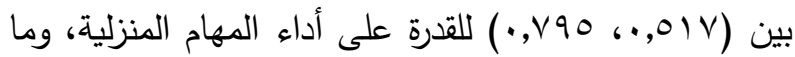

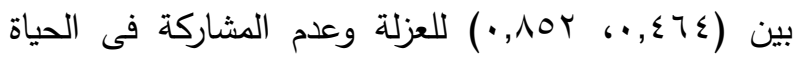

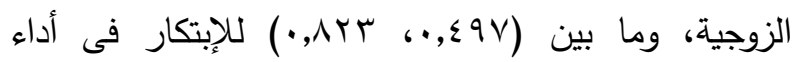
المهام المنزلية، كما ترواحت قيم معاملات الإرتباط ما بين

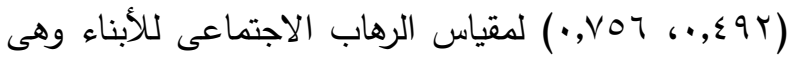

جدول r قيم معاملات الإرتباط بين الارجة الكلية لكل محور والدرجة الكلية لمقياسى الاغتراب الزواجى كما تدركه الزوجة، وكفاءتها

\begin{tabular}{|c|c|c|c|c|}
\hline مستوى الد لالة & معامل الإرتباط & عدد العبارات & المحاور & المقياس \\
\hline$\cdot, \cdot 1$ & $\cdot, \Lambda Y Y$ & 1. & الصمت الزواجى & \\
\hline$\cdot, .1$ & $\cdot, \wedge 97$ & ir & ضعف التواصل العاطفى والتآلفية & كما تاغتراب الزواجي \\
\hline$\cdot, \cdot 1$ & $\cdot, V \cdot r$ & 1. & العزلة وعدم المشاركة فى الحياة الزوجية & \\
\hline$\cdot, \cdot 1$ & $\cdot, V \leqslant 0$ & 1. & الرغبة فى أداء المهام المنزلية & \\
\hline$\cdot, \cdot 1$ & $\cdot, \wedge 77$ & 1. & القدرة على أداء المهام المنزلية & أكفاعة الانتاجية \\
\hline$\cdot, \cdot 1$ & $\cdot, V Y$. & 1. & الرضا عن أداء المهام المنزلية & فى الداء المهام \\
\hline$\cdot, .1$ & $\cdot, \lambda \mid r$ & 1. & الإبتكار فى أداء المهام المنزلية & \\
\hline
\end{tabular}


جدول r. قيم معامل الثبات للمقاييس الثلاثة (الاغتراب الزواجى كما تدركه الزوجة، وكفاءتها الإتتاجية، الرهاب الاجتماعى لأبنائها ن=

\begin{tabular}{|c|c|c|c|c|c|}
\hline جتمان & سبيرمان & معامل ألفا & عدد العبارات & المحاور & المقياس \\
\hline - , Vq & $\cdot, \mathrm{V} 90$ & $\cdot, \wedge \leqslant \wedge$ & 1. & الصدت الزواجى & \\
\hline$\cdot, \wedge 91$ & $\cdot, 9 \ldots$ & $\cdot, \wedge \wedge q$ & ir & ضعف التواصل العاطفى والتآلفية & الاغتراب الزواجى \\
\hline$\cdot, 109$ & $\cdot, \wedge \uparrow$. & $\cdot, \wedge)$ & 1. & العزلة وعدم المشاركة فى الحياة الزوجية & كما تدركه الزوجات \\
\hline$\cdot, \vee \vee \wedge$ & $\cdot, \wedge \cdot r$ & $\cdot, 911$ & r & 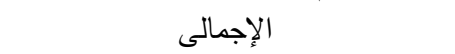 & \\
\hline$\cdot, \wedge \wedge \wedge$ & $\cdot, \wedge 91$ & $\cdot, \lambda \vee r$ & 1. & الرغبة فى أداء المهام المنزلية & \multirow{5}{*}{ أداء المهاءة الانتاجية فىلية } \\
\hline . & 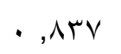 & $\cdot, \wedge т \leqslant$ & 1. & القدرة على أداء المهام المنزلية & \\
\hline$\cdot, 9 r v$ & $\cdot, 9 \uparrow ৭$ & $\cdot, 9 r r$ & 1. & الرضا عن أداء المهام المنزلية & \\
\hline . &., $9 Y \wedge$ & $\cdot 910$ & 1. & الإبتكار فى أداء المهام المنزلية & \\
\hline., 909 &., $97 r$ & $\cdot, 9 \leqslant 0$ & $\varepsilon$. & 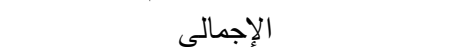 & \\
\hline$\cdot, \wedge \wedge 1$ & $\cdot, \wedge \wedge r$ & $\cdot, \wedge \vee 0$ & $1 \varepsilon$ & جتماعى للأبناء المراهقين & الرهاب \\
\hline
\end{tabular}

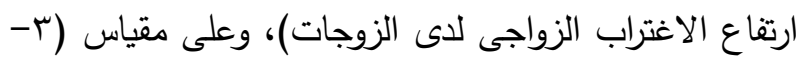
r- ( ) إذا كان إتجاه العبارة موجب (والذى يعنى انخفاض

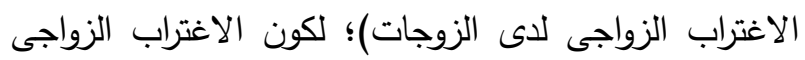
لاى الزوجات ظاهرة سلبية. كما تحددت استجابات الزوجات عينة البحث فى مقياس الكفاءة الإنتاجية بمحاورها وفق ثلاث استجابات (دائماً- أحياناً- نادراً) على مقياس متصل (1) (1) r- r) إذا كان اتجاه العبارة سالب (والذى يعنى انخفاض الكفاءة الإنتاجية لاى الزوجات)، والعكس صحيح إذا كان الناه إتجاه العبارة موجب؛ لكون الكفاءة الإنتاجية فى أداء المهام المنزلية ظاهرة موجبة، كما تحددت استجابات أبناء الزوجات عينة البحث فى مقياس الرهاب الاجتماعى وفق ثلاث

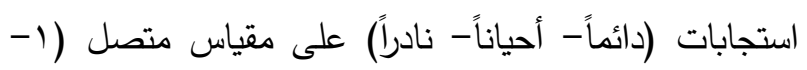
r- r) إذا كان اتجاه العبارة سالب (والذى يعنى ارتفاع

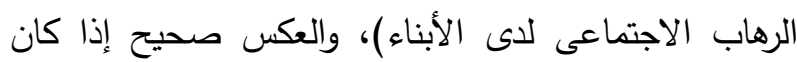
إتجاه العبارة موجب؛ لكون الرهاب الاجتماعى لإى الأبناء ظاهرة سلبية. وبذلك أمكن تقسيم المقاييس الثلاثة إلى ثلاث مستويات (منخفض - متوسط- مرتفع)، كما يتضح فى نتائج

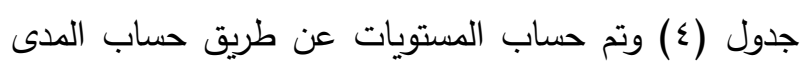
وطول الفئة.

$$
\begin{aligned}
& \text { المدى = أكبر درجة - أقل درجة }
\end{aligned}
$$

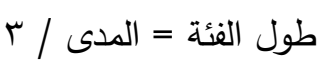

يتضح من نتائج جدول (ץ) أن قيم معامل ثبات ألفا والتجزئة النصفية لمحاور مقياس الاغتراب الزواجى والإجمالى، ومقياس الكفاءة الانتاجية لهن، والإجمالى، ومقياس الرهاب الاجتماعى لأبنائهن المراهقين كانت مرتفعة. مما يؤكد ثبات المقاييس وصلاحيتها للتطبيق فى البحث لابث

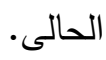
بناءً على ما سبق اشتمل مقياس الاغتراب الزواجى فى صورته النهائية على (rT) عبارة خبرية، وقد تضمن ثلاثة محاور :(الصمت الزواجى) • اعبارات، (ضعف التواصل العاطفى والتآلفية) ب اعبارة ،(العزلة وعدم المشاركة فى الحياة الزوجية) • (عبارات، كما اشتمل مقياس الكفاءة الإنتاجية فى ولى أداء المهام المنزلية فى صورته النهائية على (• (ء) عبارة خبرية، وقد تضمن أربعة محاور: (الرغبة فى أداء المهام

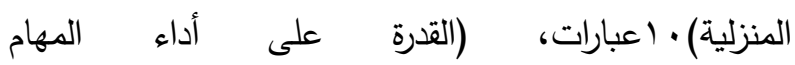
المنزلية) · اعبارات، (الرضا عن أداء المهام المنزلية). 1 عبارات، (الإبتكار فى أداء المهام المنزلية) • (عبارات، كما اشتمل مقياس الرهاب الاجتماعى للأبناء المراهقين فى صورته النهائية على (ع ا عبارة)، وقد تحددت إستجابات الزوجات عينة البحث فى مقياس الاغتراب الزواجى بمحاوره

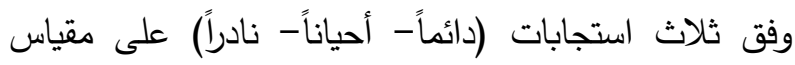
متصل (1- r- r) إذا كان اتجاه العبارة سالب(والذى يعنى 


\begin{tabular}{|c|c|c|c|c|c|c|c|c|}
\hline المنخفتوى & المتوستوى & المستوى & الفئة & المدى & الكبرى & الصغرى القراء & محاور الاستبيان البيان & \\
\hline rᄉ: & TY:IV & $17: 11$ & 0 & IV & rA & 11 & الصمت الزواجى & الاغتراب \\
\hline qז: דץ & ו & $r \cdot: l r$ & v & rr & דיץ & r & ضالتَففة التواصل العاطفى & كما تذركيه \\
\hline$r \cdot: Y \varepsilon$ & r & $17: 1$. & 7 & r. & r. & 1 . & 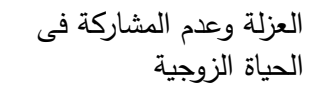 & \\
\hline q. : $\vee \leqslant \varepsilon$ & $V T: O V$ & or : : . & 17 & 0. & 9. & $\varepsilon$. & الاجمالي & \\
\hline rq: r & T): $: Y \varepsilon$ & $T T: 1 T$ & $\mathrm{~V}$ & rT & rq & 17 & الاجتماعى للابناء & الرهاب \\
\hline المستوى & المستوى & المستوى & طول & المدى & القراءة & القراءة & البيان & الكفاءة \\
\hline المرتفع & المتوسط & المنخفض & الفئة & & الكبرى & الصغرى & & الإنتاجية \\
\hline$r \cdot: r \varepsilon$ & Tr:IV & $17: 1$. & 7 & $r$. & $r$. & 1. & الرغبة فى أداء المهام & \\
\hline$r q: r \leq$ & 11 & IV:Ir & 0 & iv & rq & ir & المنزلية على أداء المهام & \\
\hline r.: & $r \leqslant: 19$ & $11: 1 \pi$ & 0 & iv & r. & r & الرضزليا عن أداء المهام & \\
\hline$r \cdot: Y \leq$ & $Y T: I V$ & $17: 1$ & 7 & r. & r. & 1 . & الإبتكار فى أداء المهام & \\
\hline & $q r: V r$ & VY:Or & 19 & 09 & $11 r$ & or & الإجمالي & \\
\hline
\end{tabular}

وفيما يلى بعض الأساليب الإحصائية المستحدمة لكثف العلاقة بين متغيرات البحث واختبار صحة الفروض: حساب الاب العدد والنسب المئوية، والمتوسطات الحسابية والإنحرافات المعيارية, معامل إرتباط بيرسون، وألفا كرونباخ، والتجزئة

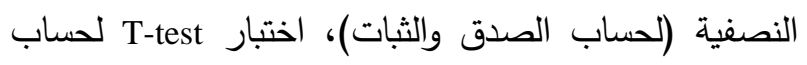
الفروق بين المتوسطات بالنسبة لمتغيرات الدراسة، وتحليل التباين أحادى الإتجاه One Way Anova للمقارنات المتعددة لتحديد اتجاه الدلالة.

\section{النتائج ومناقشتها}

أولاً: نتائج خصائص العينة من الزوجات والأبناء: وصف المتغيرات المتعلقة بخصائص عينة البحث:

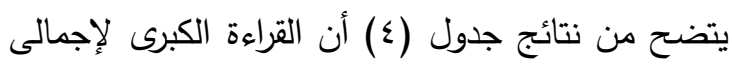
مقياس الاغتراب الزواجى كانت ـ والقراءة الصغرى كانت

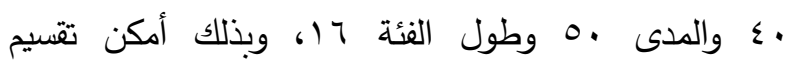
المقياس إلى ثلاث مستويات (مرتفع- متوسط- منخفض)،

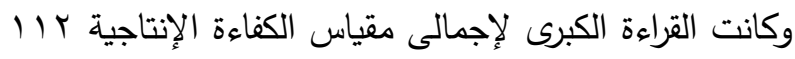

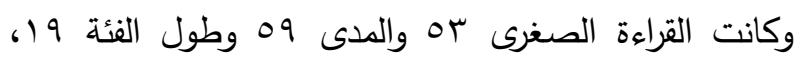
وبذلك أمكن تقسيم المقياس إلى ثلاث مستويات (منخفضمتوسط- مرتفع)، وكانت القراءة الكبرى لمقياس الرهاب

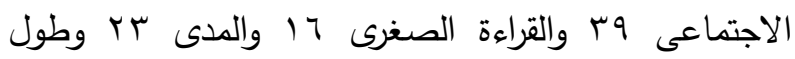
الفئة V، وبذلك أمكن تقسيم المقياس إلى ثلاث مستويات

$$
\text { (مرتفع - متوسط- منخفض). }
$$

الأساليب الإحصائية المستخدمة: بعد جمع البيانات وتفريغها تمت المعالجة الإحصائية بإستخدام برنامج (Spss) 
جدول هـ التوزيع النسبى لعينة البحث وفقا للخصائص الإجتماعية والإقتصادية (الايموغرافية)

\begin{tabular}{|c|c|c|c|c|c|}
\hline$\%$ & العدد & مكان السكن & $\%$ & العدد & جنس الأبناء \\
\hline$\leqslant 0,7$ & Iro & ريف & $\sum \wedge, r$ & ITH & ذكور \\
\hline $0 \leqslant, \varepsilon$ & $1 \leq 9$ & حضر & 01,1 & $1 \leq r$ & إناث \\
\hline $1 \ldots$ & $r V \varepsilon$ & الإجمالى & $1 \ldots$ & $r V \varepsilon$ & الإجمالى \\
\hline$\%$ & العدد الع & ترتيب الأبناء & $\%$ & العدد & عمل الزوجة \\
\hline$r \leq, \wedge r$ & 71 & الأول & $\varepsilon \vee, \Lambda)$ & |r & تعمل \\
\hline rT, §ᄉ & 19 & الأوسط & or, 19 & $1 \leqslant r$ & لا تعمل \\
\hline$\varepsilon r, V$. & 118 & الأخير & $1 \ldots$ & $r y<$ & \\
\hline $1 \ldots$ & $r V \varepsilon$ & الإجمالى & & Trz & الإل \\
\hline$\%$ & 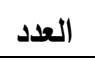 & حجم الأسرة & $\%$ & العدد & عمر الزوجة \\
\hline$\varepsilon \cdot, \wedge \wedge$ & 114 & صغير من r-ء أفراد & rA,AT & 19 & > 0 > سنة \\
\hline$r V, \cdot 1$ & $V \varepsilon$ & متوسط من 0- 7 أفراد & rq,07 & N) & من 0ب> 0؛ سنة \\
\hline rT,IT & $\wedge \wedge$ & كبير من V أفراد فأكثر & $\{1,7)$ & $11 \varepsilon$ & من 0 ـ سنة فأكثر \\
\hline $1 \ldots$ & $r V \varepsilon$ & الإجمالى & $1 \ldots$ & $r V \varepsilon$ & الإجمالى \\
\hline$\%$ & العدد الع & المستوى التعليمى للزوجة & $\%$ & العدد & مدة الزواج \\
\hline rr, $\{\Lambda$ & 19 & منخفض (يقرأ ويكتب - ابتدائية) & $r 0,9)$ & V) & من $17>$ • r سنة \\
\hline & & & $r 7, T \leq$ & $V r$ & من • • \\
\hline$r \varepsilon .7 V$ & 90 & متوسط (شهادة إعدادية- شهادة & $\leq \vee, \leqslant 0$ & $1 \pi$ & من ع r سنة فأكثر \\
\hline & & ثانوية وما يعادلها) & $1 \cdots$ & $r V \varepsilon$ & الاحمال \\
\hline rT, & 9. & مرتفع ( مؤهل جامعى - فوق & $\%$ & العدد العد & المستوى التعليمى للزوج \\
\hline $1 \ldots$ & TV乏 & الإجمالى & $r V, r V$ & vo & منخفض (يقرأ ويكتب - ابتدائية) \\
\hline$\%$ & 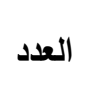 & مستوى الاخل الشهرى للأسرة & $r V, V \varepsilon$ & $V Y$ & متوسط (شهادة إعدادية- شهادة ثانوية \\
\hline r & 17 & منخفض (> > . . ب جنيه) & $\varepsilon \varepsilon, \wedge 9$ & Tr & مرتفع ( مؤهل جامعى - فوق \\
\hline$r \cdot, r q$ & $\wedge r$ & متوسط من ( . . ب > . . _ جنيه) & $1 \cdots$ & TVE & 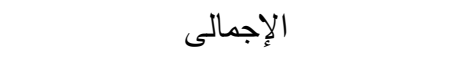 \\
\hline rᄉ,rr & 1.0 & مرتفع ( . . . ج جنيه فأكثر) & & & \\
\hline $1 \ldots$ & $r V \varepsilon$ & 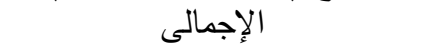 & & & \\
\hline
\end{tabular}

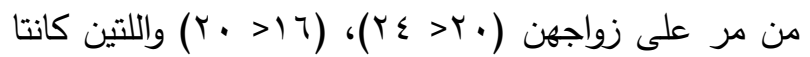

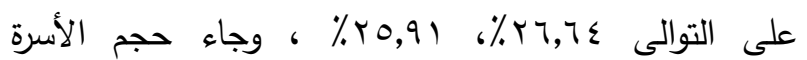

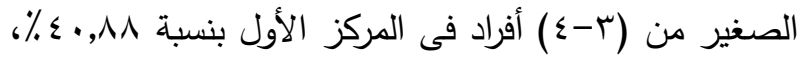

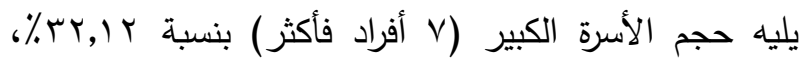

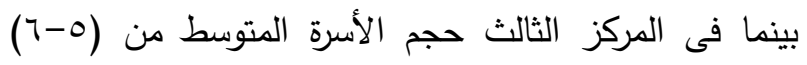

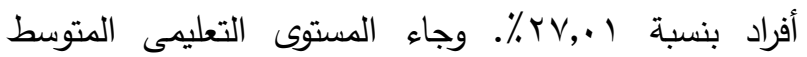
(شهادة إعدادية- شهادة ثانوية وما يعادلها) للزوجات عينة

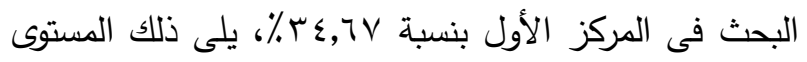
التعليمى المرتفع (الجامعى وفوق الجامعى) والذى تقارب فى نسبته مع المستوى التعليمى المنخفض(يقرأ ويكتب- شهادة
يتضح من نتائج جدول (0) إرتفاع نسبة عينة البحث

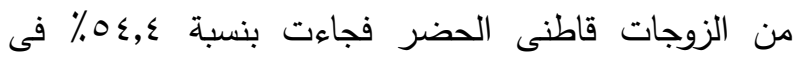
مقابل 0,7٪ ٪ من الزوجات قاطنى الريف، كما ارتفعت نسبة

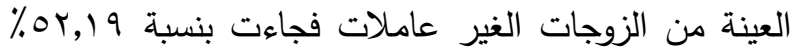

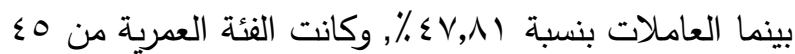
سنة فأكثر تقع بها النسبة الأكبر للزوجات عينة البحث بنسبة

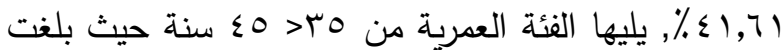

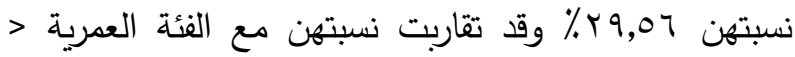

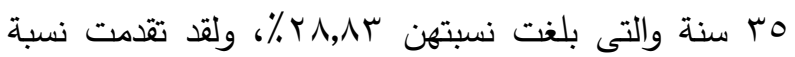

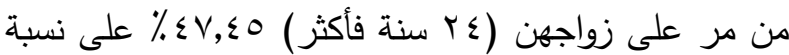


تقاربت مع نسبة الدخل الثهرى الدنخفض، وبالنسبة لأبناء العينة كان أكثرهم من الإناث بنسبة ^,1ه\%، بينما كانت لانت

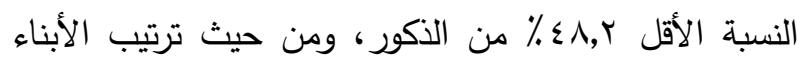

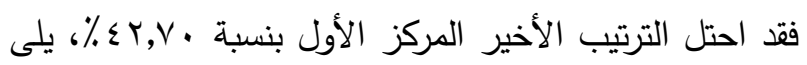

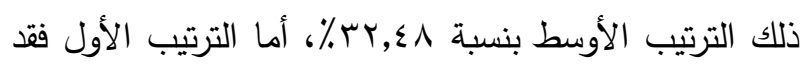

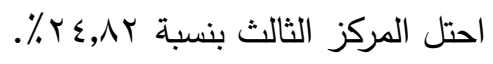
ثانياً: نتائج وصف العينة فى ضوء الإستجابات على أدوات

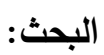

1- وصف الإستجابات على مقياس الاغتراب الزواجى كما

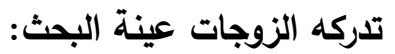

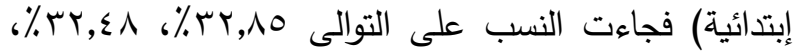
وجاء المستوى التعليمى المرتفع (الجامعى وفوق الجامعى)

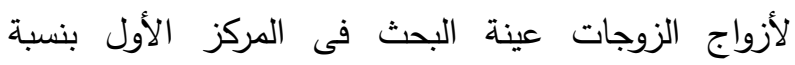

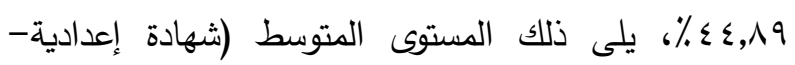

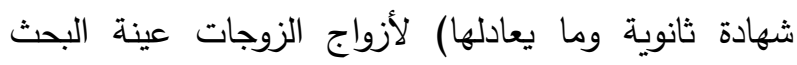
والذى تقارب فى نسبته مع المستوى التعليمى المنخفض (يقار الروات ويكتب- شهادة إبتدائية) فجاءت النسب على النى التوالى لقائى

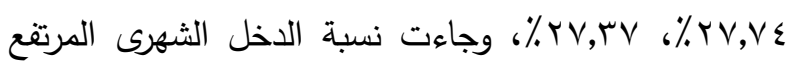

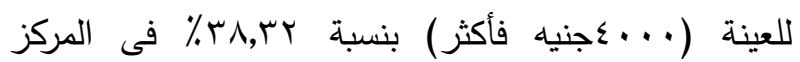

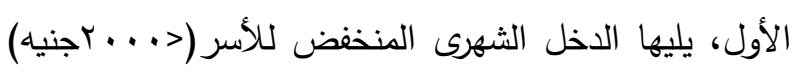

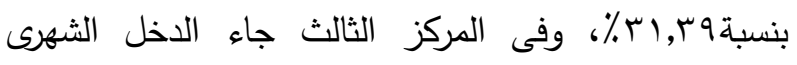

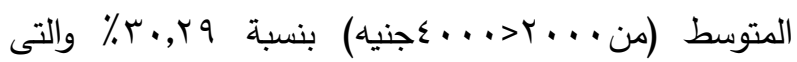

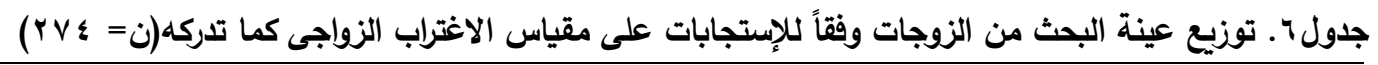

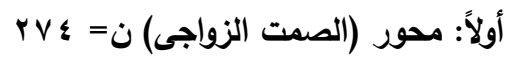

\begin{tabular}{|c|c|c|c|c|c|c|c|c|}
\hline الترتيب & 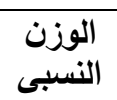 & المستوسط & نادراً & أحياناً & دائماً & العدد \% & العبارة & p \\
\hline \multirow[t]{2}{*}{1} & \multirow[t]{2}{*}{$\%$ \%,, V } & \multirow[t]{2}{*}{ I,Ar } & or & $|r|$ & 1.1 & العدد & \multirow{2}{*}{ بينى وبينه بكل الئيل. ويغلق أبواب الحوار } & \\
\hline & & & $19,$. & $\varepsilon \varepsilon, Y$ & r & $\%$ & & \\
\hline \multirow[t]{2}{*}{$\varepsilon$} & \multirow[t]{2}{*}{ \% } & \multirow[t]{2}{*}{1,91} & $7 \varepsilon$ & $|r|$ & 19 & العدد & \multirow{2}{*}{\multicolumn{2}{|c|}{ إهمالى بشتى وجودى مثل عدمه؛ فزوجى يتعد }} \\
\hline & & & $r T, \varepsilon$ & $\varepsilon \varepsilon, Y$ & rr,O & $\%$ & & \\
\hline \multirow[t]{2}{*}{ r } & \multirow[t]{2}{*}{$\%$ \%,r, } & \multirow[t]{2}{*}{$1, \wedge 7$} & 07 & ro & qr & العدد & \multirow{2}{*}{\multicolumn{2}{|c|}{ 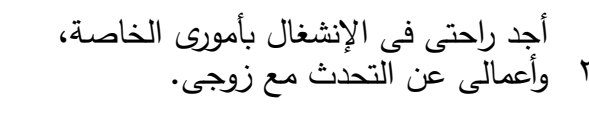 }} \\
\hline & & & $r_{\cdot, \ell}$ & $\varepsilon 0,1$ & $r r, q$ & $\%$ & & \\
\hline \multirow[t]{2}{*}{$\wedge$} & \multirow[t]{2}{*}{$\% \vee, r$} & \multirow[t]{2}{*}{$r, 1 \leq$} & $11 \varepsilon$ & $\Lambda \varepsilon$ & VI & العدد & \multirow{2}{*}{ 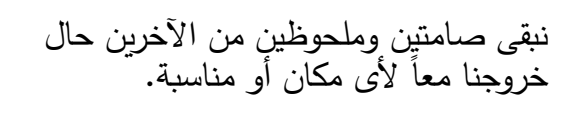 } & \\
\hline & & & $\varepsilon 1,7$ & $r \cdot, v$ & $r V, r$ & $\%$ & & \\
\hline \multirow[t]{2}{*}{9} & \multirow{2}{*}{$\% \vee r, T$} & \multirow{2}{*}{$r, r)$} & IrT & $\wedge$ & $T \varepsilon$ & العدد & \multirow{2}{*}{\multicolumn{2}{|c|}{ 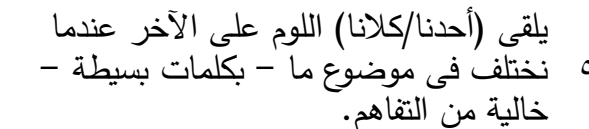 }} \\
\hline & & & $\varepsilon \leqslant, 0$ & rr, & $r r, \varepsilon$ & $\%$ & & \\
\hline \multirow[t]{2}{*}{7} & \multirow[t]{2}{*}{$\%$} & \multirow[t]{2}{*}{1,99} & vq & $11 \pi$ & NT & العدد & \multirow{2}{*}{\multicolumn{2}{|c|}{ 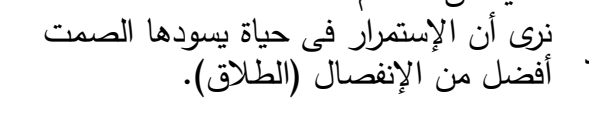 }} \\
\hline & & & $r \wedge, \Lambda$ & $\varepsilon 1, r$ & $r q, q$ & $\%$ & & \\
\hline \multirow[t]{2}{*}{$r$} & \multirow[t]{2}{*}{$\% \pi r, \wedge$} & \multirow[t]{2}{*}{$1, \wedge \Lambda$} & $7 \varepsilon$ & $11 \varepsilon$ & 97 & العدد & \multirow{2}{*}{\multicolumn{2}{|c|}{ 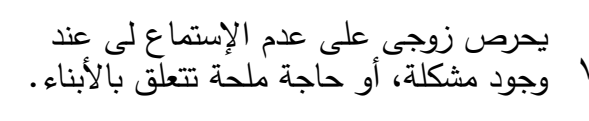 }} \\
\hline & & & $r r, \varepsilon$ & $\varepsilon 1, \uparrow$ & ro,. & $\%$ & & \\
\hline 9كرر & $\%$ & $r, r_{1}$ & 111 & 90 & 71 & العدد & \multicolumn{2}{|l|}{ 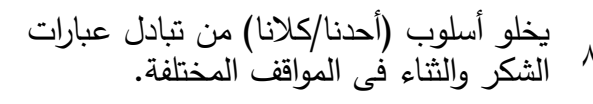 } \\
\hline \multirow[t]{2}{*}{0} & \multirow{2}{*}{$\% \neg \varepsilon, \vee$} & \multirow{2}{*}{$1,9 \leq$} & $\begin{array}{c}\varepsilon r, 1 \\
v .\end{array}$ & $\begin{array}{l}r \varepsilon, v \\
111\end{array}$ & $\begin{array}{l}r, r \\
\Lambda \tau\end{array}$ & 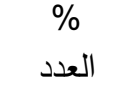 & يتردد (أحدنا/كلانا) عن إخبار الآخر عن & \\
\hline & & & ro, 0 & $\varepsilon r, 1$ & $r 1, \varepsilon$ & $\%$ & خططة المستقبلية. & \\
\hline 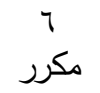 & $\% 47, r$ & 1,99 & $\begin{array}{l}V T \\
r V, V\end{array}$ & $\begin{array}{l}i r . \\
\varepsilon r, \Lambda\end{array}$ & $\begin{array}{c}r \Lambda \\
r \Lambda, 0\end{array}$ & 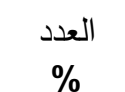 & 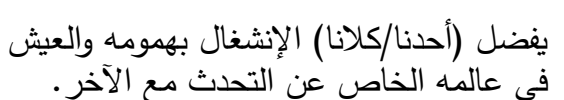 & \\
\hline
\end{tabular}


ثانياً: محور (ضعف التواصل العاطفى والتآلفية) ن=

\begin{tabular}{|c|c|c|c|c|c|c|c|c|}
\hline الترتيب & 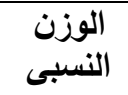 & الحسابى & نادراً & أحياناً & دائماً & $\begin{array}{l}\text { العدا } \\
\text { \% }\end{array}$ & العبارة & p \\
\hline 0 & $\%$ \%r,r. & $1, \wedge 7$ & $\begin{array}{ll}1 \cdots \\
m+0\end{array}$ & $\begin{array}{l}111 \\
\varepsilon \cdot, 0\end{array}$ & 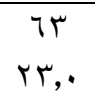 & \% & يُشعرنى زوجى أننى سأبقى المرأة الوحيدة فى & 1 \\
\hline V & $\%$ \% , & $1, \wedge 9$ & $\begin{array}{c}q \leq \\
r \leq, r\end{array}$ & $\begin{array}{l}11 V \\
\varepsilon r, V\end{array}$ & 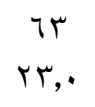 & 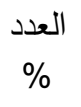 & أُو أُزمة زوجى تعاطفه معى عند مرورى بمشكلة & r \\
\hline 7 & $\%$ \%r,o. & $1, \wedge \wedge$ & $\begin{array}{l}09 \\
r 1,0\end{array}$ & $\begin{array}{l}1, r \\
\varepsilon \leqslant, 0\end{array}$ & $\begin{array}{l}q \mu \\
r, 9\end{array}$ & 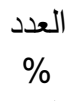 & لزوجى. أجدوبة فى التعبير عن مشاعر الضيق & $r$ \\
\hline 1 & $\% \circ \wedge, 0$. & $1, \times 7$ & $\begin{array}{l}\varepsilon r \\
10, r\end{array}$ & $\begin{array}{l}1 Y r \\
\varepsilon \leqslant, 9\end{array}$ & $\begin{array}{l}1.9 \\
r 9,1\end{array}$ & 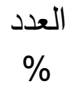 & الّعاطفية. الجفاء والخصام على علاقتنا & $\varepsilon$ \\
\hline$r$ & $\% 7,9$. & س & $\begin{array}{l}0 Y \\
r \cdot, \varepsilon\end{array}$ & $\begin{array}{l}110 \\
\varepsilon r, .\end{array}$ & $\begin{array}{l}1 \cdot r \\
r v, t\end{array}$ & 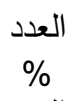 & اليجسباب. (أحدنا/كلانا) مشاعر الآخر لأتفه & 0 \\
\hline r & $\%$ & 1,1 & $\stackrel{0 .}{1 \Lambda, r}$ & $\begin{array}{l}l r \\
\varepsilon r, \Lambda\end{array}$ & $\begin{array}{l}1 \cdot \varepsilon \\
r \Lambda, .\end{array}$ & 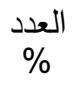 & وإهتمامه تجاه منا على عدم التعبير عن حبه، & 7 \\
\hline 9 & $\%$ \% , ¿ . & $r, \cdot r$ & $\stackrel{\mu}{\mu}$ & $\begin{array}{l}11 \leq 5 \\
1,7\end{array}$ & $\begin{array}{l}V V \\
Y \wedge, 1\end{array}$ & 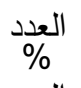 & لا يُبدى زوجى إهتمام بأى تغيير فى مظهرى. & V \\
\hline IT & $\% \vee r, 1$. & Y, 17 & $\begin{array}{l}V_{0} \\
r V, \varepsilon\end{array}$ & $\begin{array}{l}\vee q \\
r \wedge, \wedge\end{array}$ & $\begin{array}{l}1 r \\
\varepsilon r, \Lambda\end{array}$ & 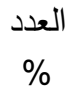 & مهما حاولت زوجى ملاحظة مضائها. & $\wedge$ \\
\hline$\varepsilon$ & $\%$ \% & $1, \wedge \varepsilon$ & $\begin{array}{c}q \leq \\
r \leq, r\end{array}$ & $\begin{array}{l}1 \times q \\
\varepsilon \vee, 1\end{array}$ & $\begin{array}{l}01 \\
11,7\end{array}$ & 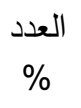 & نجى بمعرفة ما يجذب إنتباهى. & 9 \\
\hline$\wedge$ & $\% / 0,0$. & 1,97 & $\begin{array}{c}\Lambda \varepsilon \\
r \cdot, V\end{array}$ & $\begin{array}{l}117 \\
\varepsilon r, r\end{array}$ & $\begin{array}{l}V \leq \\
r V\end{array}$ & 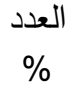 & تعوقنىيع زن أداء أعتواء مشاعر الإجهاد التى & 1. \\
\hline 1. & $\%$ \% , . & $r, \cdot V$ & $\begin{array}{l}91 \\
r r, r\end{array}$ & $\begin{array}{ll}V r \\
r T, T\end{array}$ & 11 & 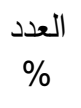 & يُشعرنى زوجى بقيمة ما أؤديه من أعمال. & 11 \\
\hline 11 & $\% \vee,,$, & $\begin{array}{l}r, 1 \\
r, \mid \Lambda\end{array}$ & $\begin{array}{l}79 \\
r 0, r\end{array}$ & $\begin{array}{l}1 \cdot 1 \\
r 9, \varepsilon\end{array}$ & $\begin{array}{l}9 V \\
r 0, \varepsilon\end{array}$ & 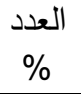 & أحب مؤانسة زوجى، وتودده لى. & it \\
\hline
\end{tabular}




$$
\text { مجلة الإسكندرية للتبادل العلمى - (مجلد \& العدد ( ) يناير - مارس اY.r }
$$

ثالثاً: محور (العزلة وعدم المثاركة فى الحياة الزوجية) ن = ؟V

\begin{tabular}{|c|c|c|c|c|c|c|c|c|}
\hline الترتيب & 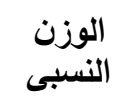 & المستوسط & نادراً & أحياناً & دائماً & العدد \% & العبارة & p \\
\hline$\varepsilon$ & $\%\ulcorner\varepsilon, 1$. & 1,94 & $\begin{array}{c}t r \\
r, T\end{array}$ & $\begin{array}{l}1 Y 9 \\
\varepsilon v, 1\end{array}$ & $\begin{array}{ll}\mu r \\
\mu \cdot, r\end{array}$ & $\begin{array}{l}\text { العدد } \\
\%\end{array}$ & 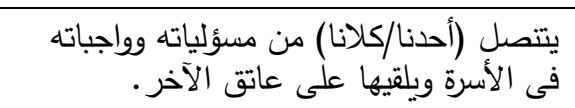 & 1 \\
\hline r & $\%$ \%, r. & $1, \wedge \varepsilon$ & $\sum \wedge$ & $\begin{array}{l}1 r \varepsilon \\
\varepsilon \wedge, 9\end{array}$ & Tr & العدد & حلتها. التهرف زوجى مشكلاتهم مصادقة مساعدتها ولا فيحاول & $r$ \\
\hline 1 & $\%, 7,0$ & $1, \wedge 1$ & $\begin{array}{l}00 \\
r \cdot, 1\end{array}$ & $\begin{array}{ll}11 r \\
\Sigma 1, r\end{array}$ & $\begin{array}{l}1.7 \\
r \Lambda, V\end{array}$ & 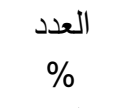 & تنسيطر الوحدة والعزلة على نعط حياتتا رغم & $r$ \\
\hline$\Lambda$ & $\% \vee, r$. & $r, 1 \varepsilon$ & $\begin{array}{l}11 \leq \\
1,7\end{array}$ & 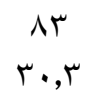 & $\begin{array}{l}V V \\
Y \wedge, 1\end{array}$ & 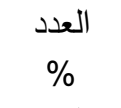 & أفيتد التعاون والمشاركة من زوجى فى المواقف & $\varepsilon$ \\
\hline 7 & $\%$ \%,$\wedge$. & $r, \cdot r$ & 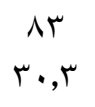 & $\begin{array}{l}11 V \\
\varepsilon r, V\end{array}$ & $\begin{array}{l}V \varepsilon \\
r V\end{array}$ & 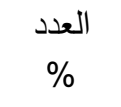 & أفضل الجلوس وحيدة عن الجلوس مع زوجى. & 0 \\
\hline v & $\%$ \% , $\vee$ & $r, . q$ & $\begin{array}{l}11 \leq \\
\leq 1,7\end{array}$ & $\begin{array}{l}v 1 \\
r 0,9\end{array}$ & $\begin{array}{c}\wedge q \\
r r, 0\end{array}$ & 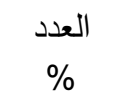 & الخلب على معظم قراراتتا الأسرية طابع & 1 \\
\hline 0 & $\%$ \%, $\vee$ & r & $\begin{array}{c}\wedge \\
r q, 4\end{array}$ & $\begin{array}{l}11 r \\
\varepsilon \cdot, 9\end{array}$ & $\begin{array}{c}\wedge \\
r q, 7\end{array}$ & 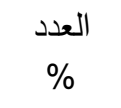 & لـ جدم جدود زوجى فى المنزل. & V \\
\hline 9 & $\% \vee r, r$. & T,IV & $\begin{array}{l}Y 1 \\
r 0,9\end{array}$ & $\begin{array}{l}14 \\
M, \varepsilon\end{array}$ & $\begin{array}{l}11 V \\
\varepsilon r, V\end{array}$ & 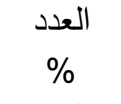 & تيقت زوجى بطرح حلول للمشاكل التى & $\wedge$ \\
\hline 1. & $\% \vee r, r$. & $r, r$ & $\begin{array}{l}r 1 \\
r 0,9\end{array}$ & $\begin{array}{l}\vee \wedge \\
r \wedge, 0\end{array}$ & $\begin{array}{l}1 r_{0} \\
\varepsilon 0,7\end{array}$ & 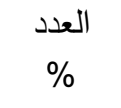 & يشارك (أحدنا/كلانا) الآخر أفراحه وهمومه. & 9 \\
\hline$r$ & \% \%, . & 1,19 & $\begin{array}{lll}n \\
r \\
r, r \\
\end{array}$ & $\begin{array}{l}l r r \\
\varepsilon \leqslant, 0\end{array}$ & $\begin{array}{ll}91 \\
M T, r \\
r\end{array}$ & 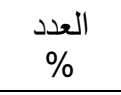 & التيحرل حتى زوجى علتى بـى قضاء وقت طويل خارج & 1. \\
\hline
\end{tabular}

ولعدم القدرة على إتاحة حوار، ومناقشة هادئة وفعالة. ونجد أن عبارة " يحرص زوجى على عدم الإستماع لى عند وجود

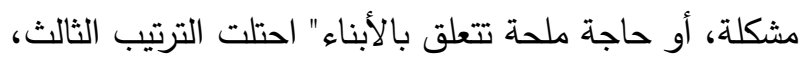
وقد جاءت بوزن نسبى ^,r؟ ٪\%، قد يرجع ذلك لقناعة كلٍ

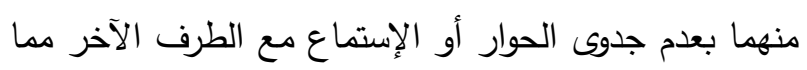
يؤدى لزيادة الفجوة بينهما، والتأثير السلبى على الإسلى التواصل

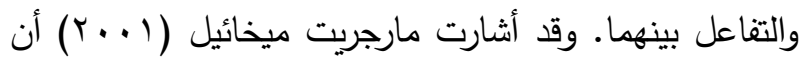
حُسن الإنصات بين الزوجين يعمل على الحفاظ على الحياة الزوجية؛ لذلك يجب أن ينصت كل طرف للآخر ويستوعب لإنبات

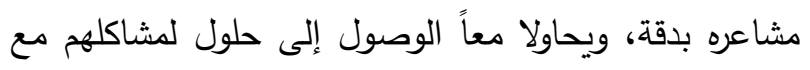
توافر الإحترام بينهما. بالنسبة للمحور الثانى ضعف التواصل العاطفى والتآلفية نجد أن أعلى استجابة للزوجات عينة البحث كانت لعبارة "يسيطر الجفاء والخصام على علاقتنا
يتضح من نتائج جدول (†) بالنسبة للمحور الأول

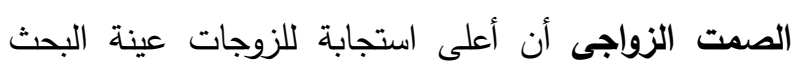
كانت لعبارة "يفضل زوجى الصمت ويغلق أبواب الحوار بينى وبينه بكل السُبل" حيث احتلت الترتيب الأول وجاءت بوزن

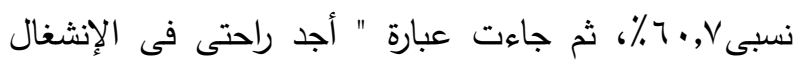
بأمورى الخاصة، وأعمالى عن التحدث مع زوجى" لتحتل

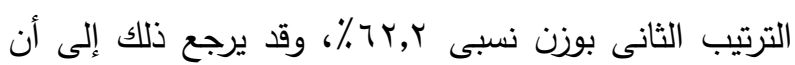

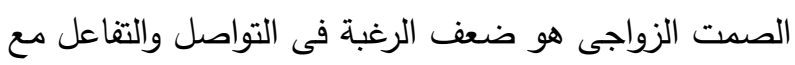
شريك الحياة، مما يجعل الحياة الزوجية باهتة، وفارغة من المضمون، ومصدر للهموم. وفى هذا الصدد أشارت نازلك

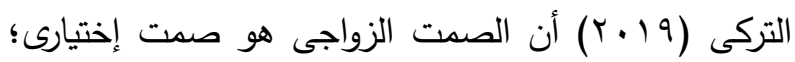

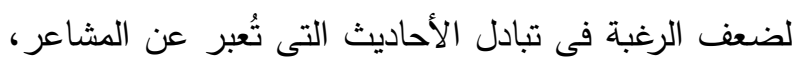

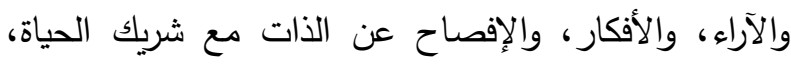


الصدد ذكر السيد جابر (T/ ب) أن من الأعراض الواضحة للاغتراب الزواجى أن يشعر المغترب بالوحدة حتى لو كان

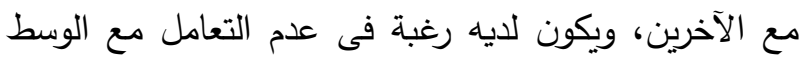

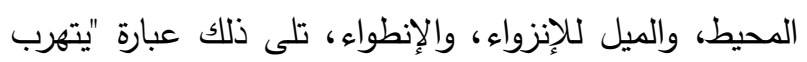

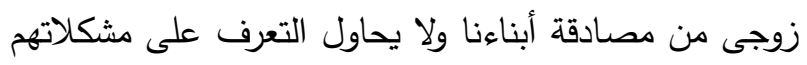

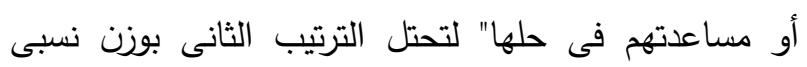

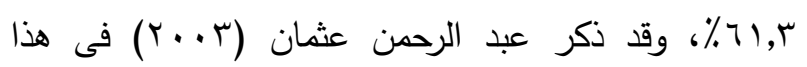

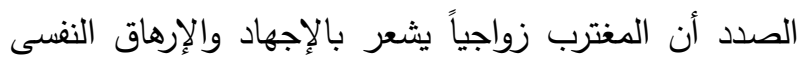

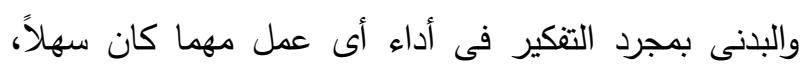

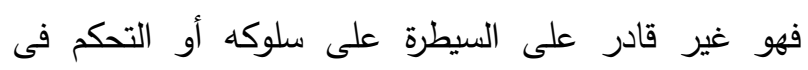

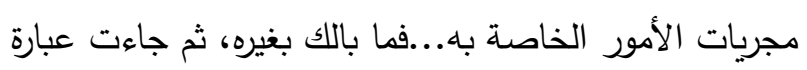

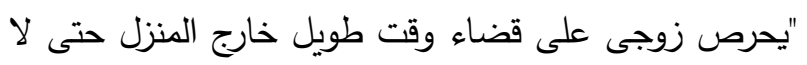

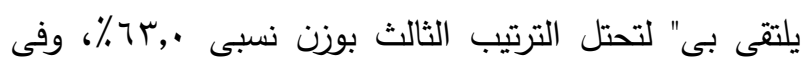

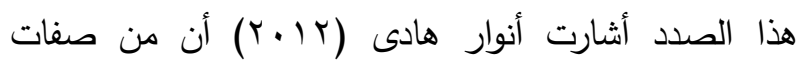

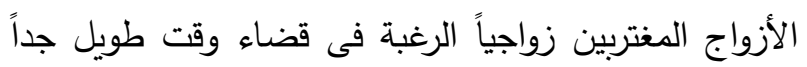
خارج المنزل؛ لرغبتهم فى عدم التواصل مع الشريك الآخر .

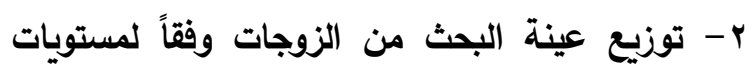

الاغتراب الزواجى (بمحاوره، والإجمالى):
العاطفية"، حيث احتلت الترتيب الأول وجاءت بوزن نسبى

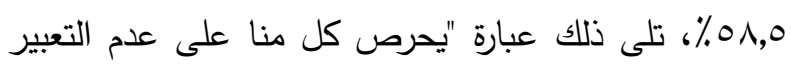

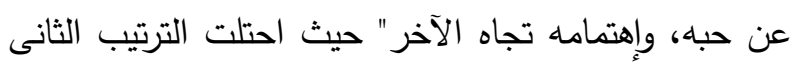
بوزن نسبى ا,.r\%٪، ثم جاءت عبارة "يجرح (أحدنا/كلانا)

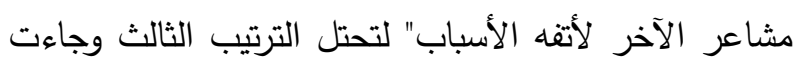

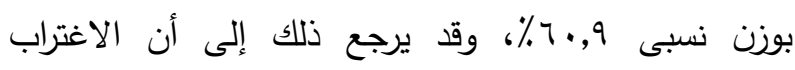

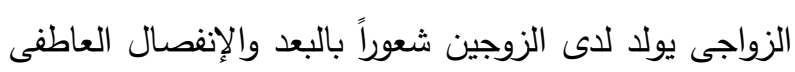

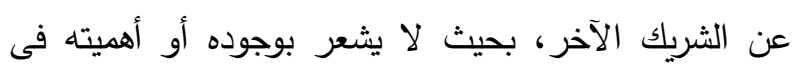

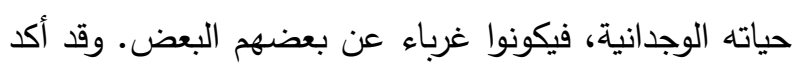

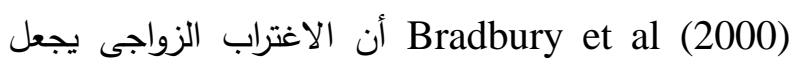

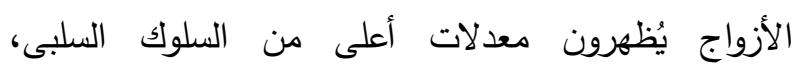

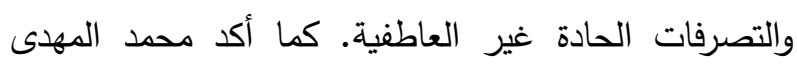

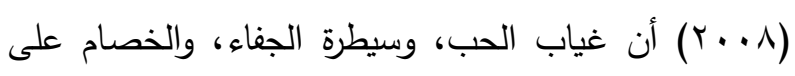
العلاقة الزوجية من أسباب فثل الحياة الزوجية والثعور

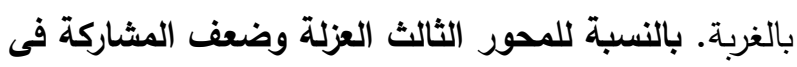
الحياة الزوجية نجد أن أعلى استجابة للزوجات عينة البحث لئل

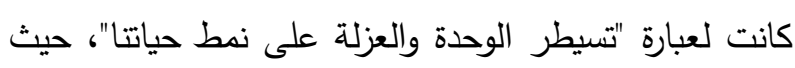

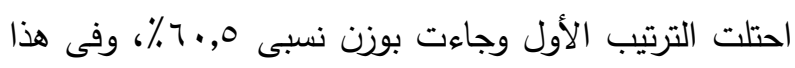

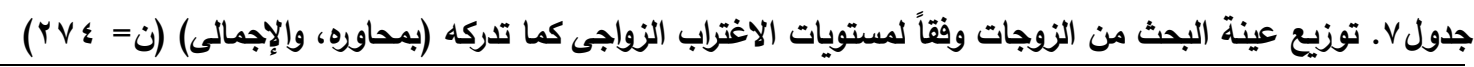

\begin{tabular}{|c|c|c|c|c|c|}
\hline الترتيب & للأزبوان التنبيبيةً & $\%$ & العدد & المستوى & المحاور \\
\hline \multirow[b]{3}{*}{ 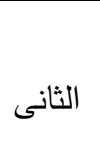 } & \multirow{4}{*}{$\% \pi 4,0$} & rI, Vo & AV & مرتفع (1/:7 1) & \multirow{5}{*}{ الصدت الزواجى } \\
\hline & & ro, V V & 91 & متوسط (Y:IV) & \\
\hline & & rY, ¿A & 19 & 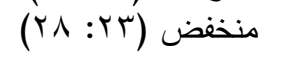 & \\
\hline \multirow{4}{*}{ 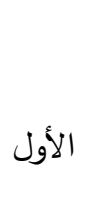 } & & $1 \ldots$ & $r V \varepsilon$ & المجموع & \\
\hline & \multirow{4}{*}{$\% \uparrow \varepsilon, \varepsilon$} & $r q, \varepsilon r$ & 1.1 & مرتفع (r/: & \\
\hline & & $\varepsilon 1, q \vee$ & 110 & متوسط (YlY: & \multirow{3}{*}{ ضعاطفى التواصلية } \\
\hline & & $|\Lambda, 7|$ & 01 & منخفض (q r: צr) & \\
\hline \multirow{9}{*}{ الثالث } & & $1 \ldots$ & $r V \varepsilon$ & الدجموع & \\
\hline & \multirow{8}{*}{$\%$ \%v, } & $Y V, V \varepsilon$ & $v_{7}$ & مرتفع (•(: 17) & \multirow{4}{*}{ فلى الحياة الزوجية المشاركة } \\
\hline & & $\varepsilon 1, r \leqslant$ & 114 & متوسط (YYIV) & \\
\hline & & rI,. r & 10 & منخفض (צ r: . .r) & \\
\hline & & $1 \ldots$ & $T V \varepsilon$ & المجموع & \\
\hline & & Tr,AO & 9. & مرتقع (. ؛: 407 & \multirow[t]{4}{*}{ الإجمالى } \\
\hline & & $\{V, \Lambda)$ & $1 \pi$ & متوسط (OV:OV) & \\
\hline & & $19, r \varepsilon$ & or & 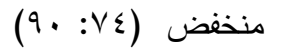 & \\
\hline & & $1 \ldots$ & $T Y \varepsilon$ & المجموع & \\
\hline
\end{tabular}


الطرف الآخر يقلل من عملية التواصل بينهما مؤدياً بدوره إلى

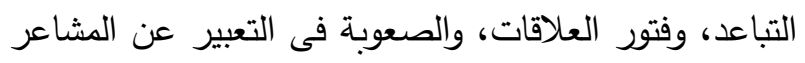

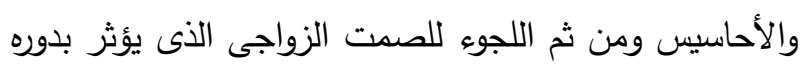

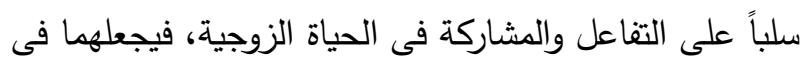
عزلة وهما تحت سقف واحد. تتفق هذه النتيجة مع كلٍ من النياه

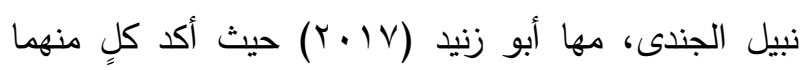
على أهمية التواصل العاطفى بين الزوجين لما له من أثرٍ بالغِ

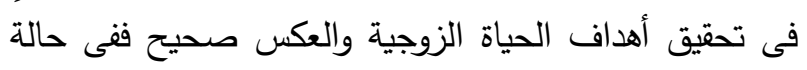

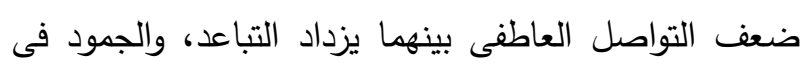

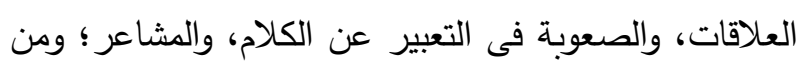
ثم اللجوء إلى الصمت الزواجى الذى يؤثر على الأسرة بشكلٍ خاص، وعلى الحياة الزوجية بشكلٍ عام.

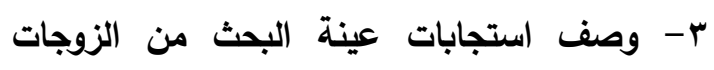
مقياس الكفاءة الإنتاجية فى أداء المهام المنزلية:
يتضح من نتائج جدول (V) بالنسبة للنسب الترجيحية للأوزان النسبية أن ضعف التواصل العاطفى والتآلفية احتل

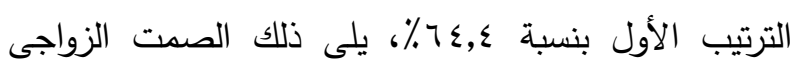

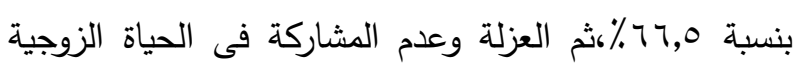

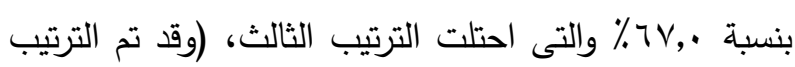

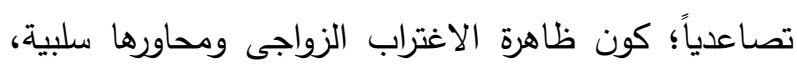
فكلما انخفضت النسبة دليل على انتشار وتفشى الظاهرة).

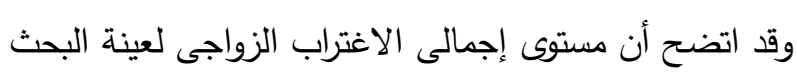

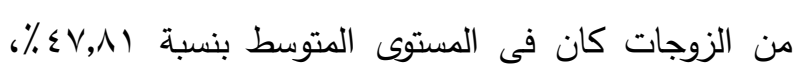

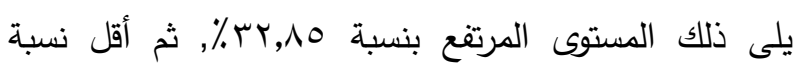

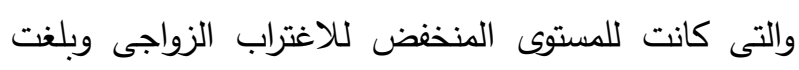
؟ ؟, 1\%٪. تلك النتائج إنذار بدق ناقوس الخطر على الحياة

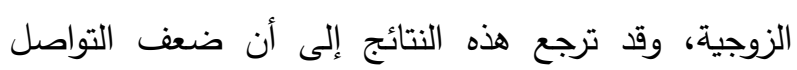

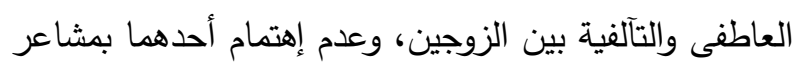

جدول ^. توزيع عينة البحث من الزوجات وفقاً للإستجابات على مقياس الكفاءة الإنتاجية فى أداء المهام المنزلية ن= ؛ ؟

\begin{tabular}{|c|c|c|c|c|c|c|c|c|}
\hline \multicolumn{9}{|c|}{ أولاً: محور (الرغبة فى أداء المهام المنزلية) ن= ؟VV } \\
\hline الترتيب & 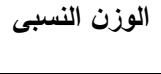 & المستبط & 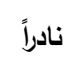 & أحياناً & دائماً & 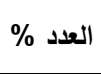 & 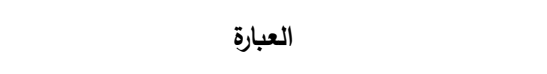 & م \\
\hline \multirow{2}{*}{$\wedge$} & \multirow[t]{2}{*}{$\%$ \% , ६. } & \multirow[t]{2}{*}{$r, \cdot r$} & TV & $1 \pi \varepsilon$ & $v \pi$ & العدد & \multirow{2}{*}{ أشعر بالسعادة عند القيام بالمهام المنزلية المفضلة لى. } & \multirow{2}{*}{1} \\
\hline & & & $r \xi, 0$ & $\sum \wedge, q$ & $r 4, T$ & $\%$ & & \\
\hline \multirow{2}{*}{$\varepsilon$} & \multirow[t]{2}{*}{$\% \vee \uparrow, \wedge}$. & \multirow[t]{2}{*}{$r, 10$} & ir. & vi & $\vee \wedge$ & العدد & \multirow{2}{*}{ تحديات. عن إكمال أى مهام منزلية أواجه فيها عقبات أو } & \multirow{2}{*}{ r } \\
\hline & & & $\varepsilon r, \wedge$ & $r v, v$ & $r \wedge, 0$ & $\%$ & & \\
\hline \multirow[t]{2}{*}{ r } & $\% \vee r, \varepsilon$. & $r, Y$ & 10 & $\wedge 9$ & ir. & العدد & \multirow{2}{*}{ أقبل على أداء المهام المنزلية بحماس. } & \multirow{2}{*}{$r$} \\
\hline & & & $r r, V$ & $r r, O$ & $\varepsilon r, \wedge$ & $\%$ & & \\
\hline \multirow{2}{*}{1.} & $\%\urcorner \varepsilon, \vee$. & $1,9 \leqslant$ & $v \varepsilon$ & $1 \leqslant r$ & 01 & 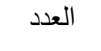 & \multirow{2}{*}{ أهتم بتحديد وقت لكل عمل وتأديته فى الوقتت } & \multirow{2}{*}{$\varepsilon$} \\
\hline & & & $r v, \cdot$ & 01,1 & $r, r$ & $\%$ & & \\
\hline \multirow{2}{*}{9} & $\%\urcorner \vee, .$. & r,. & V4 & 119 & va & 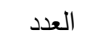 & \multirow{2}{*}{ أشعر بالثقة بالنفس عند أدائى لمهامى المنزلية. } & \multirow{2}{*}{0} \\
\hline & & & $r V, V$ & $\varepsilon r, \varepsilon$. & $\curlyvee \wedge, \wedge$ & $\%$ & & \\
\hline \multirow{2}{*}{7} & $\%$ \%,^. & $r, .9$ & 79 & 11. & 90 & العدد & \multirow{2}{*}{ أخطط لأداء المهام المنزلية وفقاً لأهميتها. } & \multirow{2}{*}{1} \\
\hline & & & ro,r & $\varepsilon \cdot, 1$ & $r \varepsilon, V$ & $\%$ & & \\
\hline \multirow{2}{*}{1} & $\% \vee r, v$. & $r, Y)$ & ir. & 94 & $T$ & العدد & \multirow{2}{*}{ أشعر بضعف الهمة بسرعة عند أداء مهامى المنزلية. } & \multirow{2}{*}{ v } \\
\hline & & & $\varepsilon r, \wedge$ & rr,T & YY,T & $\%$ & & \\
\hline \multirow{2}{*}{ v } & $\%$ \%৭,г. & $r, \cdot \Lambda$ & 91 & $11 \varepsilon$ & 79 & العدد & \multirow{2}{*}{ أشعر أن العمل فى المنزل لا يتناسب مع ما أطمح به. } & \multirow{2}{*}{$\wedge$} \\
\hline & & & rr, & $\varepsilon 1,7$ & $r 0, r$ & $\%$ & & \\
\hline$r$ & $\% \vee 1, q$. & $r, 17$ & $\begin{array}{l}11 r \\
\varepsilon \cdot, 9\end{array}$ & $\begin{array}{l}q \mu \\
r r, q\end{array}$ & $\begin{array}{l}79 \\
r 0, r\end{array}$ & 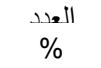 & أحرص على تأجيل عمل اليوم إلى الغد. & 9 \\
\hline \multirow{2}{*}{0} & \multirow{2}{*}{$\% \vee \cdot,+4$} & \multirow{2}{*}{ T,IT } & $\wedge$. & Ar & $11 \%$ & العدد & \multirow{2}{*}{ أشعر بالنشاط عند بدء قيامى بالمهام المنزلية. } & \multirow{2}{*}{1 . } \\
\hline & & & $r q, r$ & $r q, q$ & $\varepsilon, q$ & $\%$ & & \\
\hline
\end{tabular}




\begin{tabular}{|c|c|c|c|c|c|c|c|c|}
\hline \multicolumn{9}{|c|}{ ثانياً: محور (القدرة على أداء المهام المنزلية) ن= ؛ YV } \\
\hline 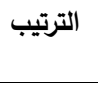 & الوزن النسبى & المستوسط المسبى & نادراً & أحياناً & دائماً & العدد \% & 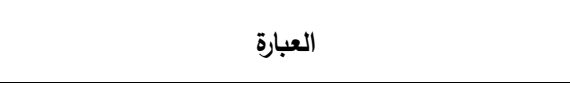 & 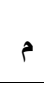 \\
\hline \multirow{2}{*}{1.} & \multirow[t]{2}{*}{$\% \circ 9,7$} & \multirow[t]{2}{*}{$1, \vee 9$} & $1 \cdot \varepsilon$ & Irs & $\varepsilon 7$ & 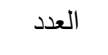 & \multirow{2}{*}{\multicolumn{2}{|c|}{ أمتلك القدرة على مواصلة أدائى لمهامى المنزلية حتى }} \\
\hline & & & rᄉ,. & $\varepsilon 0, r$ & 17,1 & $\%$ & & \\
\hline \multirow{2}{*}{$r$} & \multirow[t]{2}{*}{$\% \vee r, q$} & \multirow{2}{*}{$r, 19$} & & 1० & ir. & 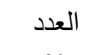 & \multirow{2}{*}{ أحرص على أخذ قسط من الراحة بمجرد الثعور بالتعب. } & \multirow{2}{*}{ r } \\
\hline & & & $r 0, r$ & r.,. & $\leqslant r, \Lambda$. & $\%$ & & \\
\hline \multirow[t]{2}{*}{1} & \multirow[t]{2}{*}{$\% \vee r, \varepsilon}$. & \multirow[t]{2}{*}{$r, r$} & 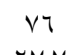 & TV & 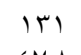 & 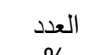 & \multirow{2}{*}{ أحاول إتباع طرق تبسيط الأعمال المنزلية. } & \multirow[t]{2}{*}{ r } \\
\hline & & & $r V, V$ & $r \leqslant, 0$ & $\varepsilon \vee, \wedge$ & $\%$ & & \\
\hline \multirow[t]{2}{*}{$\varepsilon$} & \multirow{2}{*}{$\% \vee 1, \vee$} & \multirow[t]{2}{*}{$r, 10$} & 79 & $1 \cdot 1$ & $1 \cdot v$ & 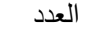 & \multirow{2}{*}{ أحرص على ترتيب مكان العمل ليسهل قيامى بمهامى } & \multirow{2}{*}{$\varepsilon$} \\
\hline & & & $r \leqslant, 1$ & ru,q & $r q, 1$ & $\%$ & & \\
\hline \multirow{2}{*}{ V } & \multirow[t]{2}{*}{$\%$ \% r. } & \multirow[t]{2}{*}{1,97} & $\vee \cdot$ & irt & Ar & 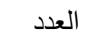 & & 0 \\
\hline & & & ro,0 & $\varepsilon \varepsilon, 0$ & r৭,१ & $\%$ & 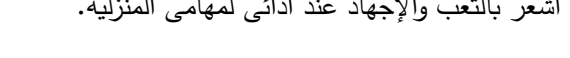 & 0 \\
\hline 1 & $\% 70,7$ & $1,9 V$ & $\wedge$ & $|r|$ & VY & 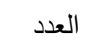 & أستطيع أداء أكثر من عمل في وقت واحد. & T \\
\hline & & & $r 9.7$ & $\varepsilon \varepsilon . r$ & r..r & $\%$ & & \\
\hline 0 & $\%$ \% , ฯ & $r, \cdot r$ & & & $\wedge \mathrm{T}$ & 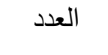 & أستطيع تنفذ الخطة البومية لمهامـ المنزلية كاملة. & $\mathrm{v}$ \\
\hline & & & $r \wedge, 0$ & $\varepsilon \cdot, 1$ & M, & $\%$ & & \\
\hline (مكر) & $\% \vee r, \varepsilon$. & $r, r$ & $7 \wedge$ & N & IrT & العدد & & ᄉ \\
\hline امحرر & & & $r \leq, \wedge$ & $r \cdot, r$ & $\varepsilon \varepsilon, 9$ & $\%$ & على اداء مهامى المنزليه بسرعه دون تباطؤ. & $\Lambda$ \\
\hline$\Lambda$ & $\%\ulcorner\varepsilon, \wedge$ & 1,90 & Ar & iro & TV & 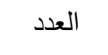 & أراعى الوضع الصحيح للجسم عند أدائى & 9 \\
\hline$\Lambda$ & & & $r 9,9$ & $\varepsilon 0,7$. & $r \leqslant, 0$ & $\%$ & لمهامى المنزلية. ل & 4 \\
\hline 9 & \% \%r, & I, $\mathrm{NV}$ & 97 & 111 & 7. & 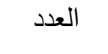 & أراعى تجزئة المهام المنزلية المطلوبة منى؛ ليسهل على & 1. \\
\hline 7 & $1.1,1$. & $1, N \mathrm{~V}$ & ro,. & $\varepsilon r, 1$ & Y 1,9 & $\%$ & & 1. \\
\hline & & & & $\varepsilon=\dot{0}$ & 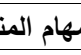 & 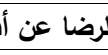 & 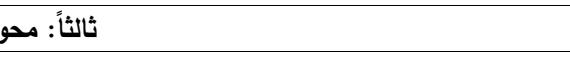 & \\
\hline 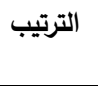 & 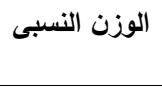 & المتوسط الحسابى & 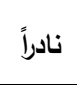 & أحياناً & 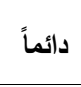 & العدد \% & العبارة & م \\
\hline 0 & $\% \vee r, 0$ & $r, r$ & 09 & $1 \cdots$ & 110 & 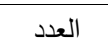 & أشعر بالفخر تجاه الأعمال والمهام المنزلية التى أقوم & 1 \\
\hline 0 & & & $r_{1,0}$ & rา,o & $\varepsilon r$, & $\%$ & & 1 \\
\hline 1 & 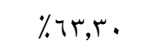 & 1,9 & V) & 17 & $\varepsilon r$ & 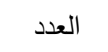 & أشعر بالرضا عن الأدوات والأجهزة المستخدمة فى أداء & $r$ \\
\hline 1 . & & & $r 0,9$ & $0 \wedge, \varepsilon$ & $10, \mathrm{~V}$ & $\%$ & مهامى المنزلية. & $T$ \\
\hline r & $\% \vee \vee, \vee$. & $r, Y V$ & 70 & $\vee \cdot$ & 149 & 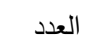 & أحرص على تحسين مستوى أدائى للمهام المنزلية & س \\
\hline 1 & & & $r r, V$ & $r_{0,0}$ & $0 ., 1$ & $\%$ & 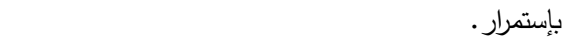 & $T$ \\
\hline 1 & $\% \vee \vee, 1$. & $r, r$, & $\varepsilon V$ & $9 \leq$ & 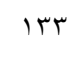 & 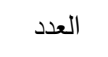 & أشعر بالسعادة عند أداء مهامى المنزلية فى الوقت & \\
\hline & & & $I V, r$ & $r \varepsilon, r$ & $\varepsilon \wedge, 0$ & $\%$ & 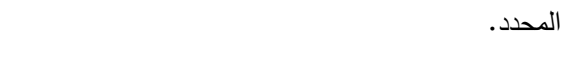 & $\varepsilon$ \\
\hline 9 & $\%$ \% , r. & $r, \cdot r$ & $V T$ & $11 \mathrm{~V}$ & $\wedge$ & 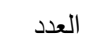 & أحاسب نفسى عند التقصير فى أداء المهام المنزلية & \\
\hline 7 & & & $r v, r$ & $\varepsilon r, V$ & r৭, & $\%$ & 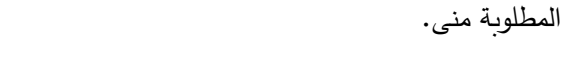 & 0 \\
\hline$\Delta$ & $\% \vee v, v$, & r,IT & $\vee \wedge$ & 10 & 111 & 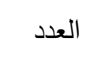 & أحرص على أداء مهامى المنزلية بأعلى كفاءة ممكنة & \\
\hline$\lambda$ & & & $r \wedge, 0$ & M,. & $\varepsilon \cdot, 0$ & $\%$ & ل التقديرى لذاتى وفخرى بها. & 7 \\
\hline r & $\% \vee r$, & $r, r \wedge$ & $\varepsilon v$ & $1 \cdot r$ & IrE & 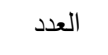 & أحرص على تقييم ما تم إنجازه من مهام منزلية لتلافى & $v$ \\
\hline T & & & $I V, r$ & $r v, t$ & $\varepsilon 0, r$ & $\%$ & الوقوع فى الخطأ. & $\mathrm{V}$ \\
\hline $\mathrm{y}$ & $\% \vee 1, \ldots$ & r,IT & vo & $\Lambda$ & 111 & 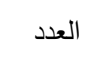 & استمتاعى بأداء مهامى المنزلية يجعلنى أقل شعوراً & $\Delta$ \\
\hline & & & $r V, \varepsilon$ & 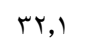 & $\varepsilon \cdot, 0$ & $\%$ & 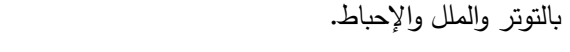 & $\lambda$ \\
\hline$\varepsilon$ & $\% \vee \vee, \varepsilon 7$ & $r, Y \leq$ & 00 & 99 & $i r$ & 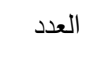 & تتتابنى مشاعر السعادة عندما يُشى أفراد أسرتى على أداء & 9 \\
\hline & & & $r \cdot, l$ & r., & $\varepsilon r, \wedge$ & $\%$ & 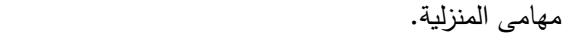 & 7 \\
\hline 1 & $\%(1) 9$. & r 10 & $\vee \wedge$ & vo & $|r|$ & 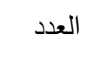 & أقدر الدور المهم الذى أقوم به كربة منزل وأحرص على & \\
\hline 1 & $1 . \mathrm{V}, 4$. & 1,10 & $r \wedge, 0$ & $r v, \varepsilon$ & $\varepsilon \varepsilon, 1$ & $\%$ & أن أؤديه على أكمل وجه. & 1 . \\
\hline
\end{tabular}




$$
\text { مجلة الإسكندرية للتبادل العلمى - (مجلد \& العدد ( ) يناير - مارس IY.r }
$$

رابعاً: محور (الإبتكار فى أداء المهام المنزلية) ن= عVV

\begin{tabular}{|c|c|c|c|c|c|c|c|c|}
\hline الترتيب & الوزن النسبى & الحسابى المتوس & نادراً & أحياناً & دائماً & العدد \% & العبارة & b \\
\hline \multirow[b]{2}{*}{1} & \multirow[t]{2}{*}{$\% \vee \cdot, \wedge}$. & \multirow[t]{2}{*}{ r,IT } & NT & $v \varepsilon$ & $11 \mathrm{~V}$ & العدد & \multirow{2}{*}{ أبحث عن طرق مبتكرة لتبسيط أدائى للمهام المنزلية. } & \\
\hline & & & $r \cdot, r$ & $r v,$. & $\varepsilon r, V$ & $\%$ & & 1 \\
\hline \multirow{2}{*}{9} & \multirow[t]{2}{*}{ 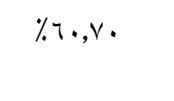 } & \multirow[t]{2}{*}{ I,Ar } & $1 . v$ & 1.9 & ON & العدد & \multirow{2}{*}{ 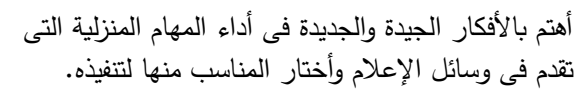 } & \multirow{2}{*}{ r } \\
\hline & & & rq, & $r q, \wedge$ & $r, r$. & $\%$ & & \\
\hline \multirow{2}{*}{$\wedge$} & \multirow[t]{2}{*}{$\% \pi, 1}$. & \multirow[t]{2}{*}{ l, $\wedge r$} & 1.0 & 11. & 09 & العدد & \multirow{2}{*}{ 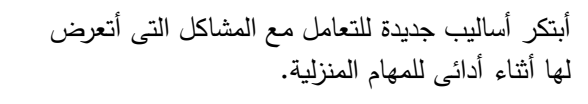 } & \multirow{2}{*}{ r } \\
\hline & & & $r \lambda, r$ & $\varepsilon \cdot, 1$ & $r, 0$ & $\%$ & & \\
\hline \multirow[b]{2}{*}{ v } & \multirow[t]{2}{*}{$\% \pi, \pi$} & \multirow[t]{2}{*}{1,10} & $1 . r$ & Mr & 7. & العدد & \multirow{2}{*}{ أحرص على إحداث تغييرات فى أساليب أدائى للمهام } & \multirow[b]{2}{*}{$\varepsilon$} \\
\hline & & & $r V, r$ & $\varepsilon \cdot, q$ & $r, q$ & $\%$ & & \\
\hline \multirow{2}{*}{$\varepsilon$} & \multirow[t]{2}{*}{$\% 10,1$. } & \multirow[t]{2}{*}{1,90} & 19 & 1.9 & Vy & العد العد & \multirow{2}{*}{ جديدة نافعة. للإنفادة بكل ما هو قديم فى المنزل لإنتاج أشياء } & \\
\hline & & & rT,O & $r q, \wedge$ & $r v, r$ & $\%$ & & 0 \\
\hline \multirow[b]{2}{*}{ 9 وكرر } & \multirow[t]{2}{*}{$\% \uparrow, \vee \vee}$. & \multirow[t]{2}{*}{ I,Ar } & 1.7 & 111 & ov & العدد & \multirow{2}{*}{\multicolumn{2}{|c|}{ أدائى للمهام المنزلية. الإتفادة من خبراتى السابقة لتطوير مستوى }} \\
\hline & & & $r \Lambda, v$ & $\varepsilon \cdot, 0$ & $r \cdot, \wedge$ & $\%$ & & \\
\hline \multirow[b]{2}{*}{0} & \multirow[t]{2}{*}{$\%$ \%, $\varepsilon}$. & \multirow[t]{2}{*}{ 1,95 } & qr & 1.9 & $v r$ & العدد & \multirow{2}{*}{ مهامى المنزلية. } & \multirow[b]{2}{*}{ v } \\
\hline & & & ד, זr & $r q, \wedge$ & $r 4, T$ & $\%$ & & \\
\hline \multirow{2}{*}{$r$} & \multirow[t]{2}{*}{$\% \neg 9, r}$. & $r, \cdot \Lambda$ & $9 \leq$ & 70 & 110 & العدد & أحرص على تتمية مهاراتى فى أشياء جديدة ومفيدة لأداء & \\
\hline & & & $r \varepsilon, r$ & $r$ r,v & $\varepsilon r, \cdot$ & $\%$ & المهام المنزلية بتلقائية ويسر • & $\lambda$ \\
\hline 7 & $\%$ & 1,91 & 91 & $11 \mathrm{~V}$ & 74 & العد القد & أنجز كل ما يُسند إلى من مهام بأسلوب متجدد ومتطور . & 9 \\
\hline 1 & & & rt, & $\varepsilon r, V$ & $r \leqslant, l$ & $\%$ & & 7 \\
\hline r & $\% \uparrow \wedge, 0$. & r..० & qv & 70 & $11 r$ & 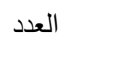 & أبتعد عن تكرار وتقليد ما يفعله الآخرون فى إنجاز المهام & 1. \\
\hline 1 & $1,1 \lambda, 0$. & 1,0 & ro, & $r r, v$ & $\varepsilon \cdot, q$ & $\%$ & المنزلية، لثقتى أن التقليد يقتل الإبتكار . & 1. \\
\hline
\end{tabular}

وعدم الحماس عند الإقبال عليها، ومن ثم الثعور بالتعب بسرعة الأمر الذى يؤدى إلى نقص الدافعية والرغبة فى الئى العمل لديها. ثم جاءت عبارة "أحرص على تأجيل عمل اليوم

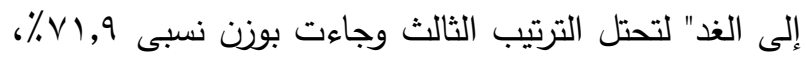

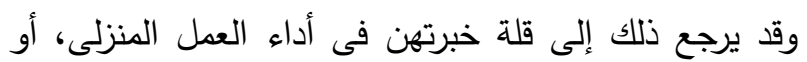
إلى إحتياجهن لمزيد من الوقت حتى يتبين لهن كافة الجوانب، أو هناك غموض ما يجعلهن تؤجلن عملهن للغد، هذا كله يؤدى إلى ضياع الوقت، وفقدان الرغبة فى العمل، للالك يجب على الزوجة تجنب التأجيل لأن التأجيل يؤدى إلى إلى الإعتياد على عدم الإيجابية (محسن الخضيرى، ... . . . بالنسبة للمحور الثانى القدرة على أداء المهام المنزلية نجد الإيدابه أن أعلى استجابة للزوجات عينة البحث كانت لعبارتى "أحاول إتباع طرق تبسيط الأعمال المنزلية، "أحرص على أداء المهام المنزلية بسرعة دون تباطؤ" حيث احتلا على التوالى الترتيب
يتضح من نتائج جدول (^) بالنسبة للمحور الأول الرغبة فى أداء المهام المنزلية نجد أن أعلى استجابة

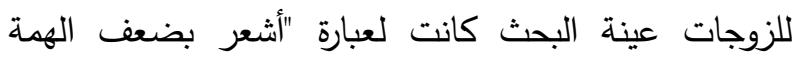
بسرعة عند أداء مهامى المنزلية" حيث احتلت الترتيب الأول وجاءت بوزن نسبى Y,Yr\%ا، و فى هذا الصدد أكد خليل

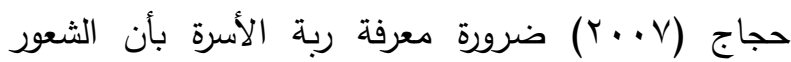

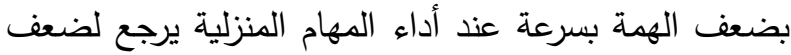
الرغبة فى العمل؛ لأن الرغبة الثديدة فى العمل تولد

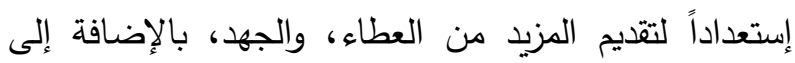
القيام بالمهام والأعمال بكل تفان. تلى ذلك عبارة "أقبل على القيل أداء المهام المنزلية بحماس"، لتحتل الترتيب الثانى وجاءت

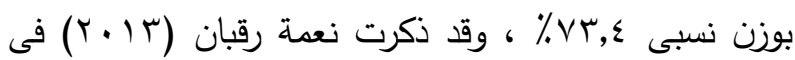
هذا الصدد ضرورة إدراك ربة الأسرة بما تتصف به الأعمال المنزلية من النمطية والتكرار والتى تؤدى إلى شعورها بالملل التيل 
التشجيع على الأداء المتميز والرضا عنه، ويرشد إلى كيفية

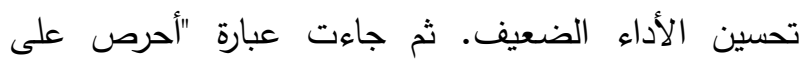

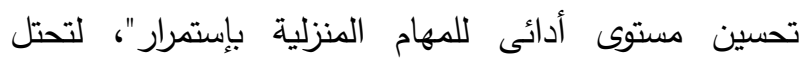

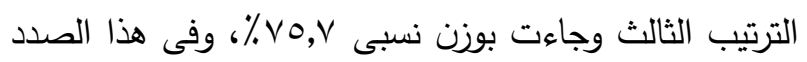

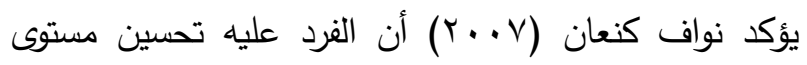
أدائه للمهام بإستمرار؛ فذلك يُشتبع الحاجة إلى الإحساس بالكفاءة والتفوق فى العمل وزيادة الإحساس بالرضا. بالنسبة لإسبة الإسية

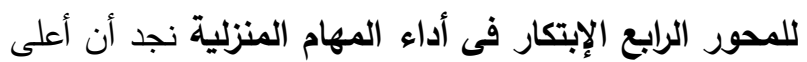

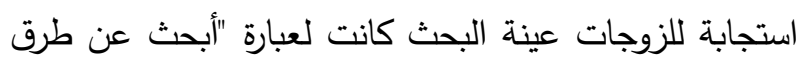
مبتكرة لتبسيط أدائى للمهام المنزلية"، حيث احتلت الترتيب الأول وجاءت بوزن نسبى ^, • ٪\%، وقد أكدت وفاء المعجل

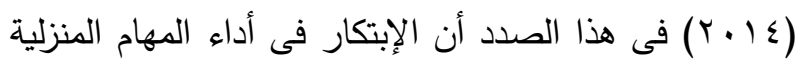
يتضمن اكتشاف الزوجة طرق جديدة ومبسطة فى أدائها

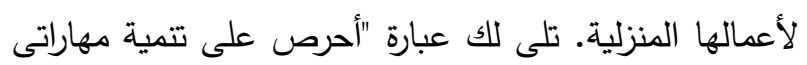

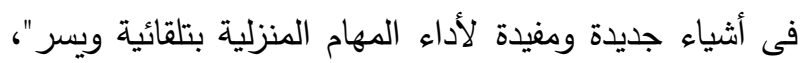
لتحتل الترتيب الثانى وجاءت بوزن نسبى ؟,9 ٪\%، ثم جاءت عبارة "أبتعد عن تكرار وتقليد ما يفعله الآخرون فى إنجاز المهام المنزلية لثقتى أن التقليد يقتل الإبتكار" لتحتل الترتيب الثالث وقد جاءت بوزن نسبى 11,0٪، وفى هذا الصدد تؤكد

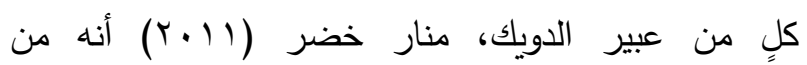
الضرورى إستعانة ربة الأسرة بأساليب جديدة، وأفكار مبتكرة

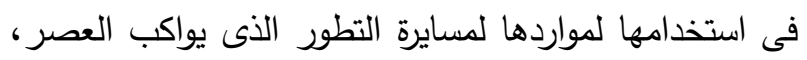
كما أن البعد عن التقليد يرفع من مستوى أدائها لأعمالها.

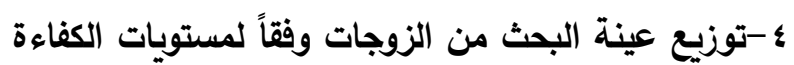
الإإتتاجية (بمحاورها، والإجمالى)
الأول، و الأول مكرر بوزن نسبى ؟بr\% لكلٍ منهما. وقد

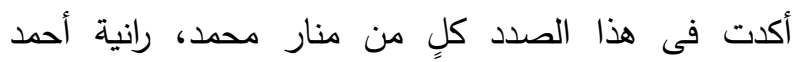
(T/ Y (Y) على أهمية إتباع طرق تبسيط الأعمال المنزلية لأنها الطريقة التى تساعد ربة الأسرة على أداء أكبر كم من الأعمال بسهولة ويسر وبقدر محدود من الطاقة والوقت. كما أكد كلٍ من Ackerman \& Gross (2005) على أهمية حرص ونس ربة الأسرة على أداء الأعمال المنزلية بسرعة ودون تباطؤ؛ خاصةً وأن المماطلة فى أداء المهام تؤدى إلى إنخفاض قدرة الفرد وفثله فى تتفيذ المطلوب منه. ثم جاءت عبارة "أحرص وأن إنى على أخذ قسط من الراحة بمجرد الثعور بالتعب" لتحتل

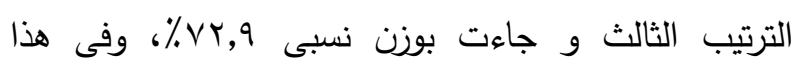
الصدد يؤكد هادى المدرسى (0. . ب) أنه يجب على ربة الأسرة الحرص على أخذ قسط من الراحة بمجرد الثعور بالتعب؛ لأن العمل الدائم بلا ترويح كالترويح الدائم بلا عمل بلتهن كلاهما يؤدى إلى توقف النشاط. بالنسبة للمحور الثالث الرضا عن أداء المهام المنزلية نجد أن أعلى استجابة للزوجات عينة البحث كانت لعبارة "أشعر بالسعادة عند أداء مهامى المنزلية فى الوقت المحدد"، حيث احتلت الترتيب

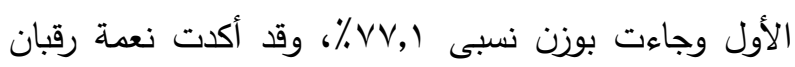

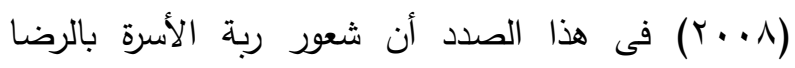
والسعادة عند أداء الأعمال المنزلية فى الوقت المحدد له له مردود إيجابى على كفاءتها الإنتاجية من حيث الكم والكيف. تلتها عبارة "أحرص على تقييم ما تم إنجازه من مهام منزلية لتلافى الوقوع فى الخطأ"، لتحتل الترتيب الثانى وجاءت بوزن مُن

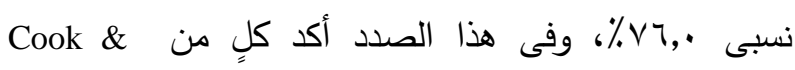

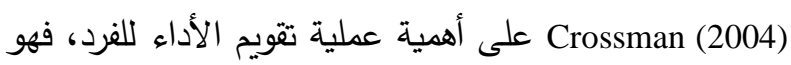
يتيح له الإلمام بمواطن القوة والضعف فى أدائه، ويسهم على الى له 


\begin{tabular}{|c|c|c|c|c|c|}
\hline الترتيب & للأوزان التربيحية & $\%$ & العدد & 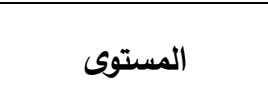 & المحاور \\
\hline \multirow{5}{*}{ الثانى } & \multirow{5}{*}{$\% \vee \cdot, \cdot$} & $r 4, r$ & VY & منخفض (• (: 7 (1) & \multirow{5}{*}{ الرغبة فى أداء المهام المنزلية } \\
\hline & & ד, & 94 & متوسط (YT:IV) & \\
\hline & & $\varepsilon \cdot, 1$ & 11. & 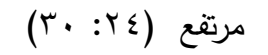 & \\
\hline & & $1 \cdots$ & $r V \varepsilon$ & 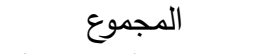 & \\
\hline & & ro, & $9 \wedge$ & منخفض (Y I I I ) & \\
\hline \multirow{3}{*}{ الثالث الثال } & \multirow{3}{*}{$\% 7 v, 7$} & $r v, V$ & $\mathrm{VI}$ & متوسط (1) & \multirow{2}{*}{ القدرة على أداء المهام المنزلية } \\
\hline & & r.,० & $1 \cdots$ & 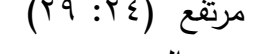 & \\
\hline & & $1 \cdots$ & $r V \varepsilon$ & 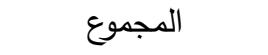 & \\
\hline \multirow{4}{*}{ الأول ال } & \multirow{4}{*}{$\% \vee r, 1$} & $r 9, r$ & $\wedge$. & منخفض (r ا: 1 /) & \multirow{3}{*}{ الرضا عن أداء المهام المنزلية } \\
\hline & & $r \varepsilon, v$ & 90 & متوسط (19 (1: & \\
\hline & & ra,l & 99 & مرتفع (ro: ·r) & \\
\hline & & $1 \cdots$ & $r V \varepsilon$ & المجموع & \multirow{5}{*}{ الإبتكار في أداء المهام } \\
\hline \multirow{8}{*}{ 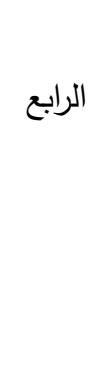 } & \multirow{8}{*}{$\% า \varepsilon, 7$} & 每, & 91 & منخفض (·(: 7 (1) & \\
\hline & & r4,l & 99 & متوسط (YT:IV) & \\
\hline & & $r \cdot, v$ & $\Lambda \varepsilon$ & مرتفع ( (Y: · ·r) & \\
\hline & & $1 \ldots$ & $r V \varepsilon$ & المجموع & \\
\hline & & $r V, V$ & $v_{7}$ & منخفض (OT:Or) & \multirow{4}{*}{ الإجمالى } \\
\hline & & $\varepsilon r, \Lambda$ & Ir. & متوسط (YT: & \\
\hline & & $r \wedge, 0$ & $\vee \wedge$ & مرتقع (19: Y 111$)$ & \\
\hline & & $1 \ldots$ & $r V \varepsilon$ & المجموع & \\
\hline
\end{tabular}

تجعلهن يحملن إتجاهات إيجابية نحوها، وكلما كان هناك رضا عن المهام التى تؤديهن كلما كان لديهن الرغبة القوية للميل إلى أدائها. فالرغبة فى العمل بمثابة الميل للأداء السريع للمهام والأعمال (صلاح مراد، أحمد عبد الخالق، (Y. . . .

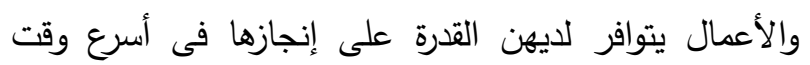
وأقل جهد، ومن ثم القدرة على الإبتكار ، والتجديد فى أداء هذه إنه المهام والأعمال وذلك للوصول إلى أعلى كفاءة إنتاجية فى الإبى ولى أداء مهامهن. 0- وصف استجابات أفراد عينة البحث من الأبناء المراهقين على مقياس الرهاب الاجتماعى:
يتضح من نتائج جدول (9) بالنسبة للنسب الترجيحية

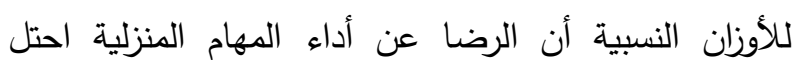
الترتيب الأول بنسبة ا,YY٪، يلى ذلك فى المرتبة الثانية

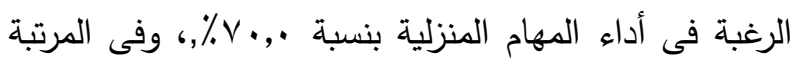

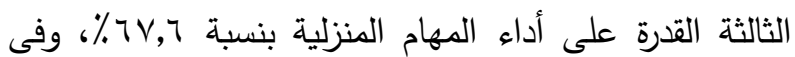
المرتبة الرابعة الإبتكار فى أداء المهام المنزلية بنسبة 7,§؟ ٪، (حيث تم الترتيب تتازلياً؛ كون ظاهرة الكفاءة الإنتاجية ومحاورها موجبة، فكلما ازدادت النسبة دليل على ألى انتشار وتفشى الظاهرة). وقد اتضح أن مستوى إجمالى إنى

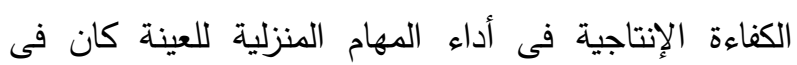
المستوى المتوسط بنسبة ^,بء ٪، يلى ذلك المستوى المرتفع ثم المستوى المنخفض والتى تقاربت نسبتهما وكانت على

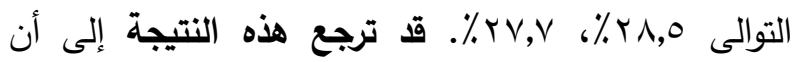

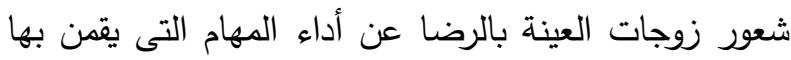




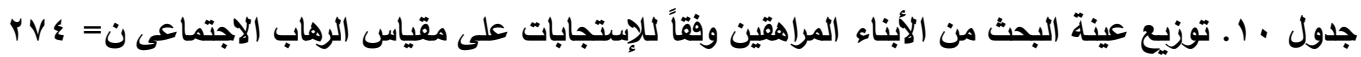

\begin{tabular}{|c|c|c|c|c|c|c|c|c|}
\hline الترتيب & الن الوزن & المتوسطى & ن ادراً & 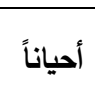 & 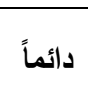 & $\begin{array}{l}\text { العدد } \\
\text { \% }\end{array}$ & 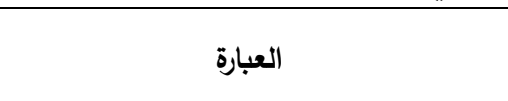 & p \\
\hline it & $\% \vee r, T$ & r,1 & $\begin{array}{l}1.0 \\
r \lambda, r\end{array}$ & $\begin{array}{ll}11 r \\
\varepsilon 1, r\end{array}$ & $\begin{array}{l}0.04 \\
r \cdot, \varepsilon\end{array}$ & 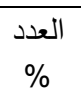 & أشعر بالتوتر عندما أتحدث أمام الآخرين. & 1 \\
\hline$\wedge$ & $\%$ \% & $r, \cdot r$ & $\stackrel{1}{r 9,7}$ & $\begin{array}{l}11 V \\
\varepsilon r, V\end{array}$ & $\begin{array}{l}V r \\
Y V, V\end{array}$ & 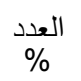 & 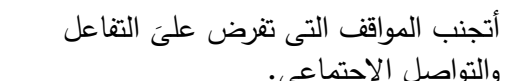 & $r$ \\
\hline ir & $\% \vee r, 4$ & $r, r_{1}$ & $\begin{array}{l}1.7 \\
r \Lambda, V\end{array}$ & $\begin{array}{l}119 \\
\varepsilon r, \varepsilon\end{array}$ & $\begin{array}{l}\varepsilon q \\
1 \vee, q\end{array}$ & 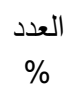 & ألجد صعوبة فى إقامة علاقات اجتماعية مع & $r$ \\
\hline r & $\% 7,0$ & $1, \wedge 1$ & $\begin{array}{c}o v \\
r \cdot, \Lambda\end{array}$ & $\begin{array}{l}1.9 \\
r 9,1\end{array}$ & $\begin{array}{l}1 \cdot 1 \\
r q, \varepsilon\end{array}$ & 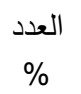 & أبحثث عن أعذار لأتجنب حضور الحفلات أو & $\varepsilon$ \\
\hline $1 \leq$ & $\% \vee r, \Lambda$ & r, r & $\begin{array}{l}110 \\
\leqslant r, .\end{array}$ & $\frac{1 \cdot r}{r v, t}$ & $\begin{array}{l}07 \\
r \cdot, \varepsilon\end{array}$ & 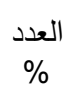 & يصعب على التعبير عن رأيى فى أى نقاش. & 0 \\
\hline 9 & $\% 79, \wedge$ & $r, . q$ & $\begin{array}{l}97 \\
\text { ro, }\end{array}$ & $\begin{array}{l}1 \cdot 1 \\
r 9, \varepsilon\end{array}$ & $\begin{array}{l}v \cdot \\
r o, 0\end{array}$ & 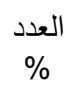 & 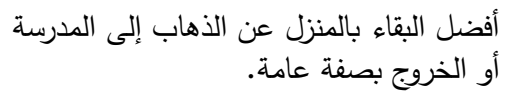 & 7 \\
\hline 1. & $\% \vee \cdot, \wedge$ & r,I & $\begin{array}{l}1 \cdot v \\
r 9,1\end{array}$ & $\underset{r \varepsilon, r}{q \varepsilon}$ & $\begin{array}{l}V T \\
r t, t\end{array}$ & 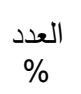 & أميل إلى التحدث بصوت منخفض (يكاد لا & $V$ \\
\hline V & $\%$ & 1,99 & $\begin{array}{l}V T \\
r q, T\end{array}$ & $\begin{array}{l}1 r_{0} \\
\leqslant 0,7\end{array}$ & $\begin{array}{l}V \tau \\
Y Y, V\end{array}$ & 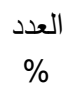 & أى شخص التحد له سلطة. الددرسين أو الديرين أو & $\wedge$ \\
\hline 0 & $\% \curlyvee \varepsilon, \uparrow$ & $1,9 \varepsilon$ & $\begin{array}{l}r \cdot \\
r 0,0\end{array}$ & $\begin{array}{l}11 V \\
\varepsilon r, V\end{array}$ & $\stackrel{\wedge v}{\mu, \Lambda}$ & 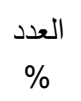 & أرتبك عند أدائى الإختبارات الثفهية. & 9 \\
\hline 7 & $\% 70, \wedge$ & $1,9 \vee$ & $\begin{array}{l}v \cdot \\
r 0,0\end{array}$ & $\begin{array}{l}\text { IrV } \\
\varepsilon 7, \varepsilon\end{array}$ & $\begin{array}{l}r V \\
r \wedge, 1\end{array}$ & 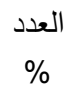 & أنثنة حتى لإثتراك فكىن أى رحلات إنتاه جماعية أو الآخرين. & 1. \\
\hline 1 & $\% .09, \varepsilon$ & $1, \vee \wedge$ & $\sum \wedge$ & $\begin{array}{ll}111 \\
\varepsilon r, 1\end{array}$ & $\begin{array}{l}1 \cdot 1 \\
r 9, \varepsilon\end{array}$ & 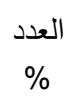 & ينظر إلىَّ أثناء قيامى بأى عمل أشعر فيه أن أحداً & 11 \\
\hline$\varepsilon$ & $\% \pi r, 1$ & $1, \wedge 9$ & $\begin{array}{c}01 \\
r, Y\end{array}$ & $\begin{array}{l}1 Y q \\
\varepsilon \vee, 1\end{array}$ & $\stackrel{\wedge v}{\mu, \Lambda}$ & 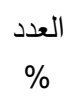 & الآرتبك عندما أشعر أننى موضع ملاحظة من & it \\
\hline r & $\%$ \%r,\& & I,AV & $\begin{array}{c}\text { ov } \\
r \cdot, \wedge\end{array}$ & $\begin{array}{l}\text { rro } \\
\leqslant 0,7\end{array}$ & $\begin{array}{l}q 4 \\
r+4\end{array}$ & 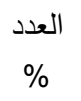 & أششعر بالإرتياح. قوية أن أكون بمغردى بإستمرار & 14 \\
\hline 11 & $\% \vee r$, & $r, 17$ & $\begin{array}{l}1 \cdot \varepsilon \\
r \wedge,\end{array}$ & $\begin{array}{l}11 \\
\varepsilon \cdot, 1\end{array}$ & $\begin{array}{l}7 . \\
\text { Y), }\end{array}$ & 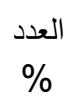 & حجرة أو مكان مكتظة بالناس. المغادرة عند دخولى & $1 \leq$ \\
\hline
\end{tabular}

حركته ويجعله يشعر بأنه مراقب من الناس بإستمرار. ثم جاءت عبارة "أشعر برغبة قوية أن أكون بمغردى بإستمرار لأشعر بالإرتياح"، لتحتل الترتيب الثالث وقد جاءت بـاءت بورنه

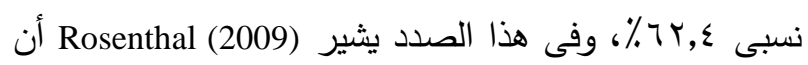

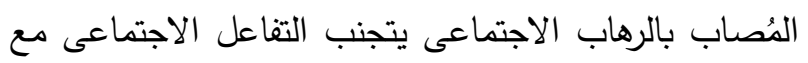
الآخرين، ويفضل الوحدة والعزلة الاجتماعية. צ-توزيع الأبناء المراهقين عينة البحث وفقاً لمستويات

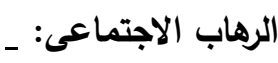

يتضح من نتائج جدول (· (1) أن أعلى استجابة لعينة

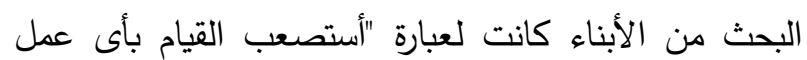
أشعر فيه أن أحداً ينظر إلى أثناء قيامى به"، حيث احتلت الترتيب الأول وجاءت بوزن نسبى ع,وه٪، تلى ذلك عبارة "أبحث عن أعذار لتجنب حضور الحفلات أو المناسبات الاجتماعية" لتحتل الترتيب الثانى بوزن نسبى 0, • $\%$ ٪، وفى هذا الصدد يؤكد كلٍ من فرنسيس شاهين، عبد الكريم جرادات

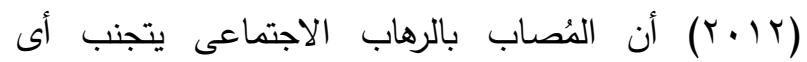
مناسبات اجتماعية تضعه أمام أنظار الآخرين. فالرهاب يشل 
جدول 1 .توزيع الأبناء المراهقين عينة البحث وفقاً لمستويات الرهاب الاجتماعى (ن= \& \&V)

\begin{tabular}{|c|c|c|c|c|}
\hline النسب الترجيحية للأوزان النسبية & $\%$ & العدد & المستوى & المحاور \\
\hline \multirow{4}{*}{$\%$ \% } & $r \leqslant, 1$ & 79 & مرتفع (T (ITY) & \multirow{4}{*}{ الاجتماعى } \\
\hline & $\varepsilon \cdot, 9$ & 114 & متوسط ( & \\
\hline & ro,. & 97 & منخفض(r (T: & \\
\hline & $1 \ldots$ & TVE & المجموع & \\
\hline
\end{tabular}

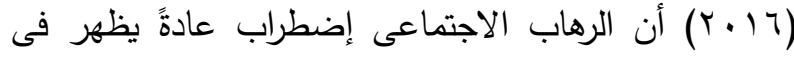
مرحلة المراهقة فى الأجواء الأسرية المضطربة. ثالثاً: النتائج فى ضوء فروض البحث: الفرض الأول: توجد علاقة إرتباطية دالة إحصائياً بين الاغتراب الزواجى كما تدركه الزوجات عينة البحث بمحاوره (الصمت الزواجى، ضعف التواصل العاطفى والتآلفية، العزلة وعدم المشاركة فى الحياة الزوجية) والإجمالى، وكلٍ من لن كفاءتهن الإنتاجية بمحاورها (الرغبة فى أداء المهام المنزلية، القدرة على أداء المهام المنزلية، الرضا عن أداء ألتهاء المهام

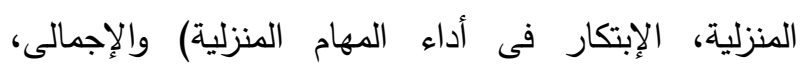

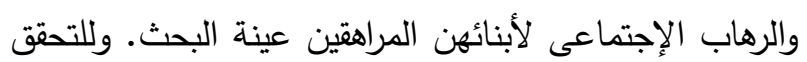
من صحة الفرض إحصائياً تم استخدام معامل ارتباط بيرسون Correlation Pearson جدول (r I) يوضح ذلك.
يتضح من نتائج جدول (11) أن مستوى إجمالى الرهاب الاجتماعى لعينة البحث من الأبناء كان فى المستوى هي

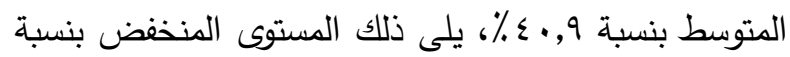

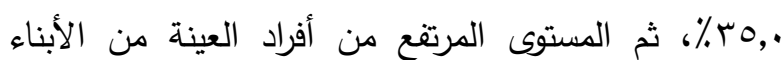

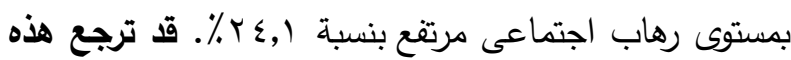
النتيجة إلى أنه كلما كانت الأجواء الأسرية بين الزوجات عينة البحث وأزواجهن مضطربة انعكس ذلك على الأبناء وأصابهم بالإضطراب، والتوتر، والعديد من الأمراض النفسية

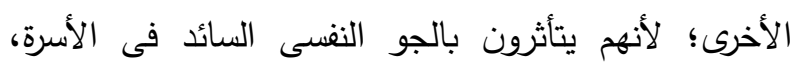
وبالعلاقات بين الأب والأم. وفى هذا الصدد فقد أشارت

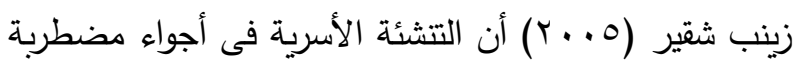
تلعب دوراً مهماً فى ظهور الرهاب الاجتماعى. كما أكد طه عبد العزيز (9 . . ب) أن الأبناء يتعلمون الكثير من العلاقات الاجتماعية عن طريق آبائهم، وأكدت أيضاً سامية إبريعم

جدول r ا. معاملات الإرتباط بين كلٍ من الاغتراب الزواجى كما تدركه الزوجات عينة البحث بمحاوره، والإجمالى والكفاءة الإتتاجية لهن

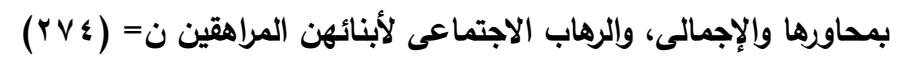

\begin{tabular}{|c|c|c|c|c|}
\hline ال الإجمالى & العزلة وعدم المثاركة فى الحياة & ضعف التواصل العاطفة & الصمت الزواجى & $B_{1}$ \\
\hline معامل الارتباط & معامل الارتباط & معامل الارتباط & معامل الارتباط & \\
\hline$* *_{\cdot}, \varepsilon \cdot r-$ & $* * ., r \vee q-$ & $* *, \Gamma ! \leq-$ & $* *, r \mid \Lambda-$ & الرغبة فى أداء المهام المنزلية \\
\hline$* *, r, r \cdot \varepsilon-$ & $* *, \backslash \wedge r-$ & $* *, r \cdot v-$ & $* *, \mid \vee \wedge-$ & القدرة على أداء المهام المنزلية \\
\hline$* *, r|r| 7-$ & $* *$, l $\vee 0-$ & $* *, \Upsilon \wedge \wedge-$ & $* *, r \leqslant 1-$ & الرضا عن أداء المهام المنزلية \\
\hline **., זง - & $* * *, 199-$ & $* * \cdot, r \cdot r-$ & $* *, r \cdot 1-$ & الإبتكار فى أداء المهام المنزلية \\
\hline$* * .,\{01-$ & **, ,rYT- & 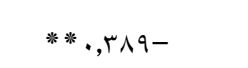 & 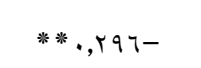 & الإجمالى \\
\hline$* *, r r T$ & $* *, 171$ & **, & $* *, r \cdot V$ & الرهاب الاجتماعى للأبناء \\
\hline
\end{tabular}


علاقة إرتباطية موجبة دالة إحصائياً عند مستوى (1 •,•) بين درجات عينة البحث من الزوجات فى الاغتراب الزواجى إله بمحاوره (الصمت الزواجى، ضعف ض التواصل العاطفى والتآلفية، العزلة وعدم المشاركة فى الحياة الزوجية)، والإجمالى، والرهاب الاجتماعى للأبناء، وذلك يعنى أنه كلما تواجد إغتراب زواجى بين الزوجين كلما انعكس ذلك إيجابياً

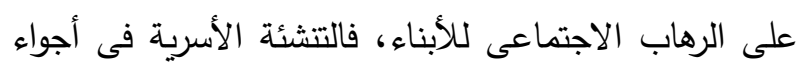

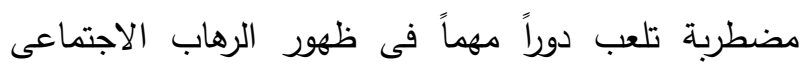
للأبناء (زينب شقير، ه . . ب)، وقد أيد ذلك كلٍ من سناء

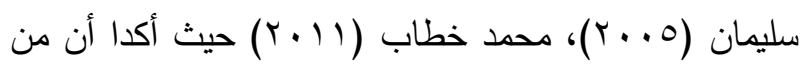
نتائج الاغتراب الزواجى بين الزوجين غياب الإحترام

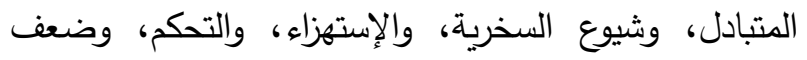
التواصل، والتى يكون من آثارها إرتقاع الإصابة بالقلق

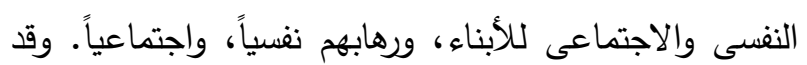
اتقق ذلك مع نتائج دراسة (2005) Baker حيث أكد وجود مجموعة من الآثار السلبية للاغتراب الزواجى على الأبناء كالتقدير المنخفض للذات، والرهاب الاجتماعى، والشعور بالوحدة.

- نستخلص مما سبق وجود علاقة إرتباطية عكسية دالة إحصائياً بين الاغتراب الزواجى كما تدركه الزوجات عينة البحث بمحاوره، والإجمالى، وكفاءتهن الإنتاجية بمحاورها والإجمالى، ووجود علاقة إرتباطية موجبة دالة إحصائياً بين الاغتراب الزواجى بمحاوره، والإجمالى للزوجات عينة

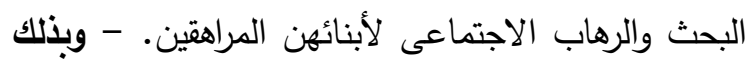
يكون الفرض الأول قـ تحقق كلياً.

الفرض الثانى: توجد فروق ذات دلالة إحصائية بين

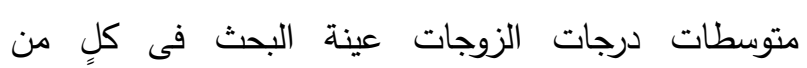

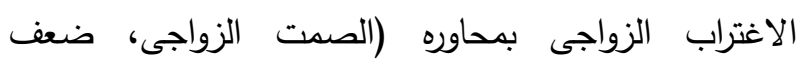

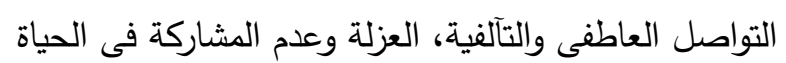

يتضح من نتائج جدول (Y I) وجود علاقة إرتباطية عكسية دالة إحصائياً عند مستوى ا.,,. بين درجات عينة البحث من الزوجات فى الاغتراب الزواجى بمحاوره (الصمت الزواجى، ضعف التواصل العاطفى والتآلفية، العزلة وعدم المشاركة فى الحياة الزوجية) والإجمالى، والكفاءة الإنتاجية

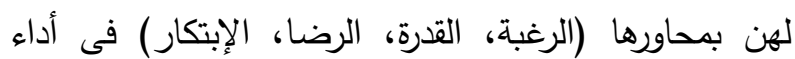
المهام المنزلية، الإجمالى، وذلك يعنى أنه كلما تواجد إغتراب الرغابها زواجى بين الزوجين كلما انعكس ذلك سلباً على الكفاءة الإنتاجية للزوجة، فالزوجة التى تعانى من الاغتراب الزواجى لهى تشعر بالإحباط، والعجز فى حياتها الزوجية، وتثعر بأنها غير كفء، وغير قادرة على الوفاء بإلتزاماتها، مما يسبب لها لها لهاهي

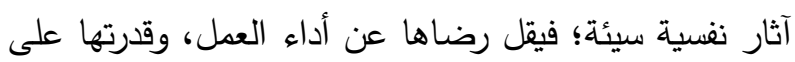
أدائه بإتقان، وتقل رغبتها ولا يكون لديها الحافز للإبتكار والإبداع فيه، كل ذلك يؤدى إلى إنخفاض كفاءتها الإنتاجية. وتتفق هذه النتيجة مع نتيجة دراسة عبد الرحمن عثمان

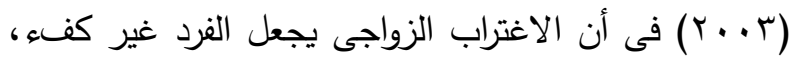

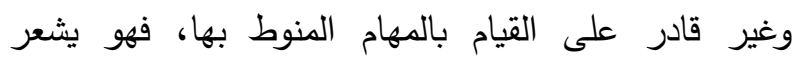
بالإجهاد والإرهاق بمجرد التقكير بأداء أى عمل مهما كان

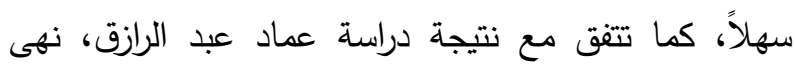

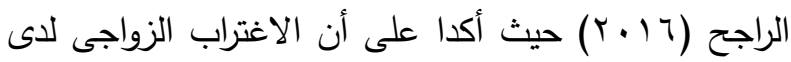
الزوجة يجعلها تعيش حالة من الإحباط، وتققد هدفها فى حياتها الزوجية نتيجة لفثلها المستمر فى كل ما تقوم به من أعمال. كما تتفق مع نتيجة دراسة (2015) Miley حيث أكد أن شعور الأزواج بالاغتراب يؤدى إلى الخلافات الزوجية

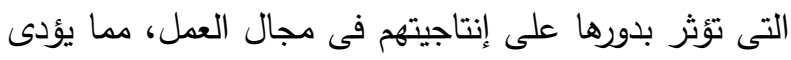

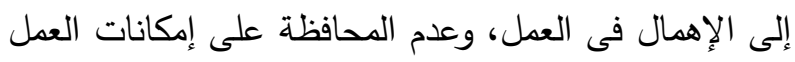
وأدواته، وكثرة الأخطاء، وقلة الإنتاج، وعدم الجودة فى في الإنى

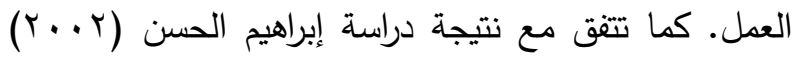
حيث أكد أن الاغتراب الزواجى يجعل الفرد مضطرباً فى صحته النفسية مما ينعكس على أدائه اليومى، وكفاءته الإنتاجية فى مختلف مجالات الحياة. كذلك اتضح وجود 
جدول ب ا ـ دلالة الفروق بين متوسطات درجات الزوجات عينة البحث فى الاغتراب الزوجى تبعاً (لمكان السكن، عمل الزوجة) ن= \& YV

\begin{tabular}{|c|c|c|c|c|c|c|c|}
\hline مستوى الدلالة & قيمة & المتوسطات & الإلحعيارى المرى & الحستوسطى & ن & السكن & لمت تف \\
\hline \multirow{2}{*}{ دالة } & \multirow{2}{*}{$\cdot, V \backslash r-$} & & $\varepsilon, \varepsilon \cdot \uparrow$ & $19, V O r$ & 1ro & ريف & \multirow{2}{*}{ الصدت الزواجى } \\
\hline & & 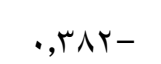 & $\varepsilon, \Sigma Y\rceil$ & $r \cdot, \mid r \varepsilon$ & $1 \leq 9$ & حضر & \\
\hline \multirow{2}{*}{ دالة ب , • غير } & \multirow{2}{*}{1,0 r $9-$} & & $0,0 \vee 7$ & YT,TוT & Iro & ريف & \multirow{2}{*}{ العاطفى والتآلفية } \\
\hline & & $1,$. To- & $0,0 \wedge V$ & $r r, 701$ & $1 \leqslant 9$ & حضر & \\
\hline \multirow{2}{*}{ دالة ا , • غير } & \multirow{2}{*}{$1, \leqslant \circ Y-$} & & $\varepsilon,|\wedge|$ & $19,7 \vee r$ & lro & ريف & \multirow{4}{*}{ فلى الحزلة وعدم المشاركة الزوجية } \\
\hline & & $\cdot, \vee \vee \vee 1-$ & ¿,OMT & $r \cdot, \varepsilon \leqslant r$ & $1 \leqslant 9$ & حضر ل & \\
\hline \multirow{2}{*}{ دالة 9 •, • غير } & \multirow{2}{*}{ 1,דז- } & & $1 \cdot, v \cdot 1$ & Tr, $\leq$. & Iro & ريف & \\
\hline & & $r, \mid \wedge \wedge-$ & $1 \cdot, 977$ & $Y \Sigma, Y Y \wedge$ & $1 \leq 9$ & حضر & \\
\hline مستوى الدلالة & قيمة & المتوسطات بين & الإلحعيارى & الحتوسطى & ن & الزوجة & \\
\hline \multirow{2}{*}{ 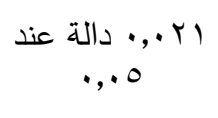 } & \multirow{2}{*}{ r,TrA } & \multirow{2}{*}{ I, } & $\varepsilon, 0 \vee 9$ & $r \cdot, T \cdot r$ & $1 T$ & تعمل & \multirow{2}{*}{ الصدت الزواجى } \\
\hline & & & $\varepsilon .110$ & $19.4 \mathrm{~V}$ & $1 \leqslant r$ & لا تعمل & \\
\hline \multirow{2}{*}{ دال عند ا •,. } & \multirow{2}{*}{$\varepsilon, O H T$} & \multirow{2}{*}{ r,974 } & 0,人r. & $r \varepsilon, Y Y_{0}$ & (1T) & تعمل & \multirow{2}{*}{ ضعفف التواصل } \\
\hline & & & $\varepsilon, 9 \wedge 7$ & r),VTr & $1 \leq r$ & لا تعمل & \\
\hline \multirow{2}{*}{ دال عند ا •,. } & \multirow{2}{*}{$\varepsilon, 7 \cdot 1$} & \multirow{2}{*}{ r, ז०ד } & $\varepsilon, Y q Y$ & TI,TY & (1T) & تعمل & \multirow{2}{*}{ فلى الحياة الزوجية المشاركة } \\
\hline & & & $\varepsilon, \mid \vee \wedge$ & 11,970 & $1 \leqslant r$ & لا تعمل & \\
\hline دال عند ا .,. & $0, r \cdot 9$ & 7,001 & $1 \cdot, \pi 7 \pi$ & $77,7 \leqslant 9$ & $1 \pi$ & تعمل & الإجمالى \\
\hline
\end{tabular}

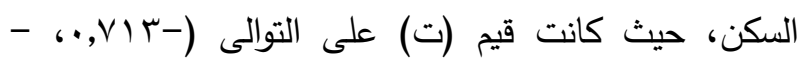

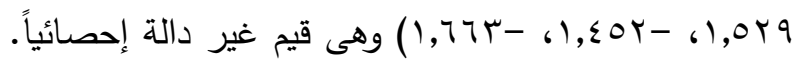
وقد ترجع هذه النتيجة إلى أن الاغتراب الزواجى بين الزوجين يرتبط بغياب الحوار بينهما، وضعف التفاء التواصل

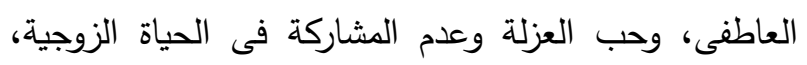
الأمر الذى يؤدى إلى إتساع الهوة والفجوة بينهما، ويكون

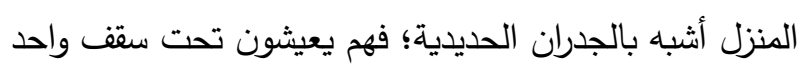
وهم غرباء بغض النظر عن مكان السكن أو البيئة الجغرافية التى يتواجدان فيها؛ فالاغتراب الزواجى ليس حكراً على مكان

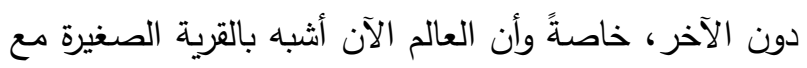

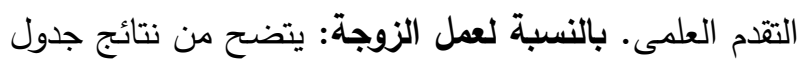

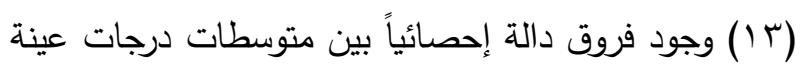
البحث من الزوجات فى الاغتراب الزواجى، ومحاوره
الزوجية) والإجمالى، والكفاءة الإنتاجية لهن بمحاورها (الرغبة فى أداء المهام المنزلية، القدرة على أداء المهام المنزلية، الرضا عن أداء المهام المنزلية، الإبتكار فى أداء المهام المنزلية)، والإجمالى تبعاً (لمكان السكن، عمل الزوجة). T وللتحقق من صحة الفرض إحصائياً تم إستخدام إختبار test للوقوف على دلالة الفروق بين متوسطات درجاتهن فى إحى كلٍ من الاغتراب الزواجى بمحاوره، والكفاءة الإنتاجية

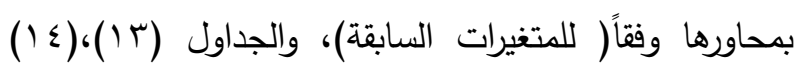
توضح ذلك.يتضح من نتائج جدول (r) بالنسبة لمكان السكن: عدم وجود فروق دالة إحصائياً بين متوسطات درجات الزوجات عينة البحث فى الاغتراب الزواجى بمحاوره (الصمت الزواجى، ضعف التواصل العاطفى والتآلفية، العزلة وعدم المشاركة فى الحياة الزوجية) والإجمالى تبعاً لمكان 
على مواجهة الظروف والمواقف المختلفة المحيطة بها، بالإضافة إلى كسر الملل والروتين فى حياتها، مما يكون له

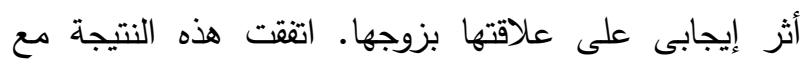

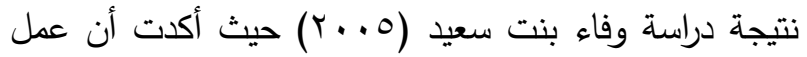

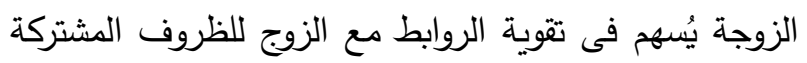
التى يمرون بها، وبالتالى يؤثر إيجابياً على طبيعة الحياة لزئه الزوجية بينهما. وتختلف هذه النتيجة مع نتيجة روان أبو

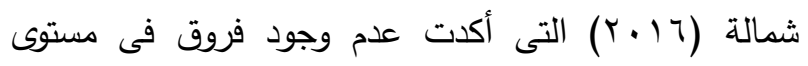
الاغتراب الزواجى بين الزوجات تعزى لعمل الزوجة.
(الصدت الزواجى، ضعف التواصل العاطفى والتآلفية، العزلة

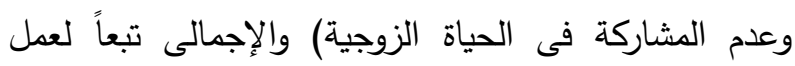

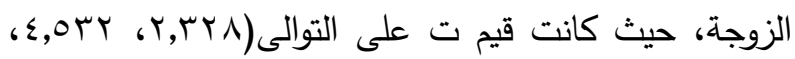

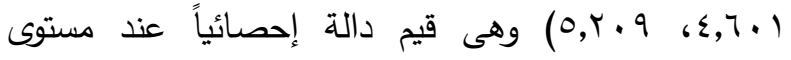

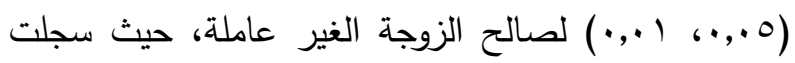
الزوجة الغير عاملة مستوى منخفض من المتوسط الحسابى بالمقارنة بالزوجة العاملة، وقد ترجع هذه النتيجة إلى أن الزوجة العاملة بحكم عملها تحتك بنوعيات مختلفة من البشر

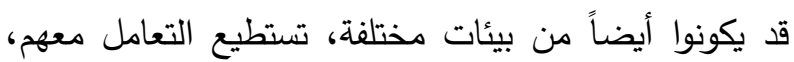
وتقبل آرائهم، إذاً العمل يُكسبها مهارات وخبرات تساعدها

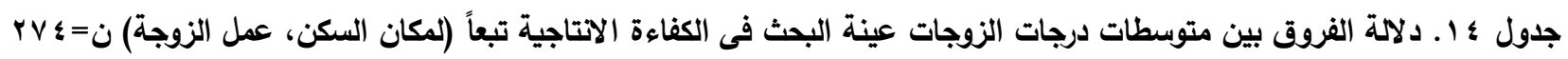

\begin{tabular}{|c|c|c|c|c|c|c|c|}
\hline مستوى الدلالة & قيمة & المترسطات بين & الإلحريارى & الحسابى المسط & ن & السكن & \\
\hline \multirow{2}{*}{ | } & \multirow{2}{*}{$1,7.0$} & & $\Sigma, \Gamma \wedge$. & Yl, ¿A. & Iro & ريف & أ اء المهام \\
\hline & & . & $\varepsilon, \wedge \leq r$ & $r \cdot, O V V$ & $1 \leqslant 9$ & حضر & المنزلية \\
\hline \multirow{2}{*}{ 7م/ ا, • غير دالة } & \multirow{2}{*}{ I, } & & $\varepsilon, 709$ & $r \cdot, V I r$ & iro & ريف & القدرة على أداء المهام \\
\hline & & $\cdot, V Y Y$ & $\varepsilon, 919$ & $19,9 \varepsilon$. & $1 \leqslant 9$ & حضر & المنزلية \\
\hline \multirow{2}{*}{ r آץ, • غير دالة } & \multirow{2}{*}{$1, Y 01$} & & $0,19$. & Yr,.0T & iro & ريف & الرضا عن أداء المهام \\
\hline & & $\cdot, \vee \wedge)$ & $0,1 \cdot v$ & rI, rVo & $1 \leq 9$ & حضر & المنزلية \\
\hline \multirow{2}{*}{ 100, • غير دالة } & \multirow{2}{*}{$\cdot, \wedge \wedge-$} & & $0, \pi 10$ & $19, \Gamma \cdot \Sigma$ & iro & ريف & الإبتكار فى أداء المهام \\
\hline & &., $119-$ & $0, r V Y$ & $19, \varepsilon r \pi$ & $1 \leq 9$ & حضر & \\
\hline \multirow{2}{*}{ rV ا, • غير دالة } & \multirow{2}{*}{1, 1,74 } & & $1 \leqslant, 110$ & Ar,oOr & iro & ريف & \\
\hline & & r,ru & $1 \leqslant, \cdot \leqslant \Lambda$ & $11, r 10$ & $1 \leq 9$ & حضر & \\
\hline مستوى الدلالة & قيمة & المتوسطات بين & الإنحراف & الحستوسط & ن & الزوجة & \\
\hline \multirow{2}{*}{ ץ" •., •., دال عند } & \multirow{2}{*}{$r, 101$} & \multirow[t]{2}{*}{$1, Y \cdot T$} & $\varepsilon, \varepsilon \wedge r$ & $(1,7) \wedge$ & $1 \pi$ & تعمل & الرغبة فى أداء المهام \\
\hline & & & $\varepsilon, V \leq r$ & $r \cdot, \varepsilon \mid r$ & $1 \leqslant r$ & لاتعمل & المنزلية \\
\hline \multirow{2}{*}{ دال عند ا •,. } & \multirow{2}{*}{$r, 11$} & \multirow[t]{2}{*}{$1, \vee \wedge 1$} & $\varepsilon, \vee \circ 9$ & YI,YYI & 1 & تعمل & القدرة على أداء المهام \\
\hline & & & $\varepsilon, \vee \backslash 1$ & $19, \varepsilon \leqslant 1$ & $1 \leqslant r$ & لاتعمل & ل \\
\hline \multirow{2}{*}{ دال عند ا .,. } & \multirow{2}{*}{$r, T) V$} & \multirow[t]{2}{*}{$1, \pi) T$} & 0,170 & $r Y, \Sigma V T$ & וTו & تعمل & الرضا عن أداء المهام \\
\hline & & & $0, \cdot r r$ & $r \cdot, \wedge T$. & $1 \leqslant r$ & لاتعمل & المنزلية الما \\
\hline \multirow{2}{*}{ دال عند ا •,• } & \multirow{2}{*}{$r, 011$} & \multirow[t]{2}{*}{$1,7.0$} & $0, r \cdot q$ & $r \cdot, r \cdot r$ & ו" & تعمل & الإبتكار في أداء المهام \\
\hline & & & $0, Y \backslash \varepsilon$ & $\mid \wedge, 7 \cdot 1$ & $1 \leq r$ & لاتعمل & 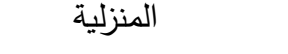 \\
\hline \multirow{2}{*}{ دال عند ا •,. } & \multirow{2}{*}{$r, v) \leq$} & & IT,ETY & 10,019 & וTו & تعمل & الإجمالى \\
\hline & & $7, Y \cdot \varepsilon$ & $I \varepsilon, I T V$ & $\vee 9, \Gamma 10$ & $1 \leq r$ & لاتعمل & \\
\hline
\end{tabular}


مع نتيجة دراسة عبير الدويك، منار خضر (11) (1) حيث أكدا على وجود فروق ذات دلالة إحصائية فى الكفاءة الإنتاجية لربات الأسر لصالح العاملات. وتختلف هذه النتيجة

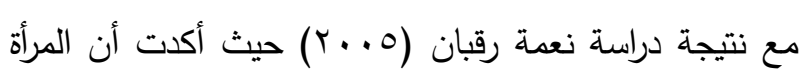
العاملة أقل دافعية لإنجاز أعمالها عن غير العاملة، واختلفت

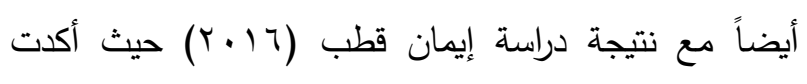

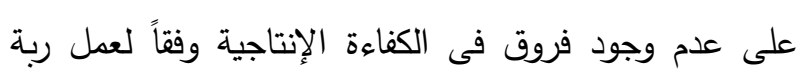
الأسرة.

- - نستخلص مما سبق: عدم وجود فروق بين متوسطات درجات الزوجات عينة البحث فى كلٍ من الاغتراب الزواجى ومحاوره والإجمالى، وكفاءتهن الإنتاجية

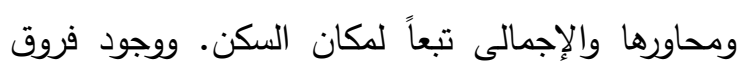
دالة بين متوسطات درجاتهن فى كلٍ من الاغتراب الزواجى، ومحاوره، والإجمالى، تبعاً لعمل الزوجة لصالح غير العاملات، ووجود فروق فى كفاءتهن الإنتاجية،

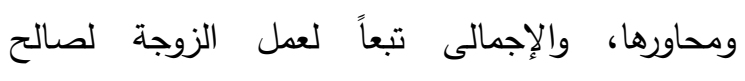

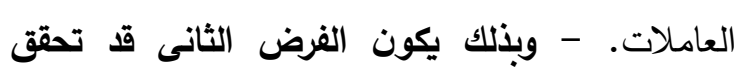
جزئياً.

الفرض الثالث: يوجد تباين دال إحصائياً بين متوسطات درجات الزوجات عينة البحث فى الاغتراب الزواجى بمحاوره (الصمت الزواجى، ضعف التواصل العاطفى والتآلفية، العزلة وعدم المشاركة فى الحياة الزوجية) والإجمالى، تبعاً لمتغيرات البحث (عمر الزوجة، مدة الزواج، حجم الأسرة، المستوى التعليمى للزوجة، المستوى التعليمى للزوج، متوسط الدخل الثهرى للأسرة). وللتحقق من صحة الفرض إحصائياً تم

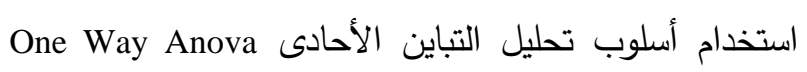
وتطبيق اختبار LSD لبيان دلالة إتجاه الفروق إن وجدت وفقاً لمتغيرات البحث (السابق ذكرها). يتضح ذلك فى الجداول من

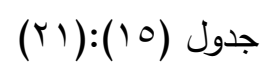

يتضح من نتائج جدول (ع 1) بالنسبة لمكان السكن: عدم وجود فروق بين متوسطات درجات الزوجات فى الكفاءة الإنتاجية بمحاورها (الرغبة فى أداء المهام المنزلية، القدرة

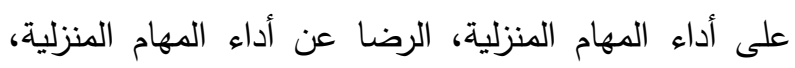
الإبتكار فى أداء المهام المنزلية) والإجمالى تبعاً لمكان

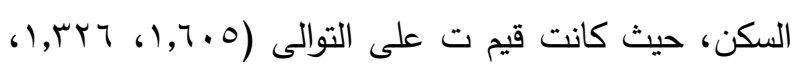

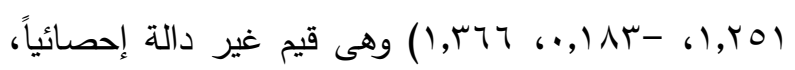
وقد ترجع هذه النتيجة من وجهة نظر الباحثة إلى تمدين

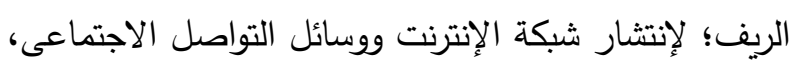
فأصبحت المرأة الريفية أكثر وعياً عما سبق بطرق تبسيط لإنترن

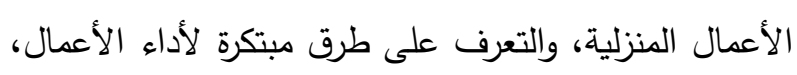
الأمر الذى يؤثر على مستوى كفاءتها الإنتاجية فى أداء المهام المنزلية. تتفق هذه النتيجة مع نتيجة دراسة إيمان قطب (7 ا • r) التى أكدت على عدم وجود فروق فى الكفاءة الإنتاجية لربة الأسرة تعزو لمكان السكن، وتختلف هذه

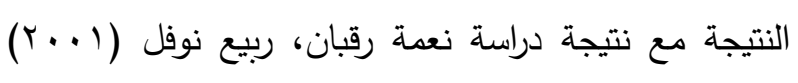

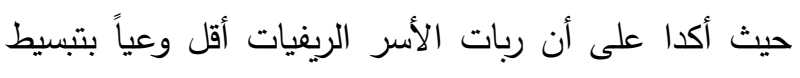

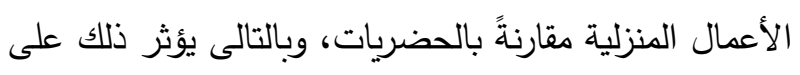
رغبتهن، وقدرتهن، وكفاءتهن فى أداء الأعمال المنزلية.

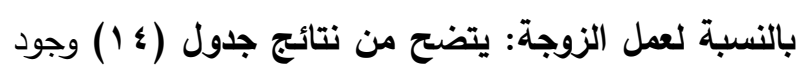
فروق بين متوسطات درجات الزوجات فى الكفاءة الإنتاجية بمحاورها (الرغبة، القدرة، الرضاءالإبتكار) فى أداء المهام

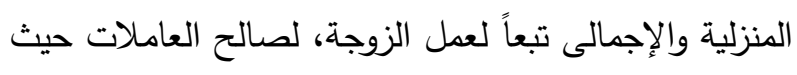

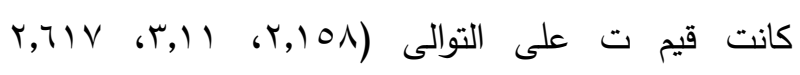

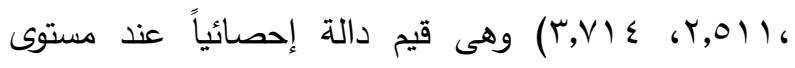
(0.,، 1., 1.,)، وقد ترجع هذه النتيجة إلى أن خروج

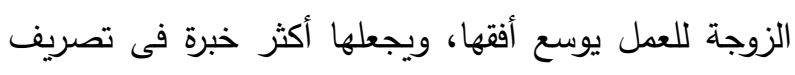
أمور حياتها، ويجعلها تقدر قيمة الوقت وتُحسن استغلاله، بالإضافة إلى اكتسابها الخبرات من إحتكاكها بزملائها فى وئى العمل سواء من حيث تبسيط الأعمال، أو الإبتكار فى أدائها مما ينعكس على مستوى كفاءتها الإنتاجية. تتفق هذه النتيجة 
جدوله 1 ـ تحليل التباين أحادى الإتجاه للفروق بين متوسطات درجات الزوجات عينة البحث فى الاغتراب الزواجى تبعاً (لعمر الزوجة،

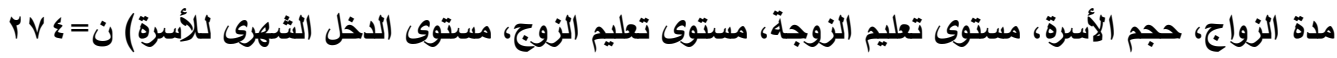

\begin{tabular}{|c|c|c|c|c|c|c|c|}
\hline مستوى الد لالة & قيمة ف & متوسط المربعات & درجات الحرية & مجموع المربعات & مصادر التباين & محاور الاغتراب & المتغيرات \\
\hline \multirow[t]{3}{*}{ دال عند ا ,, . } & V,VTr & $1 \leq \varepsilon, \cdot \leqslant \wedge$ & r & rA^,.9V & بين المجموعات & & \\
\hline & & 11,000 & rVI & $0 . Y \wedge, \leqslant 7\}$ & داخل المجموعات & الصمت الزواجى & \\
\hline & & & rVT & Or 17,001 & الكلى & & \\
\hline \multirow[t]{3}{*}{ دال عند ا ,., } & 7,0 & $197,0.0$ & r & rqr,. & بين المجموعات & & \\
\hline & & $r \cdot, . q r$ & rvi & N100,rrV & داخل المجموعات & ضعف التواصل & \\
\hline & & & rVT & $\Lambda 0 \leqslant \Lambda, Y r V$ & الكلى & العاطفى والتالفية & \\
\hline \multirow{3}{*}{ 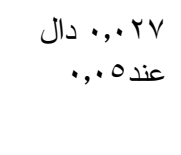 } & r,דז & $79, \cdot \wedge V$ & r & $|r \Lambda|, v \varepsilon$ & بين المجموعات & & \\
\hline & & $\curlywedge \wedge, \wedge \vee \mu$ & rVI & $011 \leqslant, 0 \leqslant 0$ & داخل المجموعات & فلعزلة وعدم المشاركة & \\
\hline & & & trR & oror,rig & الكلى & فى الحياة الزوجية & عمر الزوجة \\
\hline \multirow[t]{3}{*}{ دال عند ا ,., } & $1 \cdot$, Or & 1170,195 & r & & بين المجموعات & & \\
\hline & & $11 \cdot, \vee \wedge \wedge$ & rVI & דr, & داخل المجموعات & الإجمالى & \\
\hline & & & rVT & rrTs.,010 & الكلى & & \\
\hline مستوى الد لالة & قيمة ف & متوسط المربعات & درجات الحرية & مجموع المربعات & مصادر التباين & محاور الاغتراب & المتغيرات \\
\hline \multirow[t]{3}{*}{ دال عند ا •,. } & $\varepsilon, \wedge \wedge r$ & $q r, \varepsilon V r$ & $r$ & $11 \leq, 9 \leq 7$ & بين المجموعات & & \\
\hline & & 11,947 & rVI & rוT, & داخل المجموعات & الصدت الزواجى & \\
\hline & & & TVT & 17,001 & الكلى & & \\
\hline \multirow{3}{*}{ عنده .,., عال } & $\varepsilon, 100$ & $1 Y V, 17$ & $r$ & YOS,rY & بين المجموعات & & \\
\hline & 2,100 & r., & rit & דrqr,qו7 & داخل المجموعات & ضعف التواصل & \\
\hline & & & rVT & 10 $1 \wedge, r T V$ & الكلى & العاطفى والتالفيا & \\
\hline \multirow{3}{*}{ 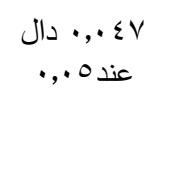 } & $r, 1.1$ & ON, Y O V & r & $11 V, 01 \pi$ & بين المجموعات & & مدة الزواج \\
\hline & & $11,9 \leq 9$ & rri & ד. T & داخل المجموعات & العزلة وعدم المشاركة & \\
\hline & & & tru & oror,rig & الكلى & فى الحياة الزوجية & \\
\hline \multirow[t]{3}{*}{ دال عند ا .,. } & $8, .79$ & ג. ו,var & r & $17 . r, 014$ & بين المجموعات & & \\
\hline & & $\| r, \varepsilon r$ & rVI & r.vrч,qץq & داخل المجموعات & الإجمالى & \\
\hline & & & rVT & TrTE.,010 & الكلى & & \\
\hline
\end{tabular}




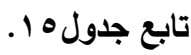

\begin{tabular}{|c|c|c|c|c|c|c|c|}
\hline مستوى الدلالة & قيمة ف & متوسط المربعات & درجات الحرية & مجموع المربعات & مصادر التباين & محاور الاغتراب & المتغيرات \\
\hline دالة عند & $7, \leqslant 1$ & $\begin{array}{l}\text { I r.,.VT } \\
\text { IN,VTr }\end{array}$ & $\begin{array}{l}\text { t } \\
r R \\
r R T\end{array}$ & $\begin{array}{l}r \varepsilon \cdot, 1 \leq V \\
0 . V 7, \varepsilon 1 r \\
0 r 17,001\end{array}$ & 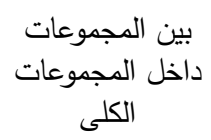 & الصمت الزواجى & \\
\hline دالة عند & $0, r \leq$ & $\begin{array}{l}109,1 \% \varepsilon \\
r ., 49\end{array}$ & $\begin{array}{c}r \\
r V t \\
r V t\end{array}$ & 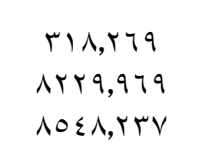 & 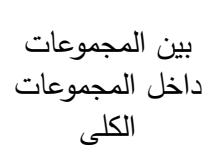 & العاطفى والتآلكية & \\
\hline 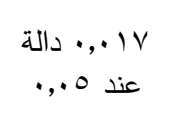 & $\varepsilon, 1 \leq r$ & $\begin{array}{l}\vee \vee, q|| \\
\mid \wedge, \wedge \cdot \wedge\end{array}$ & $\begin{array}{l}r \\
r V t \\
r V t\end{array}$ & $\begin{array}{l}100, \wedge Y T \\
0.97, \wedge 97 \\
\text { OrOY,V19 }\end{array}$ & 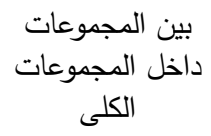 & فلى الحياة الزوجية المشاركة & حجم الأسرة \\
\hline دالة عند & $9,+r 7$ & $\begin{array}{l}1 \cdots 9, \wedge 7 \\
111, \wedge \wedge 0\end{array}$ & $\begin{array}{l}r \\
r V I \\
r V T\end{array}$ & $\begin{array}{l}r .19, V T \\
r . r r ., V q \varepsilon \\
r r r \varepsilon ., 010\end{array}$ & 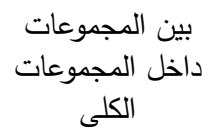 & الإجمالى & \\
\hline
\end{tabular}

\begin{tabular}{|c|c|c|c|c|c|c|c|}
\hline مستوى الد لاكة & ق قيمة ف & متوسط المربعات & درجات الحرية & مجموع المربعات & مصادر التباين & محاور الاغتراب & المتغيرات \\
\hline دالة عند & $\lambda, 0 Y 1$ & $\begin{array}{l}10 V, Y Y \\
11, \varepsilon O 1\end{array}$ & $\begin{array}{l}r \\
r v 1 \\
r v r\end{array}$ & $\begin{array}{l}\text { r) } 1 \leq, 0 \leq \\
0 . . r, .11 \\
0 r 17,001\end{array}$ & $\begin{array}{c}\text { داخل المجموعات المجوعات } \\
\text { داخلى }\end{array}$ & الصدت الزواجى & \\
\hline دالة عند & 9,011 & $\begin{array}{l}r \wedge r, r \leq q \\
r q, \leqslant T\end{array}$ & $\begin{array}{l}r \\
r V t \\
r V t\end{array}$ & $\begin{array}{l}0 \curlyvee \leq, \leq q \wedge \\
\vee ৭ \wedge r, \vee r q \\
\wedge 0 \leq \wedge, Y r \vee\end{array}$ & 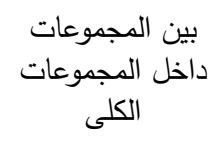 & ضعفف التواصل & المستوى التعليمى \\
\hline دالة عند & $1 \cdot, r V$ & $\begin{array}{l}110, \cdot \leq r \\
11, \cdot 1 V\end{array}$ & $\begin{array}{l}r \\
r R \\
r V t\end{array}$ & $\begin{array}{l}r V \cdot, . \wedge T \\
\text { ENAY,TrT } \\
\text { OrOY,VIq }\end{array}$ & 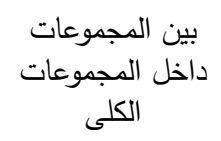 & فلى الحياة الزوجية العشاركة & 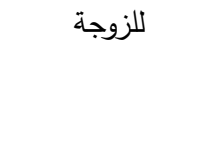 \\
\hline دالة عند & ס & $\begin{array}{l}1 \vee r q, 7 Y q \\
1.7, \Sigma 99\end{array}$ & 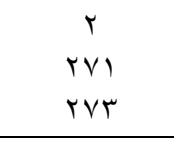 & $\begin{array}{l}r \leqslant \vee q, Y \circ Y \\
r \wedge \wedge T,, Y T r \\
r Y r \leq ., 010\end{array}$ & 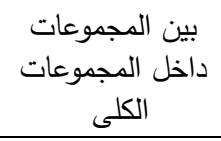 & الإجمالى & \\
\hline مستوى الدالة & قيمة ف & متوسط المربعات & درجات الحرية & مجموع المربعات & مصادر التباين & محاور الاغتراب & المتغيرات \\
\hline دالة عند & 9,790 & $\begin{array}{l}\mid V V, O \cdot \varepsilon \\
\mid \Lambda, r \cdot \Lambda\end{array}$ & $\begin{array}{l}r \\
r V T \\
r V t\end{array}$ & $\begin{array}{l}500, \ldots 1 \\
5971,001 \\
0417,001\end{array}$ & داخل المجموعات المجوعات & الصدت الزواجى & \\
\hline 9ץ 1ا, • غير & $r, . T$ & $\begin{array}{l}7 r, 999 \\
r 1, . v 1\end{array}$ & $\begin{array}{l}r \\
r V t \\
r V t\end{array}$ & $\begin{array}{l}1 r \vee, q 9 \wedge \\
\wedge \leq r \cdot, r r q \\
\wedge 0 \leq \Lambda, r r V\end{array}$ & داخل المجموعات المجوعات & ضاطعف التواصل والتآلفية & المستوى التعليمى \\
\hline دالة عند & $\varepsilon, \varepsilon) \varepsilon$ & $\begin{array}{l}A Y, \wedge \circ T \\
|\Lambda, Y Y|\end{array}$ & $\begin{array}{l}r \\
r V t \\
r V t\end{array}$ & $\begin{array}{l}170, V 1 T \\
0 . \wedge V, \ldots T \\
\text { oror,V19 }\end{array}$ & داخل المجموعات المجوعات & فلى الحياة الزوجية العزلة & للزوج \\
\hline دالة عند & $V, 99 \leq$ & $\begin{array}{l}q \ldots, \wedge \circ \wedge \\
\| r, 7 \wedge 9\end{array}$ & $\begin{array}{l}r \\
r V t \\
r V t\end{array}$ & $\begin{array}{l}1 \Lambda .1, V 19 \\
r .0 r \Lambda, V 99 \\
r r r \leq ., 010\end{array}$ & داخل المجموعات المجوعات & الإجمالى & \\
\hline
\end{tabular}




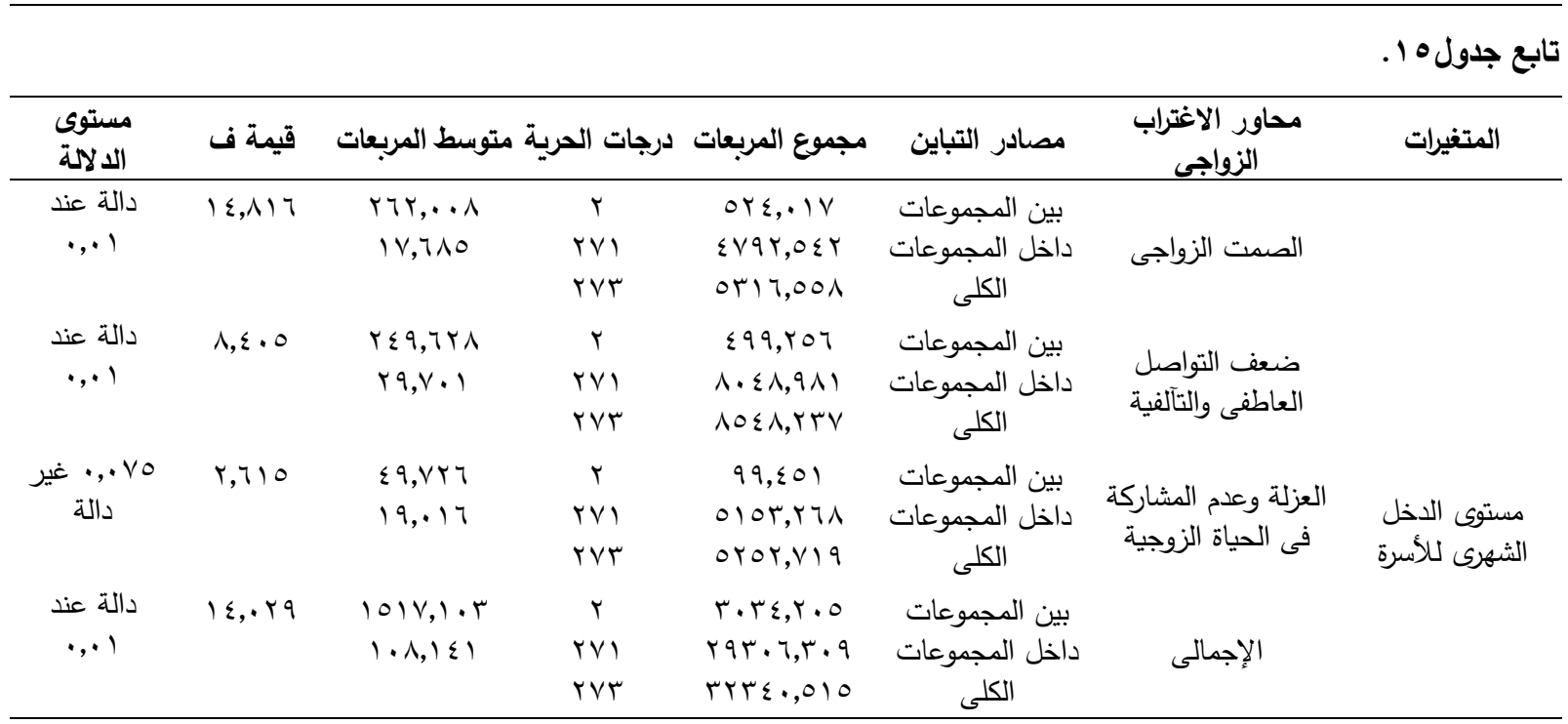

جدول 1 . اختبار LSD لمعرفة دلالة الفروق بين متوسطات درجات الزوجات عينة البحث فى الاغتراب الزواجى تبعاً لعمر الزوجة

\begin{tabular}{|c|c|c|c|c|c|c|c|}
\hline \multicolumn{3}{|c|}{ ضعف التواصل العاطفى والتآلفية } & \multicolumn{3}{|c|}{ الصمت الزواجى } & \multirow[t]{2}{*}{ ن } & \multirow{2}{*}{ عمر الزوجة } \\
\hline$r \leqslant, 0 q=p$ & 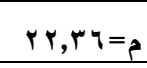 & P1,9q & $r 1,10=p$ & $1, d, r \Lambda=p$ & $\mid \Lambda, \Lambda \leq=0$ & & \\
\hline \multirow{4}{*}{-} & & - & & & - & $\vee q$ & أقل من هب \\
\hline & - & $\cdot, r v \cdot \neg \Lambda-$ & & - &., $0 \leqslant V Y V-$ & $\wedge 1$ & من \\
\hline & "Y,YYq४- & $" Y, Y \ldots \varepsilon-$ & - & "1,V74- & "Y,rITV- & \multirow{3}{*}{$\begin{array}{c}11 \varepsilon \\
ن\end{array}$} & من 0؛ فأكثر \\
\hline & الإجمالى & & \multicolumn{3}{|c|}{ العزلة وعدم المشاركة فى الحياة الزوجية } & & عمر الزوحة \\
\hline $77,71=8$ & $91,7 \mu=p$ & $1 \cdot, \ldots=p$ & $r \cdot, \Lambda V=s$ & $19, \wedge 9=p$ & $19,11=8$ & & \\
\hline & & - & & & - & V9 & أقل من هب \\
\hline & - & 1,7ץ97- & & - & $\cdot, \vee \backslash 17 \vee-$ & $\wedge$ & من \\
\hline- & $" \varepsilon, 9 \vee 07-$ & $" 7,7.0 \mathrm{Or}$ & - & .,9マ9०५- & $1,791,1-$ & $11 \varepsilon$ & من 0ـ فأكثر \\
\hline
\end{tabular}

يتضح من نتائج جدول (7 ا ) وجود فروق دالة إحصائياً بين متوسطات درجات الزوجات عينة البحث فى الاغتراب الزواجى تبعاً لعمر الزوجة عند مستوى دلالة (0.. • ) لصالح

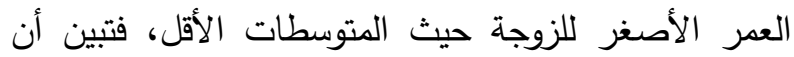
العزلة وعدم المشاركة الزوجية للزوجات ذات العمر (>مبر)

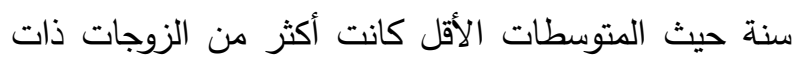

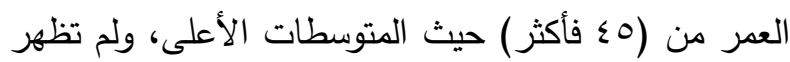

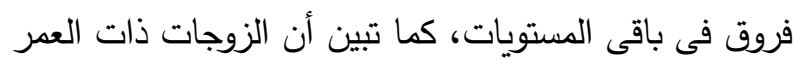

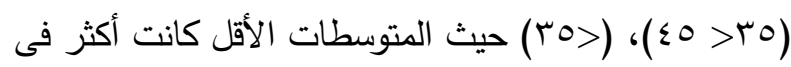

يتضح من نتائج جدول (10) بالنسبة لعمر الزوجة: وجود تباين دال إحصائياً بين متوسطات درجات الزوجات عينة البحث فى الاغتراب الزواجى بمحاوره (الصمت الزواجى، ضعف التواصل العاطفى والتآلفية، العزلة وعدم المشاركة فى الحياة الزوجية) والإجمالى تبعاً لعمر الزوجة الزوالهي

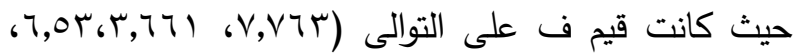
Y Y, • 1) وهى قيم دالة إحصائياً عند مستوى (1 (.,.، ه., • ) ولمعرفة إتجاه الفروق تم تطبيق إختبار LSD. جدول (7 ( ) يوضح ذلك (1) 
جدول IV أ. اختبار LSD لمعرفة دلالة الفروق بين متوسطات درجات الزوجات عينة البحث فى الاغتراب الزواجى تبعاً لمدة الزواج $r \vee \varepsilon=\dot{0}$

\begin{tabular}{|c|c|c|c|c|c|c|c|}
\hline \multicolumn{3}{|c|}{ ضعف التواصل العاطفى والتآلفية } & \multicolumn{3}{|c|}{ 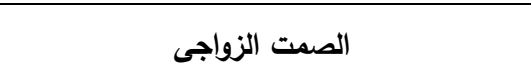 } & \multirow[t]{2}{*}{ ن } & \multirow{2}{*}{ مدة الزواج } \\
\hline$r \leqslant, I r=p$ & 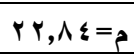 & $r,, \Lambda r=p$ & $r \cdot, \Lambda \cdot=r$ & $19, \varepsilon V=p$ & $1 \wedge, q Y=p$ & & \\
\hline \multirow{4}{*}{-} & & & & & & $v_{1}$ & من $17>>$ > זسنة \\
\hline & & $1, \cdot 1 \wedge \mathrm{V}-$ & & & . & \multirow{4}{*}{$\begin{array}{l}V T \\
\text { ir. } \\
\text { i }\end{array}$} & \multirow{4}{*}{ 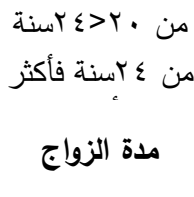 } \\
\hline & $1, r \vee q-$ & "r,rq৭- & & " & $" 1, \wedge \vee \cdot-$ & & \\
\hline & الإجمالى & & \multicolumn{3}{|c|}{ العزلة وعدم المشاركة فى الحياة الزوجية } & & \\
\hline $10,0 \Lambda=5$ & $t_{t r, r q}$ & $0 Q, \wedge r=p$ & $r \cdot, T V=p$ & $r_{0,, . \theta=p}$ & $19, \cdot V=5$ & & \\
\hline & & - & & & - & vi & من $17>>$ • זسنة \\
\hline & & r,orq- & & & $\cdot, 9 \wedge \leq \leqslant-$ & 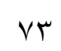 & من • • \\
\hline- & "r,YY^- & "0,VTV- & & $\cdot, 7) \leq \varepsilon-$ & $1,099-$ & 1r. & من ع זسنة فأكثر \\
\hline
\end{tabular}

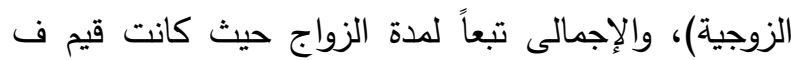
على التوالى (س ( دالة إحصائياً عند مستوى(1 (•,•، 0 •, •) ولمعرفة إتجاه الفروق تم تطبيق إختبار LSD. جدول ( V ) يوضح ذلك يتضح من نتائج جدول (IV) وجود فروق دالة إحصائياً بين متوسطات درجات عينة البحث من الزوجات فى الاغتراب الزواجى تبعاً لمدة الزواج عند مستوى دلالة

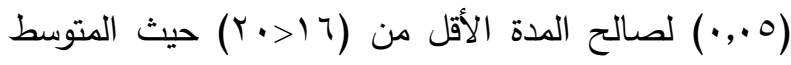
الأقل، فتبين أن ضعف التواصل العاطفى والتآلفية، العزلة وعدم المشاركة للزوجات من ذوات مدة الزواج (T (> ب) كانت أكثر من ذوات مدة الزواج من (ءזسنة فأكثر)، ولم تظهر فروق فى باقى المستويات، كما تبين أن الصمت دن دوات الزواجى، إجمالى الاغتراب الزواجى لذوات مدة الزواج

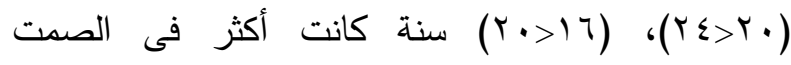
الزواجى، إجمالى الاغتراب الزواجى حيث المتوسطات الأقل عن ذوات مدة الزواج من (عاسنة فأكثر) حيث المتوسط الأعلى ولم تظهر فروق فى باقى المستويات، قد ترجع هذه النتيجة إلى أن طول مدة الزواج تساعد على تعميق روابط المودة، والرحمة، والتعاون، وتزايد الإهتمامات المشتركة بينهم
الصمت الزواجى، ضعف التواصل العاطفى والتآلفية، الإجمالى عن ذوات العمر(0ء فأكثر) حيث المتوسطات الأعلى، ولم تظهر فروق فى باقى المستويات. وقد يرجع ذلك إلى أن صغر عُمر الزوجة فى كثير من الأحيان يكون مقترناً بمحدودية الخبرة فى الحياة الزوجية، وتكون مهاراتها

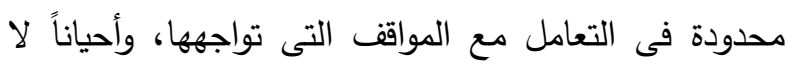
تستطيع إدارة أمورها بحكمة الأمر الذى يُسلب من الحياة الزوجية المشاعر الجميلة ويؤثر على التوافق والإنسجام بين الزوجين وينتهى بهم الأمر للاغتراب الزواجى. تتقق هذه وله

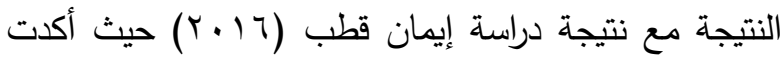
أنه كما صغر عمر الزوجة كلما كانت محدودة الخبرة فى ليى لهي حياتها الزوجية، وكلما زاد الكدر مع زوجها، واختلفت هذه

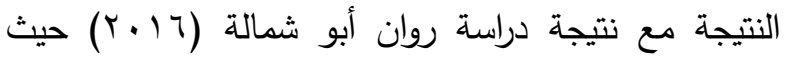
أكدت على عدم وجود فروق دالة إحصائياً فى الاغتراب الزواجى تعزو لمتغير عمر الزوجات. بالنسبة لمدة الزواج: يتضح من نتائج جدول (0 1 ) وجود تباين دال إحصائياً بين متوسطات درجات الزوجات عينة البحث فى الاغتراب الزواجى بمحاوره (الصمت الزواجى، ضعف التواصل العاطفى والتآلفية، العزلة وعدم المشاركة في الحياة 
جدول 1^ا. اختبار LSD لمعرفة دلالة الفروق بين متوسطات درجات الزوجات عينة البحث فى الاغتراب الزواجى تبعاً لحجم الأسرة $r \vee \varepsilon=\dot{0}$

\begin{tabular}{|c|c|c|c|c|c|c|c|}
\hline \multicolumn{3}{|c|}{ ضعف التواصل العاطفى والتآلفية } & \multicolumn{3}{|c|}{ الصمت الزواجى } & \multirow[t]{2}{*}{ ن } & \multirow{2}{*}{ حجم الأسرة } \\
\hline$r r, I r=p$ & $r Y,\{q=\rho$ & $r \leqslant, \leqslant Y=\beta$ & $1 \Lambda, v_{0}=5$ & 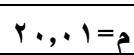 & $r \cdot, q 1=p$ & & \\
\hline & & & & & & $M r$ & صغير (r-§) أفراد \\
\hline & & $1,9 \vee \wedge$ & & & $\cdot, \wedge 9 \vee r$ & $v \leq$ & متوسط (0-7) أفراد \\
\hline & 0 & 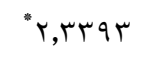 & & i,r. 9. & "Y,Y & $\wedge \wedge$ & كبير (Vأفراد فأكثر) \\
\hline \multicolumn{3}{|c|}{ الإجمالى } & \multicolumn{3}{|c|}{ العزلة وعدم المشاركة } & ن & ألأس \\
\hline $1 \cdot, 1 \leq=5$ & $1 t, 1 \Lambda=5$ & $74, \% 4=0$ & $|9, r|=p$ & $19,7 \Lambda=5$ & $r \cdot, q \Lambda=p$ & & م الاسمره \\
\hline & & - & & & - & 114 & صغير (T-乏) أفراد \\
\hline & & $" \varepsilon, \mid \wedge Y$ & & & "1,r. & $v \varepsilon$ & متوسط (0-7) أفراد \\
\hline- & $r, ., r q r$ & ${ }^{*} \Psi, Y Y \cdot \Lambda$ & & , & ${ }^{*} 1,7 \vee 0$ & $\wedge \wedge$ & كبير (Vأفراد فأكثر) \\
\hline
\end{tabular}

جدول 9 ـ. اختبار LSD لمعرفة دلالة الفروق بين متوسطات درجات الزوجات عينة البحث فى الاغتراب الزواجى تبعاً لمستوى تعليم

\begin{tabular}{|c|c|c|c|c|c|c|c|}
\hline \multicolumn{3}{|c|}{ ضعف التواصل العاطفى والتآلفية } & \multicolumn{3}{|c|}{ الصمت الزواجى } & \multirow[t]{2}{*}{ ن } & \multirow{2}{*}{ مستوى تعليم الزوجة } \\
\hline$r \leqslant, q V=p$ & $r \mu, 1 \leqslant=p$ & $r 1, \leqslant r=p$ & $r 1, r \leqslant=5$ & $r \cdot, \cdot r=p$ & $1 \wedge, 7=$ p & & \\
\hline \multirow{4}{*}{-} & & - & & & - & 19 & تعليم منخفض \\
\hline & - & $* 1, V Y \backslash 1-$ & & - & $* 1, \varepsilon$ Y $07-$ & \multirow{4}{*}{$\begin{array}{l}90 \\
9 . \\
ن\end{array}$} & تعليم متوسط \\
\hline & $* 1, \wedge \curlyvee 9 \wedge-$ & $* r, 001-$ & \multirow{2}{*}{\multicolumn{3}{|c|}{ العزلة وعدم المشاركة فى الحياة الزوجية }} & & تعليم مرنفع \\
\hline & الإجمالى & & & & & & 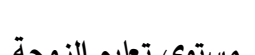 \\
\hline \multirow[t]{3}{*}{$Y V, I Y=p$} & $1 \leqslant$, , . P & $\Delta \wedge, \leqslant \mu=p$ & $r \cdot, q 1=p$ & $r \cdot, \Lambda \Lambda=p$ & $1 \wedge, \leqslant Y=p$ & & مسنوى ستيم الروجه \\
\hline & & - & & & - & 19 & تعليم منخفض \\
\hline & & $0,7101-$ & & - & $" r, \Sigma>10-$ & 90 & تعليم متوسط \\
\hline- & "r,.А.- & "ᄉ, $790 \mathrm{r}-$ & - & ., . Y & $* Y, \leqslant 90 \leqslant-$ & 9. & تعليم مرنفع \\
\hline
\end{tabular}

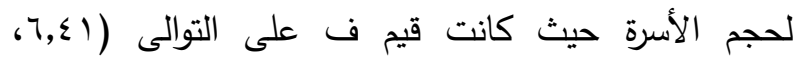
ع مستوى (1 (,.•، ه.,.)، ولمعرفة إتجاه الغروق تم تطبيق

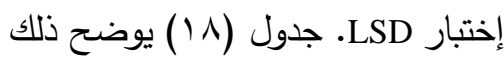
يتضح من نتائج جدول (^l ) وجود فروق دالة إحصائياً بين متوسطات درجات الزوجات عينة البحث فى الاغتراب الزواجى تبعاً لحجم الأسرة عند مستوى دلالة (0., •) لصالح الأسر كبيرة الحجم (V فأكثر) حيث المتوسط الأقل، حيث تبين أن الصمت الزواجى للأسرة الكبيرة الحجم من ( الأكثر) حيث المتوسط الأقل كان أكثر من الأسر ذات الحجم
وبالتالى شعور الزوجين بالسكينة والإرتياح، مما يساعد

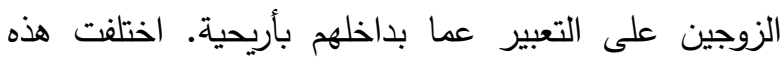

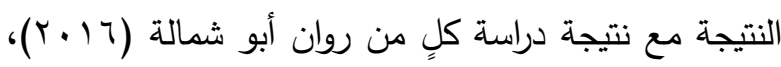

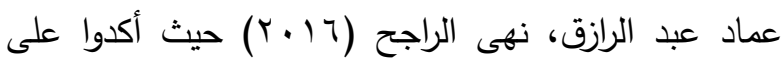
عدم وجود فروق فى مستوى الاغتراب الزواجى للزوجات

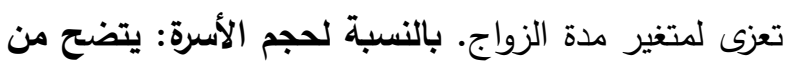
نتائج جدول (0 10) وجود تباين دال إحصائياً بين متوسطات درجات الزوجات عينة البحث فى الاغتراب الزواجى بمحاوره (الصمت الزواجى، ضعف التواصل العاطفى والتآلفية، العزلة وعدم المشاركة فى الحياة الزوجية)، والإجمالى تبعاً 


$$
\text { مجلة الإسكندرية للتبادل العلىى - (مجلد \& العدد ( ) يناير - مارس اY.r }
$$

المرتفع حيث المتوسطات الأعلى، ولم تظهر فروق فى باقى المستويات، كما تبين أن ضعف التواصل العاطفى والتآلفية، وإجمالى الاغتراب الزواجى للزوجات ذوات التعليم المتوسط،

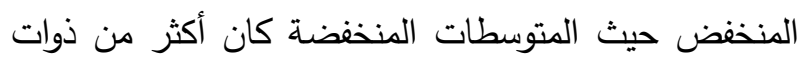

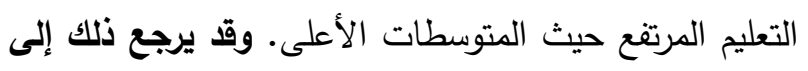
أن المستوى التعليمى المرتفع للزوجة يجعلها تسمو بتفكيرها،

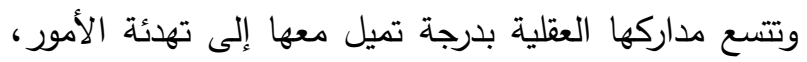
والتواصل الفعال مع زوجها، الأمر الذى يساعد فى توفير حياة هادئة أكثر توافقاً واستقراراً، تتفق هذه النتيجة مع نتيجة لاهر

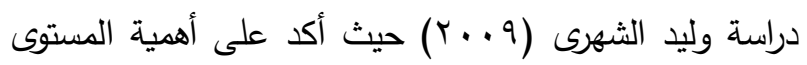
التعليمى المرتقع للزوجة فى التفاهم، والتوافق الزواجى، والدور الإيجابى الذى يقوم به فى استمرارية العلاقة الزوجية. وتختلف هذه النتيجة مع نتيجة دراسة كلٍ من روان أبو شمالة

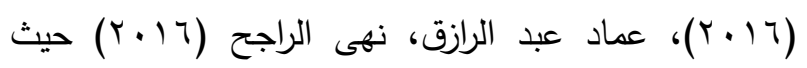

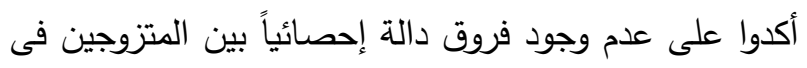
الاغتراب الزواجى تعزى للمستوى التعليمى. بالنسبة لمستوى تعليم الزوج: يتضح من نتائج جدول (10) عدم وجود تباين

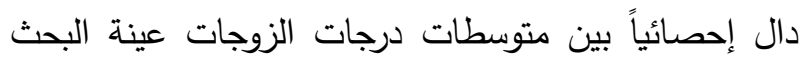

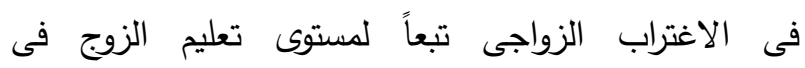
محور (ضعف التواصل العاطفى والتآلفية) حيث كانت قيمة ف (T (Y, وهى قيمة غير دالة إحصائياً، ووجود تباين دال إحصائياً بين متوسطات درجات عينة البحث فى الاغتراب الزواجى ومحاوره (الصمت الزواجى، العزلة وعدم المشاركة

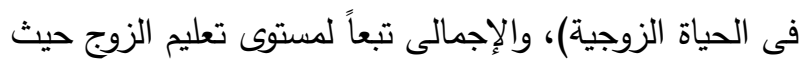

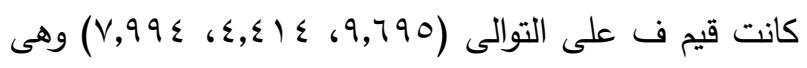
قيم دالة إحصائياً عند مستوى( ( ., ))، ولمعرفة إتجاه الفروق

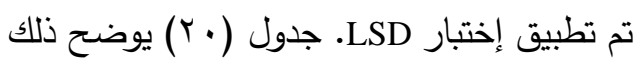

الصغير حيث المتوسطات الأعلى، ولم تظهر فروق فى باقى المستويات، كما تبين أن ضعف التواصل العاطفى والتآلفية، العزلة وعدم المشاركة وإجمالى الاغتراب الزواجى للأسر الكبيرة الحجم، والأسر المتوسطة الحجم، حيث المتوسطات الأقل كانت أكثر من الأسر الصغيرة الحجم حيث المتوسط الأعلى، ولم تظهر فروق فى باقى المستويات، وقا يرجع

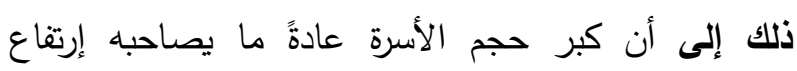
معدلات الأمية، وتدنى فى المستوى الإقتصادى، وكثرة الأعباء الملقاة على عاتق الزوجين، مما يؤدى إلى اقتحام

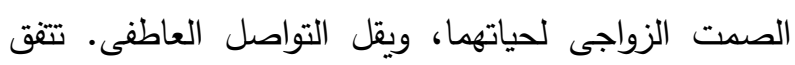

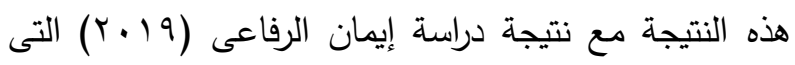

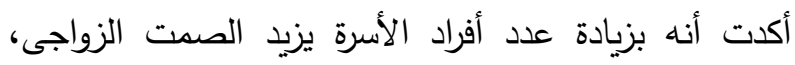
ويقل التواصل العاطفى بين الزوجين. بالنسبة لمستوى تعليم الزوجة: يتضح من نتائج جدول (10) وجود تباين دال إحصائياً بين متوسطات درجات الزوجات عينة البحث فى هي الاغتراب الزواجى بمحاوره ( الصمت الزواجى، ضعف ضإنف التواصل العاطفى والتآلفية، العزلة وعدم المشاركة فى الحياة الزوجية)، والإجمالى تبعاً لمستوى تعليم الزوجة، حيث كانت

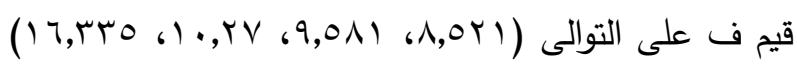
وهى قيم دالة إحصائياً عند مستوى (1 (,.•) ولمعرفة إتجاه الفروق تم تطبيق إختبار LSD. جدول (9 ( ) يوضح ذلك يتضح من نتائج جدول (9 (1) وجود فروق دالة إحصائياً بين متوسطات درجات الزوجات عينة البحث فى في الاغتراب الزواجى تبعاً لمستوى تعليمهن عند مستوى دلالة

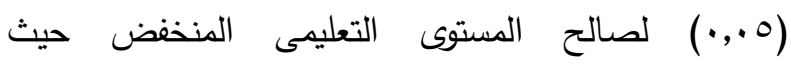
المتوسطات الأقل، فتبين أن الصمت الزواجى، والعزلة وعدم

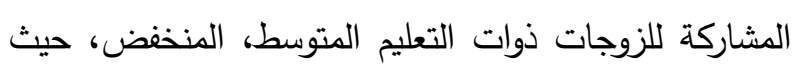
المتوسطات المنخفضة كان أكثر من الزوجات ذوات التعليم 
جدول · r. اختبار LSD لمعرفة دلالة الفروق بين متوسطات درجات الزوجات عينة البحث فى الاغتراب الزواجى تبعاً لمستوى تعليم

\begin{tabular}{|c|c|c|c|c|c|c|c|}
\hline \multicolumn{3}{|c|}{ العزلة وعدم المشاركة فى الحياة الزوجية } & \multicolumn{3}{|c|}{ الصمت الزواجى } & \multirow[t]{2}{*}{$\dot{~ ن ~}$} & \multirow{2}{*}{ مستوى تعليم الزوج } \\
\hline 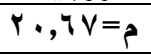 & $r \cdot, r \Lambda=p$ & $1 \wedge, \wedge \varepsilon=p$ & $r \cdot, q \leq=p$ & $r \cdot, r=p$ & $11,19=p$ & & \\
\hline \multirow{8}{*}{-} & \multirow{8}{*}{$\cdot, Y q T Y-$} & \multirow{8}{*}{$\begin{array}{l}\text { "1,0 } 017- \\
" 1, \wedge r \leqslant \wedge-\end{array}$} & & & & vo & تعليم منخفض \\
\hline & & & & - & $* 1,9 \leq \leq 9-$ & $v 4$ & تعليم متوسط \\
\hline & & & - & 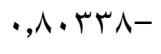 & $" Y, V \leq \wedge r-$ & \multirow{3}{*}{ ن } & تعليم مرنفع \\
\hline & & & & الإجمالى & & & \\
\hline & & & $10, \leqslant q=5$ & $I r, \Sigma V=\beta$ & $\Delta Q, r \wedge=p$ & & مستوى سعيم الروج \\
\hline & & & & & - & vo & تعليم منخفض \\
\hline & & & & - & $\varepsilon, 19 \mu v-$ & VI & تعليم متوسط \\
\hline & & & - & $Y, \cdot 1 \leq 1-$ & $" 7, Y \cdot V \wedge-$ & Tra & تعليم مرنفع \\
\hline
\end{tabular}

جدول ا ـ اختبار LSD لمعرفة دلالة الفروق بين متوسطات درجات الزوجات عينة البحث فى الاغتراب الزواجى تبعاً لمستوى الاخل

\begin{tabular}{|c|c|c|c|c|c|c|c|}
\hline \multicolumn{3}{|c|}{ ضعف التواصل العاطفى والتآلفية } & \multicolumn{3}{|c|}{ الصمت الزواجى } & \multirow[t]{2}{*}{ ن } & \multirow{2}{*}{ الثهرىى للأسرة } \\
\hline$r \varepsilon, V \theta=p$ & $r Y, \wedge q=p$ & Ml,Or $=5$ & $r 1,\{\tau=8$ & $19,97=0$ & $1 \Lambda, 1 \mu=5$ & & \\
\hline \multirow{8}{*}{ - } & & - & & & - & $\wedge 7$ & دخل منخفض \\
\hline & & I,rotV- & & & $* 1, \wedge \wedge 0-$ & $\Delta r$ & دخل متوسط \\
\hline & $* 1, \wedge \uparrow \cdot \wedge-$ & $*$ *, r $\vee 0_{-}$ & & *1, & 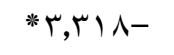 & 1.0 & دخل مرنفع \\
\hline & & & & الإجمالى & & ن & مستوى الاخل \\
\hline & & & $47,97=5$ & $q r, q \mu=p$ & $0 \wedge, q \vee=p$ & & الثهرى للأسرة \\
\hline & & & & & - & $\wedge T$ & دخل منخفض \\
\hline & & & & & *ฯ,Ятイฯ- & $\wedge r$ & دخل متوسط \\
\hline & & & & $* \varepsilon, \cdot r \leq r-$ & $* \vee, 9979-$ & 1.0 & دخل مرنفع \\
\hline
\end{tabular}

عواقبها، كما أنه يكون أقل مرونة مع أوضاع الحياة المختلفة

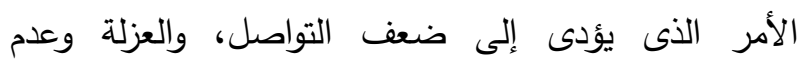
المشاركة الزوجية، مما يكون له أثره على إغتراب الزوجين وعدم توافقهم. وتتقق هذه النتيجة مع نتيجة دراسة عماد عبد

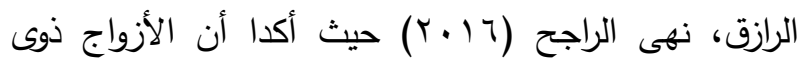

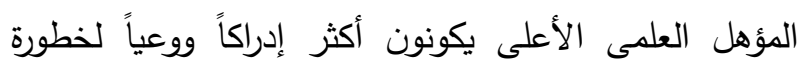
الاغتراب الزواجى وأكثر حرصاً على تحقيق التوافق فى لـى لدونى حياتهم الزوجية. بالنسبة لمستوى الاخل الشهرى للأسرة: يتضح من نتائج جدول (0 1 ) عدم وجود تباين دال إحصائياً بين متوسطات درجات الزوجات عينة البحث فى الاغتراب الزواجى تبعاً لمستوى دخل الأسرة الثهرى فى محور (العزلة

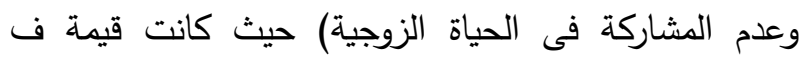

يتضح من نتائج جدول (·r) وجود فروق دالة إحصائياً بين متوسطات درجات الزوجات عينة البحث فى هي الاغتراب الزواجى تبعاً لمستوى تعليم الزوج عند مستوى دلالة (0., (•) لصالح المستوى التعليمى المنخفض للزوج حيث المتوسطات الأقل، فتبين أن الصمت الزواجى، والعزلة وعدم المشاركة فى الحياة الزوجية، والإجمالى كانت أكثر لذوات الأزواج ذوى التعليم المنخف حيث المتوسطات الأقل عن الزوجات ذوات الأزواج ذوى التعليم المتوسط، والمرتفع حيث المتوسطات الأكبر ، ولم تظهر فروق فى باقى المستويات. قد يرجع ذلك إلى أن المستوى التعليمى المنخفض للزوج ينتج

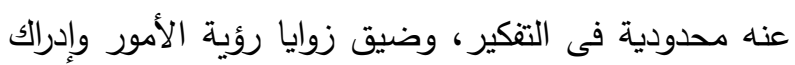




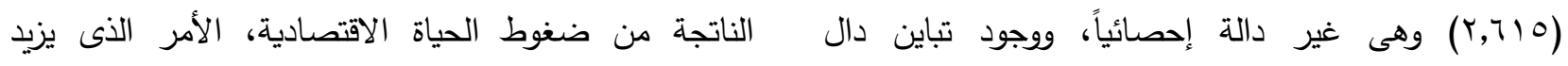
إحصائياً بين متوسطات درجات الزوجات عينة البحث فى التباعد والغربة بينهم. - نستخلص مما سبق: وجود تباين دال إحصائياً بين متوسطات درجات الزوجات عينة البحث فى الاغتراب الزواجى بمحاوره والإجمالى تبعاً لكلٍ من (عمر الزوجة، مدة

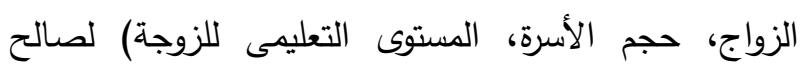

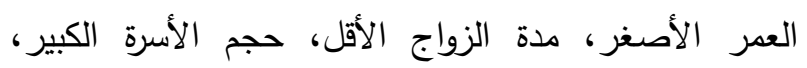
المستوى التعليمى المنخفض للزوجة. وعدم وجود تباين دال إحصائياً بين متوسطات درجاتهن فى الاغتراب الزواجى تبعاً لمستوى تعليم الزوج فى (محور ضعف التواصل العاطفى والتآلفية)، ووجود تباين فى باقى محاور الاغتراب الزواجى والإجمالى لصالح الزوجات اللاتى أزواجهن فى المستوى ولى لهولى التعليمى المنخفض. وعدم وجود تباين دال إحصائياً بين

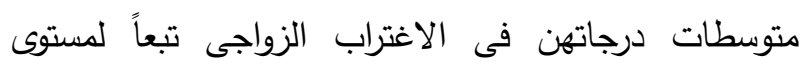
الاخل الشهرى للأسرة فى محور (العزلة وعدم المشاركة فى لهى الحياة الزوجية)، ووجود تباين دال إحصائياً فى باقى محاور

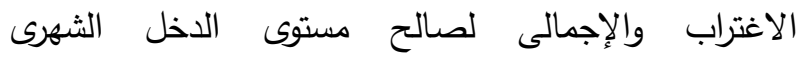
المنخفض.

- وبذلك يكون الفرض الثالث قد تحقق جزئياً. الفرض الرابع: يوجد تباين دال إحصائياً بين متوسطات

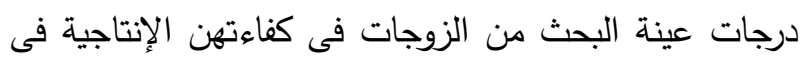
أداء المهام المنزلية بمحاورها (الرغبة فى أداء المهام المنزلية، القدرة على أداء المهام المنزلية، الرضا عن أداء المهام

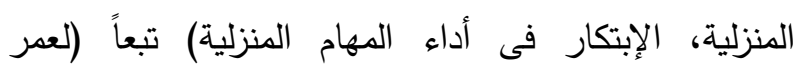
الزوجة، مدة الزواج، حجم الأسرة، المستوى التعليمى للزوجة، لإبهاء المستوى التعليمى للزوج، متوسط الاخل الثهرى للأسرة) وللتحقق من صحة الفرض إحصائياً تم استخدام أسلوب تحليل التباين الأحادى One Way Anova وتطبيق اختبار لبيان دلالة إتجاه الفروق إن وجدت وفقاً لمتغيرات

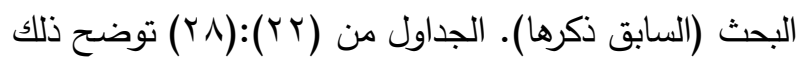

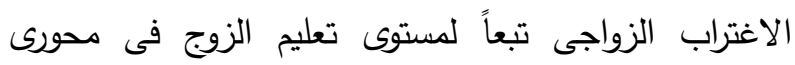
(الصمت الزواجى، ضعف التواصل العاطفى والتآلفية)،

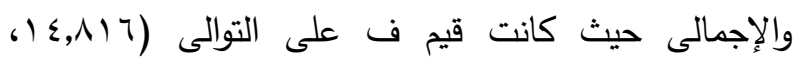

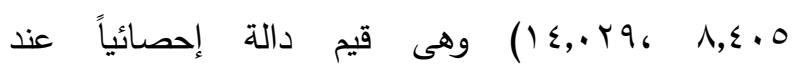
LSD مستوى( ا , • ) ولمعرفة إتجاه الفروق تم تطبيق إختبار يتضح من نتائج جدول (Yl) وجود فروق دالة إحصائياً بين متوسطات درجات الزوجات عينة البحث فى في الاغتراب الزواجى تبعاً لمستوى الدخل الثهرى للأسرة عند مستوى دلالة (0., • ) لصالح مستوى الدخل المنخفض حيث المتوسطات الأقل، فتبين أن ضعف التواصل العاطفى والتآلفية للأسر من ذوات الدخل المتوسط، والمنخفض حيث المتوسطات الأقل كان أعلى من الأسر ذات الاخل المرتفع دوات حيث المتوسطات الأكبر، ولم تظهر فروق فى باقى

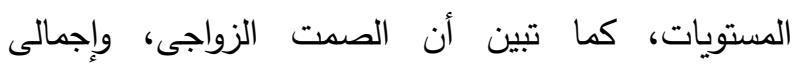
الاغتراب الزواجى للأسر ذات الدخل المتوسط، والمنخفض حيث المتوسطات الأقل كان أعلى من ذوات الدخل المرتقع حيث المتوسطات الأكبر ، كما أن الأسر ذات الدخل المتوسط حيث المتوسطات الأقل كانت أعلى فى الصمت الزواجى، وإجمالى الاغتراب الزواجى عن الأسر ذات الدخل المرتقع حيث المتوسطات الأكبر. وقد ترجع هذه النتيجة إلى أن إنخفاض مستوى الاخل الشهرى للأسرة يُسهم فى زيادة الضغوط والخلافات بين الزوجين الأمر الذى يكون لله عواقبه الوخيمة على العلاقة الزوجية بينهم. واتفقت هذه النتيجة مع نتيجة دراسة كلٍ من ربيع نوفل (r..r) حيث أكد أنه بإنخفاض مستوى الدخل الثهرى فى الأسرة تزداد الضغوط الاقتصادية التى تكون سبباً رئيسياً فى معاناة الزوجين، إيمان

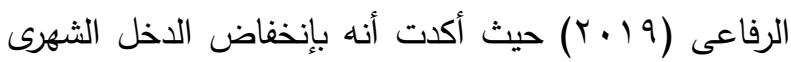
للأسرة يلجأ (كلا الزوجين أو أحدهما) للصمت الزواجى كنوع من أنواع الحلول لمنع المواجهة بين الزوجين بسبب المشاكل 
جدول r r . تحليل التباين أحادى الإتجاه للفروق بين متوسطات درجات الزوجات عينة البحث فى الكفاءة الإتتاجية تبعاً (لعمر الزوجة،

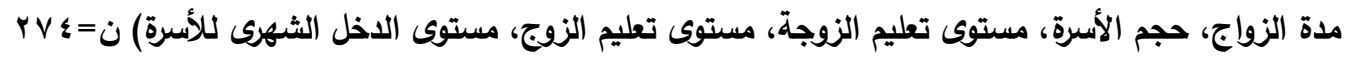

\begin{tabular}{|c|c|c|c|c|c|c|c|}
\hline مستوى الدلالة & قيمة ف & متوسط المربعات & درجات الحرية ه & مجموع المربعات & مصادر التباين & محاور الكفاءة الإنتاجية & المتغيرات \\
\hline دال عند & $7,9 \cdot r$ & $\begin{array}{l}1 \leqslant r, 1 \cdot T \\
r \cdot, V r r\end{array}$ & $\begin{array}{l}\text { r } \\
r V I \\
r V t\end{array}$ & $\begin{array}{l}r \wedge T, Y I Y \\
07) \wedge, V 04 \\
09 . \Sigma, 97 V\end{array}$ & داخل المجموعات المجوعات & الرغبة فى أداء المهام & \\
\hline دال عند & T,OVV & $\begin{array}{l}1 \leq T, 1 \cdot \varepsilon \\
Y Y, K \backslash T\end{array}$ & $\begin{array}{l}r \\
r v 1 \\
r v r\end{array}$ & $\begin{array}{l}r q r, r \cdot \Lambda \\
r \cdot r \cdot, \leq r \leq \\
r r, r, T \leq r\end{array}$ & داخل المجموعات المجموعات & القدرة على أداء المهام & \\
\hline 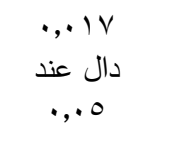 & $\varepsilon, 17 r$ & $\begin{array}{l}1 \cdot v, q \cdot V \\
\text { ro,qry }\end{array}$ & $\begin{array}{l}r \\
r V t \\
r V T\end{array}$ & $\begin{array}{l}r 10,110 \\
V \cdot r 0,900 \\
V Y \leq 1, V V\end{array}$ & داخل المجموعات المجوعات & الرضا عن أداء المهام & عمر الزوجة \\
\hline 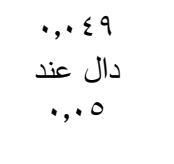 & $r, \cdot \leq r$ & $\begin{array}{l}10, r v q \\
r 1, .00\end{array}$ & $\begin{array}{l}r \\
r v 1 \\
r v r\end{array}$ & $\begin{array}{l}\mid V \cdot, v \circ q \\
V T \cdot r,, I 1 \\
V \vee V T, V V\end{array}$ & $\begin{array}{c}\text { داخل المجموعات المجوعات } \\
\text { داتلى }\end{array}$ & الإبتكار فى أداء المهام & \\
\hline دال عند & 9,9 . & $\begin{array}{l}\text { 1107,EYT } \\
\text { lNV,OYT }\end{array}$ & 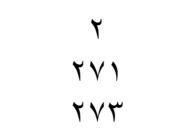 & $\begin{array}{l}r V \mid r, \wedge \leq 0 \\
0 . \lambda \mid \wedge, 017 \\
0 \leq 041, r 41\end{array}$ & داخل المجموعات & الإجمالى & \\
\hline مستوى الدلالة & قيمة ف & متوسط المربعات & درجات الحرية ه & مجموع المربعات & مصادر التباين & محاور الكفاءة الإنتاجية & المتغيرات \\
\hline 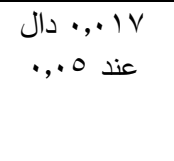 & $\varepsilon, 1 Y$ & $\begin{array}{l}A V, I r r \\
r, I \leq V\end{array}$ & $\begin{array}{l}r \\
r v 1 \\
r v r\end{array}$ & $\begin{array}{l}\text { IV } \leq, Y \leq 0 \\
O V Y \cdot, V Y r \\
09 \cdot \leq, 97 V\end{array}$ & داخل المجموعات المجوعات & الرغبة فى أداء المهام & \\
\hline دال عند ا .,. & $0, \cdot \leq \leqslant$ & $\begin{array}{l}M r, Y \wedge T \\
r Y, \Sigma O \wedge\end{array}$ & $\begin{array}{l}r \\
r V I \\
r V t\end{array}$ & $\begin{array}{l}\text { YYT,OVT } \\
T \cdot \wedge T, \cdot V \\
T r T, T \leq r\end{array}$ & داخل المجموعات المجوعات & القدرة على أداء المهام & \\
\hline دال عند ا .,. & $11,7.1$ & $\begin{array}{l}r \wedge 0,0 T \leqslant \\
r \leqslant, T 10\end{array}$ & $\begin{array}{l}r \\
r v i \\
r v r\end{array}$ & $\begin{array}{l}\text { OVI,IYA } \\
T T V \cdot, T \leq Y \\
V Y \leq I, V V\end{array}$ & داخل المجموعات المجوعات & الرضا عن أداء المهام & مدة الزواج \\
\hline دال عند ا +,., & 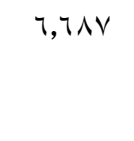 & $\begin{array}{l}|A r, N| \\
r V, r r T\end{array}$ & $\begin{array}{l}\text { r } \\
r v i \\
r v r\end{array}$ & 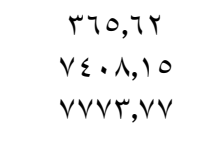 & داخل المجموعات المجوعات & الإبتكار فى أداء المهام & \\
\hline دال عند ا.,, & Ir,.Av & $\begin{array}{l}r \leqslant \cdot V, V \cdot \mid \\
\mid \wedge r, q \wedge r\end{array}$ & $\begin{array}{c}r \\
r v 1 \\
r v r\end{array}$ & $\begin{array}{l}\leq \wedge 10, \varepsilon \cdot r \\
\leq 9109, r \\
0 \leqslant T V \leqslant, T \cdot r\end{array}$ & داخل المجموعات المجوعات & الإجمالى & \\
\hline
\end{tabular}




\begin{tabular}{|c|c|c|c|c|c|c|c|}
\hline مستوى الدلالة & قيمة ف & متوسط المربعات & درجات الحرية & مجموع المربعات & مصادر التباين & محاور الكفاءة الإنتاجية & المتغيرات \\
\hline دال عند ا +,. & \&,qTr & $\begin{array}{l}1 \cdot r, T \wedge q \\
r 1, \cdot r \leq\end{array}$ & $\begin{array}{l}r \\
r v i \\
r v r\end{array}$ & $\begin{array}{l}Y \cdot V, r V V \\
079 V, 09 \\
09 \cdot \Sigma, 97 V\end{array}$ & داخل المجموعات المجوعات & الرغبة فى أداء المهام & \\
\hline دال عند ا +,., & 7,174 & $\begin{array}{l}r r, r \wedge \\
r V, r \Lambda\end{array}$ & $\begin{array}{l}r \\
r \\
r \\
r \\
r\end{array}$ & $\begin{array}{l}r \vee \varepsilon, V \circ 9 \\
T \cdot r V, \wedge \wedge r \\
T r, T, T \leq r\end{array}$ & داخل المجموعات المجوعات & القدرة على أداء المهام & \\
\hline ون •.,. دال & r,rیr & $\begin{array}{c}10,701 \\
r 7, .9\end{array}$ & $\begin{array}{l}r \\
r v 1 \\
r v r\end{array}$ & $\begin{array}{l}|V|, T \mid 0 \\
V \cdot V \cdot, \leq 00 \\
V Y \leq \mid, V V\end{array}$ & داخل المجموعات المجوعات & الرضا عن أداء المهام & حجم الأسرة \\
\hline دال عند ا +,., & $8, .79$ & $\begin{array}{l}\text { I9r,VIN } \\
\text { rV,rTr }\end{array}$ & $\begin{array}{l}r \\
r v 1 \\
r v r\end{array}$ & 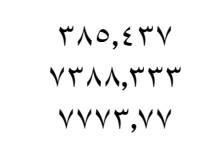 & داخل المجموعات المجموعات & الإبتكار فى أداء المهام & \\
\hline دال عند ا +,. & $1,1,1$ & 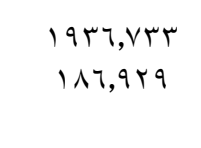 & $\begin{array}{l}r \\
r R T \\
r v r\end{array}$ & $\begin{array}{l}r \wedge V T, \varepsilon T V \\
0.70 V, \Lambda 9 \leq \\
0 \leq 0 T 1, r T 1\end{array}$ & داخل المجموعات & الإجمالى & \\
\hline مستوى الدلالة & قيمة ف & متوسط المربعات & درجات الحرية & مجموع المربعات & مصادر التباين & محاور الكفاءة الإنتاجية & المتغيرات \\
\hline عند • •., ., دال & r, ¿TY & $\begin{array}{l}V r, O \leq r \\
r, Y \leq V\end{array}$ & $\begin{array}{l}r \\
r v i \\
r v r\end{array}$ & $\begin{array}{l}1 \leqslant V, .9 Y \\
\text { OVOV, AVO } \\
09 . \Sigma, 97 V\end{array}$ & 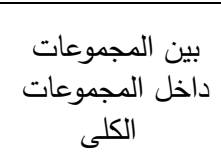 & الرغبة فى أداء المهام & \\
\hline دال عند ا .,. & $T, V 4$ & $\begin{array}{l}1 \leq 9,99 \leq \\
r Y, 1 \wedge V\end{array}$ & $\begin{array}{l}r \\
r R \\
r R T \\
r\end{array}$ & $\begin{array}{l}r 99,9 \wedge 9 \\
7.14,70 \leq \\
7 r, r, 7 \leq r\end{array}$ & داخل المجموعات المجوعات & القدرة على أداء المهام & \\
\hline ع د., · غير &., 101 & $\begin{array}{l}\varepsilon, r r q \\
r צ, 7 q 1\end{array}$ & $\begin{array}{l}r \\
r v 1 \\
r v r\end{array}$ & 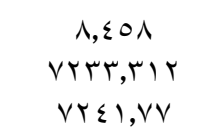 & داخل المجموعات المجوعات & الرضا عن أداء المهام & التعليمى للزوجة \\
\hline دال عند ا +,. & V,rTr & $\begin{array}{l}\text { 197,qro } \\
\text { rV,rrt }\end{array}$ & $\begin{array}{l}r \\
r v i \\
r v r\end{array}$ & 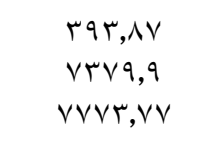 & داخل المجموعات المجوعات & الإبتكار فى أداء المهام & \\
\hline دال عند ا +,.. & 0,100 & $\begin{array}{l}11 r q, \varepsilon \mid r \\
\mid q r, \wedge \wedge \wedge\end{array}$ & $\begin{array}{l}r \\
r v 1 \\
r V t\end{array}$ & $\begin{array}{l}\text { rYON,NTY } \\
\text { OrrYT,OrO } \\
\text { OSOTI,TTI }\end{array}$ & داخل المجموعات المجوعات & الإجمالى & \\
\hline
\end{tabular}




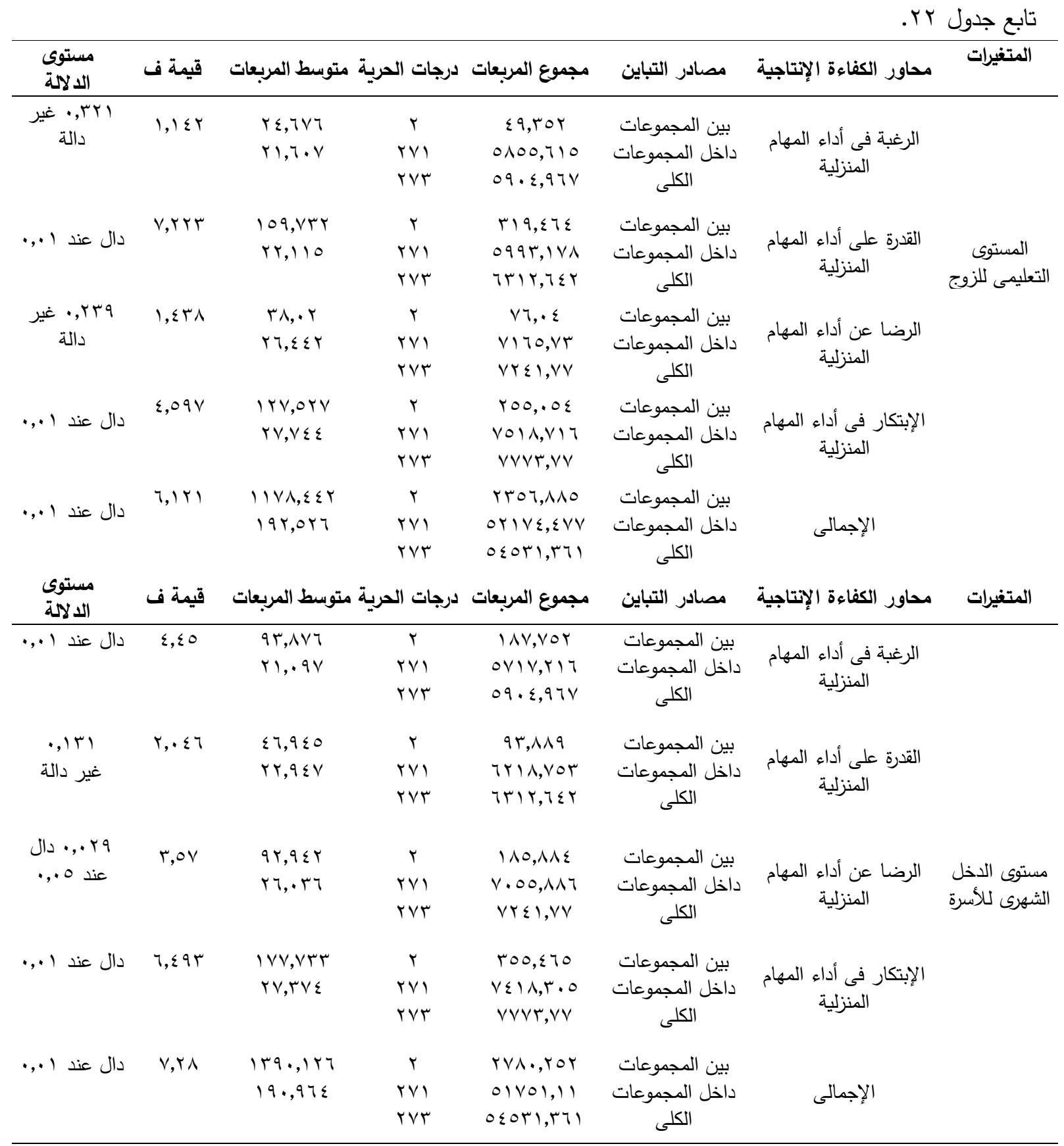

لعمر الزوجة حيث كانت قيم ف على التوالى ( ( . 9,9،

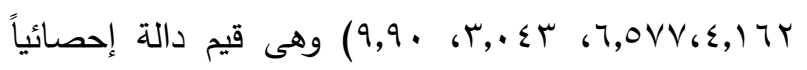
عند مستوى (1 (,., ، 0.,·)، ولمعرفة إتجاه الفروق تم تطبيق إختبار LSD. جدول (rr) يوضح ذلك
يتضح من نتائج جدول (r r) بالنسبة لعمر الزوجة: وجود تباين دال إحصائياً بين متوسطات درجات عينة البحث من الزوجات فى الكفاءة الانتاجية بمحاورها (الرغبة، القدرة، الرضا، الإبتكار) فى أداء المهام المنزلية والإجمالى تبعاً 
جدول r r. اختبار LSD لمعرفة دلالة الفروق بين متوسطات درجات الزوجات عينة البحث فى الكفاءة الإتتاجية تبعاً لعمر الزوجة $Y V \varepsilon=\dot{0}$

\begin{tabular}{|c|c|c|c|c|c|c|c|}
\hline \multicolumn{3}{|c|}{ القدرة على أداء المهام المنزلية } & \multicolumn{3}{|c|}{ الرغبة فى أداء المهام } & \multirow{2}{*}{ ن } & \multirow{2}{*}{ عمر الزوجة } \\
\hline$r \cdot, q q=p$ & $r \cdot, \wedge q=p$ & $1 \Lambda, 7 V=5$ & 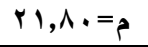 & $r 1, \varepsilon=p$ & $19, \varepsilon 1=p$ & & \\
\hline & & - & & & - & 19 & أقل من هب \\
\hline & - & "r,YIN- & & - & $" 1,99 \ldots-$ & 八 & من هr> 0؛ \\
\hline- & $\cdot, 1 \cdot r r-$ & "r,rr- & - & 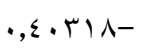 & "r,rqur- & $11 \leq$ & من 0ء فأكثر \\
\hline \multicolumn{3}{|c|}{ الإبتكار فى أداء المهام المنزلية } & \multicolumn{3}{|c|}{ الرضا فى أداء المهام المنزلية } & & 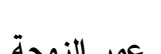 \\
\hline$r \cdot, 1 \leqslant=p$ & $19,8 \cdot=5$ & $\mid \Lambda, Y M=p$ & $\begin{array}{r}r, O r=P \\
P\end{array}$ & $r 1, T r=5$ & $r \cdot, r v=p$ & u & صعز اتروج" \\
\hline \multirow{8}{*}{-} & & - & & & - & vq & أقل من هب \\
\hline & - & $1,17 V-$ & & & $1, Y O \cdot Y-$ & $\wedge$ & من هr> 0؟ \\
\hline & $\cdot, V \leq$ or $q-$ & $" 1.91 \%-$ & & $\cdot, 9 \ldots r-$ & r, $10.0-$ & $11 \leq$ & من 0ـ فأكثر \\
\hline & & & & الإجمالى & & & عمر الزوجة \\
\hline & & & $\Lambda \theta,\{0=5$ & Pr, & $V 4, T V=5$ & & \\
\hline & & & & & - & V9 & أقل من هب \\
\hline & & & & - & $" 7,7$ Y $0 \leqslant-$ & $\wedge$ & من \\
\hline & & & - & $r, 1011-$ & "ᄉ, $\vee \vee>0-$ & $11 \leq$ & من 0؛ فأكثر \\
\hline
\end{tabular}

النتيجة مع نتيجة دراسة عبير الدويك، منار خضر (11) (1) حيث أكدتا على وجود فروق دالة إحصائياً فى مستوى الكفاءة

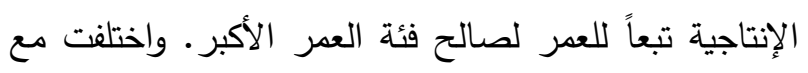

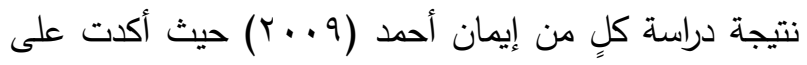

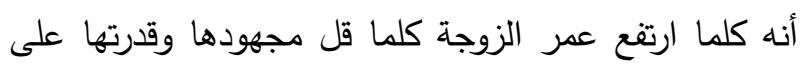

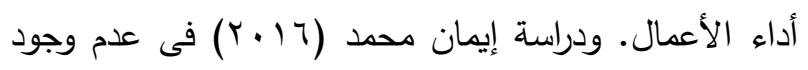
علاقة إرتباطية بين عمر ربة الأسرة وكفاءتها الإنتاجية.

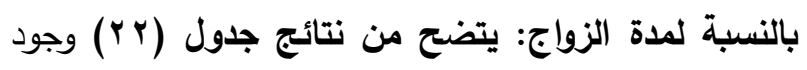
تباين دال إحصائياً بين متوسطات درجات الزوجات عينة البحث فى الكفاءة الإنتاجية بمحاورها (الرغبة، القدرة، الرضا،

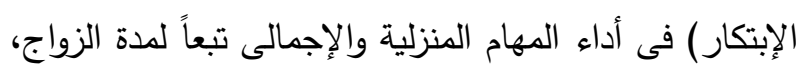

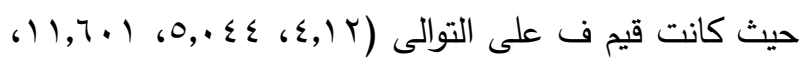

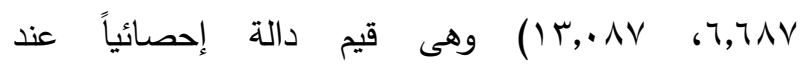
مستوى( (.,•، 0.,.)، ولمعرفة إتجاه الفروق تم تطبيق

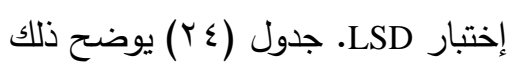

يتضح من نتائج جدول (rr) وجود فروق دالة إحصائياً بين متوسطات درجات الزوجات عينة البحث فى هن الكفاءة الانتاجية تبعاً لعمرهن عند مستوى دلالة (0.,.•) لصالح العمر الأكبر للزوجة حيث المتوسطات الأكبر، فتبين أن الرضا، والإبتكار فى أداء المهام المنزلية لذوات العمر (من 0؛ فأكثر) حيث المتوسط الأكبر كان أكثر من الإبخر الزوجات ذوات العمر (ب0>) حيث المتوسط الأقل، ولم تظهر فروق فى باقى المستويات، كما تبين أن الرغبة، والقدرة على أداء المهام المنزلية، وإجمالى الكفاءة الإنتاجية كان أكثر للزوجات ذوات العمر (0ب> 0ـ)، (من 0ـ فأكثر)

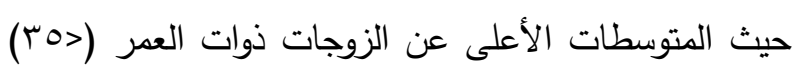
حيث المتوسط الأقل، ولم تظهر فروق فى باقى المستويات. وقد ترجع هذه النتيجة إلى أنه كلما زاد عمر الزوجة كلما إزدادت خبراتها، واتسعت مداركها بسبب عامل الخبرة

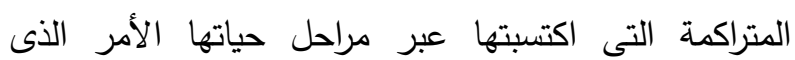
يدفعها إلى تطوير نفسها، وأدائها عند القيام بالمهام المنزلية مما يؤثر على مستوى كفاءتها الإنتاجية. وقد اتفقت هذه 
جدول ؛ ؟ . اختبار LSD لمعرفة دلالة الفروق بين متوسطات درجات الزوجات عينة البحث فى الكفاءة الإنتاجية تبعاً لمدة الزواج $r \vee \varepsilon=\dot{0}$

\begin{tabular}{|c|c|c|c|c|c|c|c|}
\hline \multicolumn{3}{|c|}{ القدرة على أداء المهام المنزلية } & \multicolumn{3}{|c|}{ الرغبة فى أداء المهام } & \multirow{2}{*}{ ن } & \multirow{2}{*}{ 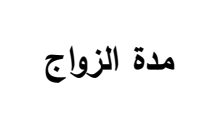 } \\
\hline$r 1, r r=p$ & $19,71=5$ & $19, r \cdot=p$ & $r \backslash, V \wedge=p$ & $r \cdot, r r=p$ & $19,9 r=p$ & & \\
\hline & & - & & & - & (1) & من $1>>$. זسنة \\
\hline & & $\cdot, \sum \wedge \vee \wedge-$ & & & $\cdot, \vee \cdots 90-$ & vr & 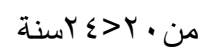 \\
\hline- & $1,0 \leq 7-$ & "r,,$r \leq-$ & & $1,171-$ & $" 1,1791-$ & $1 r$. & من ع זسنة فأكثر \\
\hline \multicolumn{3}{|c|}{ الإبتكار فى أداء المهام المنزلية } & \multicolumn{3}{|c|}{ الرضا فى أداء المهام المنزلية } & & \\
\hline$r \cdot, 1 q=p$ & $19, \vee \wedge=p$ & $I V, \varepsilon \leq=p$ & $r Y, \wedge q=p$ & $r 1,0 q=p$ & $19, r V=p$ & ن & مده الرواج \\
\hline \multirow{7}{*}{-} & \multirow{7}{*}{$\cdot, \varepsilon) 10-$} & - & & & - & (1) & من $1>>$.اسنة \\
\hline & & $" Y, r \leq \varepsilon-$ & & & "Y,YYYA- & $\mathrm{vr}$ & من. • \\
\hline & & "Y,V०Y- & & I,r- & "r,oryl- & r. & من ع اسنة فأكثر \\
\hline & & & $\wedge 7,1 \cdot=$ p & 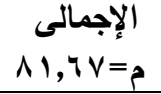 & $V \theta, q r=p$ & $\dot{ن}$ & مدة الزواج \\
\hline & & & & & & (1) & من $1>>$ •rسنة \\
\hline & & & & & $" 0, v 00 \mathrm{~V}-$ & $v r$ & من • إسنا \\
\hline & & & & $" \varepsilon, \Sigma \curlyvee \wedge \Lambda-$ & $1,1 \wedge \leq 0-$ & $1 \pi$. & من ع זسنة فأكثر \\
\hline
\end{tabular}

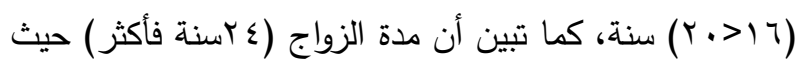

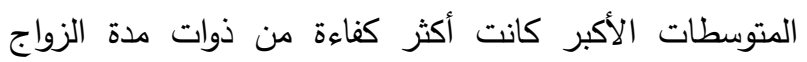

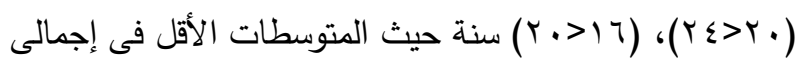
الكفاءة الإنتاجية، وقا ترجع هذه النتيجة إلى أنه كلما طالت مدة الزواج، كلما اكتسبت الزوجة المزيد من الخبرات والمهارات

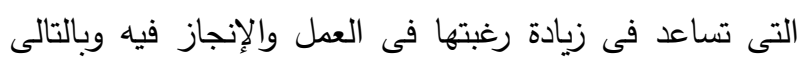
ترفع من مستوى كفاءتها الإنتاجية عند أداء المهام المنزلية. وقد اختلفت هذه النتيجة مع نتيجة دراسة كلٍ من منى منى السعيد

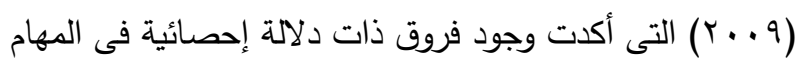

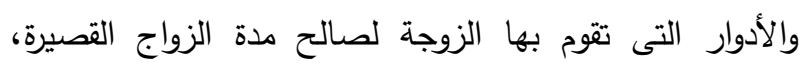

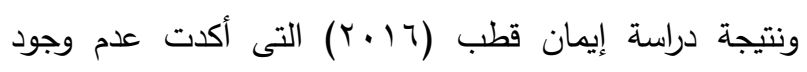
علاقة إرتباطية بين مدة الزواج والكفاءة الإنتاجية. بالنسبة

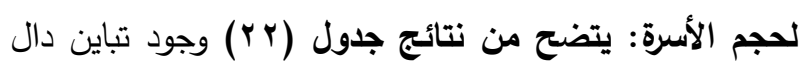

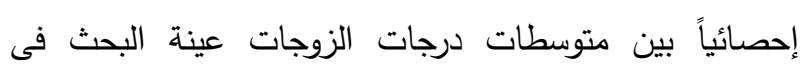

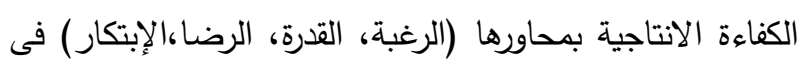

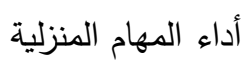

يتضح من نتائج جدول (ع Y) وجود فروق دالة إحصائياً بين متوسطات درجات الزوجات عينة البحث فى الكفاءة الإنتاجية تبعاً لمدة الزواج عند مستوى دلالة (0.,.) لصالح

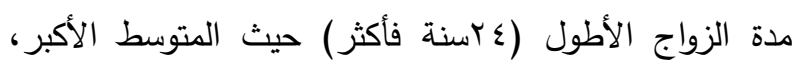

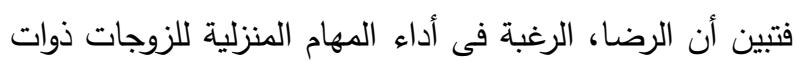

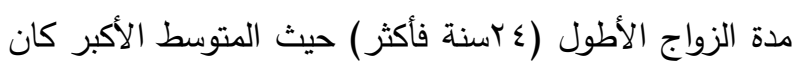

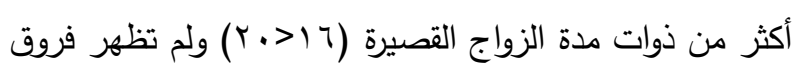
فى باقى المستويات، كما تبين أن القدرة على أداء المهام

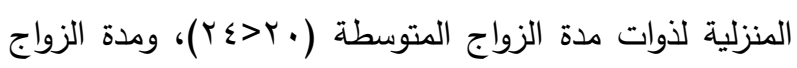

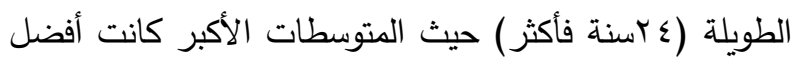

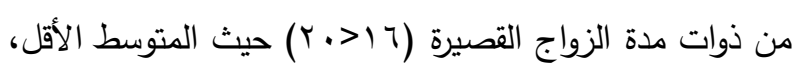
ولم تظهر فروق فى باقى المستويات، كما تبين أن الرضا،

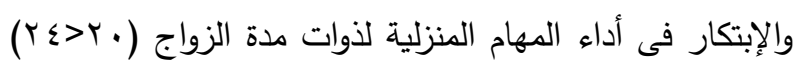

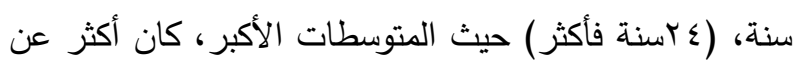

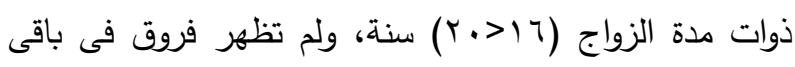
المستويات، كما تبين أن إجمالى الكفاءة الإنتاجية للزوجات ذوات مدة الزواج (•r\&>r) كانت أكثر من مدة الزواج 
جدوله r.اختبار LSD لمعرفة دلالة الفروق بين متوسطات درجات الزوجات عينة البحث فى الكفاءة الإنتاجية تبعاً لحجم الأسرة

\begin{tabular}{|c|c|c|c|c|c|c|c|}
\hline \multicolumn{3}{|c|}{ القدرة على أداء المهام المنزلية } & \multicolumn{3}{|c|}{ الرغبة فى أداء المهام } & \multirow[t]{2}{*}{ ن } & \multirow{2}{*}{ حجم الأسرة } \\
\hline $1 \wedge, \wedge q=p$ & $r \cdot, O V=\rho$ & $M I, Y I=p$ & $r \cdot, \cdot r=p$ & $r \cdot, T 1=5$ & $r r_{,}, \ldots=p$ & & \\
\hline & & - & & & - & $M$ & صغير (r- §) أفراد \\
\hline & - & .,$\tau \leqslant 7 V$ & & - & $" 1,4 q 19$ & $V \varepsilon$ & متوسط (0-7) أفراد \\
\hline- & $" 1,7 \wedge 1$ & "T,rTA & - &., $010 \mathrm{r}$ & $" 1,9 \vee \vee r$ & $\wedge \wedge$ & كبير (v أفراد فأكثر) \\
\hline \multicolumn{3}{|c|}{ الإبتكار فى أداء المهام المنزلية } & \multicolumn{3}{|c|}{ الرضا فى أداء المهام المنزلية } & $\dot{~ ن ~}$ & حجم الأسرة \\
\hline $1 \mathrm{~V}, 74=5$ & $19,90=p$ & $r \cdot r r=p$ & $r \cdot, 0 q=p$ & $r 1, T r=p$ & YY, $\{Y=\beta$ & & \\
\hline \multirow{8}{*}{-} & & - & & & - & 114 & صغير (r-§) أفراد \\
\hline & & $\cdot, \Gamma \wedge \leq \varepsilon$ & & & •, • & $v \leq$ & متوسط (0-7) أفراد \\
\hline & "Y, Y人 & "r,TVוT & & $1, \cdot r \cdot V 1$ & $" 1, \wedge \tau \leq \varepsilon 0$ & $\wedge \wedge$ & كبير (v أفراد فأكثر) \\
\hline & & & & الإجمالى & & $\dot{ن}$ & حجم الأسرة \\
\hline & & & $R V, 17=5$ & $\Lambda r, V \leqslant=p$ & $\Lambda q, \cdots=p$ & & \\
\hline & & & & & - & $M r$ & صغير (r- \\
\hline & & & & & r,Y०4ג & $V \varepsilon$ & متوسط (0-7) أفراد \\
\hline & & & - & $0,0 \wedge \leq 10$ & $" \wedge, \wedge \varepsilon \cdot q$ & $\Lambda \wedge$ & كبير (Vأفراد فأكثر) \\
\hline
\end{tabular}

ذوات الأسر الصغيرة، والمتوسطة الحجم حيث المتوسطات الأكبر كانت أفضل من الزوجات للأسر كبيرة الحجم حيث المتوسطات الأقل، ولم تظهر فروق فى باقى المستويات. قد

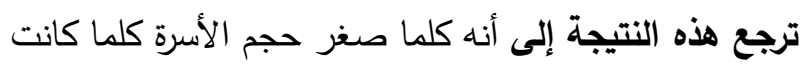
المهام والمسؤليات الملقاه على عاتقها صغير، مما يشجعها ذلك أن تكون أكثر رغبةً، رضا، وقدرةً، وإبتكاراً عند أداء هذه

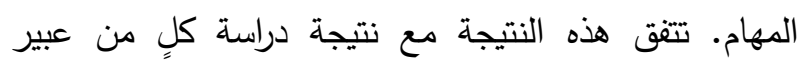

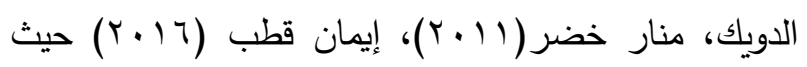
أكدوا على وجود فروق فى الكفاءة الإنتاجية لربات الأسر، إنسان

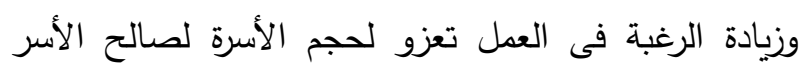
صغيرة الحجم. بالنسبة للمستوى التعليمى للزوجة: يتضح من نتائج جدول (Yr) عدم وجود تباين دال إحصائياً بين متوسطات درجات الزوجات عينة البحث فى الكفاءة الانتاجية تبعاً لمستوى تعليم الزوجة فى محور (الرضا عن أداء المهام

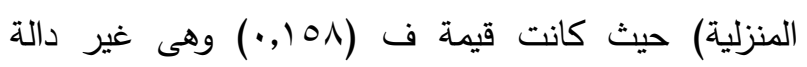
إحصائياً، ووجود تباين دال إحصائياً بين متوسطات درجاتهن
والإجمالى تبعاً لحجم الأسرة، حيث كانت قيم ف على التوالى

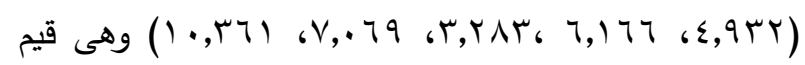
دالة إحصائياً عند مستوى( (.,.•، 0.,.)، ولمعرفة إتجاه

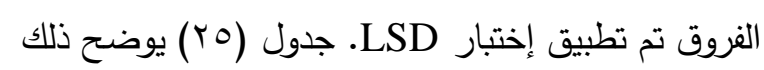
يتضح من نتائج جدول (ro) وجود فروق دالة

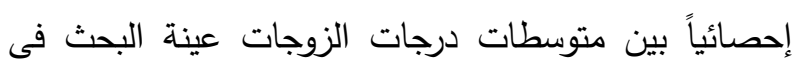
الكفاءة الإنتاجية تبعاً لحجم الأسرة عند مستوى دلالة (0.,. •)

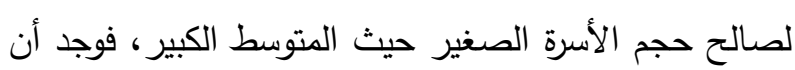
الرغبة فى أداء المهام المنزلية لدى الزوجات للأسر ذات الحجم المتوسط، الصغير حيث المتوسط الأكبر كانت أكثر رغبةً من الأسر كبيرة الحجم (V) أفراد فأكثر) حيث المتوسطات الأقل، ولم تظهر فروق فى باقى المستويات، كما

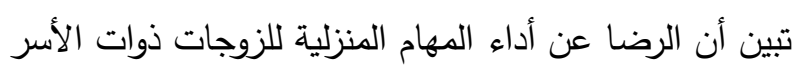

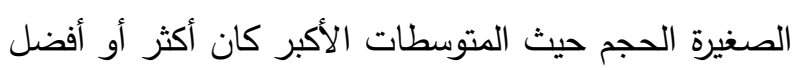
من الزوجات لأسر كبيرة الحجم حيث المتوسطات الأقل، ولم تظهر فروق فى باقى المستويات، كما تبين أن القدرة، والإبتكار فى أداء المهام المنزلية وإجمالى الكفاءة للزوجات 
جدول צr. اختبار LSD لمعرفة دلالة الفروق بين متوسطات درجات الزوجات عينة البحث فى الكفاءة الإنتاجية تبعاً للمستوى

\begin{tabular}{|c|c|c|c|c|c|c|c|}
\hline \multicolumn{3}{|c|}{ القدرة على أداء المهام المنزلية } & \multicolumn{3}{|c|}{ الرغبة فى أداء المهام } & \multirow[t]{2}{*}{ ن } & \multirow{2}{*}{ المستوى التعليمى } \\
\hline PI, & $r \cdot, T \Lambda=\rho$ & IN,NM=s & $r r, \cdot r=p$ & $r \cdot, \Delta \theta=\beta$ & $r^{*, \varepsilon} \cdot=5$ & & \\
\hline & & - & & & - & 19 & منخفض \\
\hline & & $" 1, \wedge \circ r_{1}-$ & & & $\cdot, 1 \leq Y \wedge \vee-$ & 90 & متوسط \\
\hline & . & $" r, 乏 q \cdot \wedge-$ & & "1, 1 1 $097-$ & 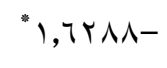 & 9. & مرتفع \\
\hline \multicolumn{3}{|c|}{ الإجمالى } & \multicolumn{3}{|c|}{ الإبتكار في أداء المهام المنزلية } & $\dot{ن}$ & المستوى التعليمى \\
\hline \multirow[t]{4}{*}{$10,19=p$} & $\Lambda r, r \theta=s$ & $V \wedge, r \cdot=5$ & $r \cdot, r r=5$ & $r \cdot, l V=\rho$ & $1 \mathrm{~V}, 1 \leqslant=5$ & & للزوجة " ل ل \\
\hline & & & & & & 19 & منخفض \\
\hline & & $" 0, .1 V-$ & & & "Y,OYA.- & 90 & متوسط \\
\hline & $1,947-$ & $" 7,90 \%-$ & & $\cdot,+7 \leq 91-$ & "r,oqr- & 9. & مرتفع \\
\hline
\end{tabular}

جدول VV. اختبار LSD لمعرفة دلاةة الفروق بين متوسطات درجات الزوجات عينة البحث فى الكفاءة الإنتاجية تبعاً للمستوى

\begin{tabular}{|c|c|c|c|c|c|c|c|}
\hline \multicolumn{3}{|c|}{ الإبتكار فى أداء المهام المنزلية } & \multicolumn{3}{|c|}{ القدرة على أداء المهام المنزلية } & \multirow[t]{2}{*}{ ن } & \multirow{2}{*}{ المستوى التعليمى } \\
\hline$r \cdot, r T^{p}$ & $19,0=p$ & $1 \Lambda, \cdot V=p$ & $r 1, \cdot V=p$ & $r \cdot, V \theta=p$ & $11,00=p$ & & \\
\hline \multirow{8}{*}{-} & \multirow{8}{*}{$1, r .01-$} & - & & & - & vo & منخفض \\
\hline & & $\cdot, 91097-$ & & & $* H, Y \cdot r r-$ & $v 4$ & متوسط \\
\hline & & $* r, \Upsilon 911-$ & & . TYMIV- & *ห,ฯYฯ०- & Trt & 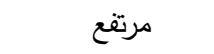 \\
\hline & & & & الإجمالى & & ن & المستوى التعليمى \\
\hline & & & $\Lambda \varepsilon, \Lambda \cdot=\Omega$ & $\Lambda r, V \cdot=R$ & $V V, V Y=\rho$ & & 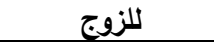 \\
\hline & & & & & - & vo & منخفض \\
\hline & & & & & $* \varepsilon, 9 \vee \vee \varepsilon-$ & VY & متوسط \\
\hline & & & & $r, 1 \cdot$ ro- & $* \vee, \cdot \wedge \leq q-$ & IrT & 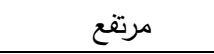 \\
\hline
\end{tabular}

المتوسطات الأكبر، فتبين أن الرغبة فى أداء المهام المنزلية

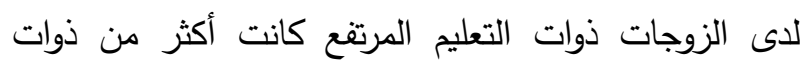
التعليم المنخفض، والمتوسط، ولم تظهر فروق فى باقى المستويات، كما تبين أن القدرة، والإبتكار فى أداء المهام

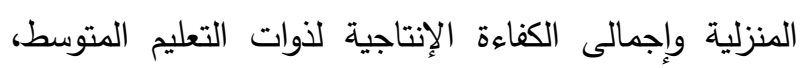
والمرتفع حيث المتوسطات الأكبر كانت أكثر أو أفضل من الزوجات ذوات التعليم المنخفض حيث المتوسطات الأقل ولم تظهر فروق فى باقى المستويات. وقد يرجع ذلك إلى أن المستوى التعليمى المرتفع للزوجة يعطيها الكفاءة لكيفية إدارة

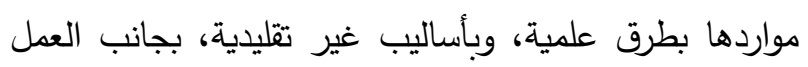

فى الكفاءة الانتاجية تبعاً لمستوى تعليم الزوجة فى محاور (الرغبة، القدرة على أداء المهام المنزلية، الإبتكار)

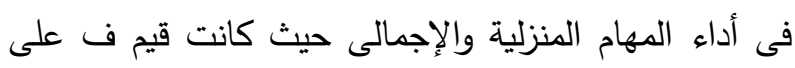

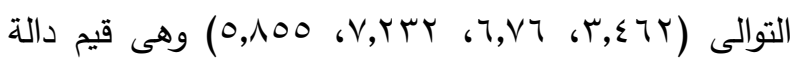
إحصائياً عند مستوى( (.,.، ه... •.) ولمعرفة إتجاه الفروق تم تطبيق إختبار LSD. جدول (Tr) يوضح ذلك يتضح من نتائج جدول († Y) وجود فروق دالة إحصائياً بين متوسطات درجات عينة البحث من الزوجات

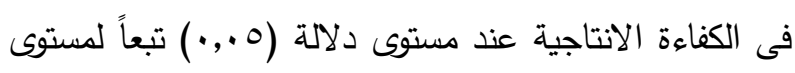
تعليم الزوجة لصالح المستوى التعليمى الأعلى حيث 
أزواجهن من ذوى التعليم المرتفع، كان أكثر أو أفضل عن

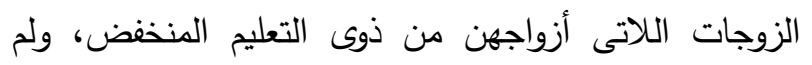

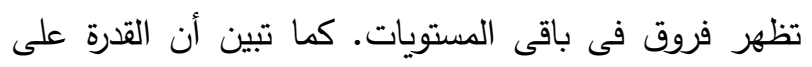

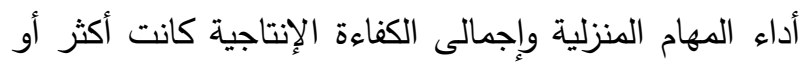

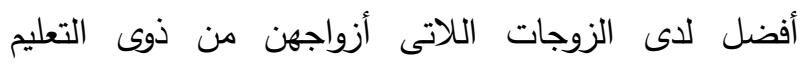

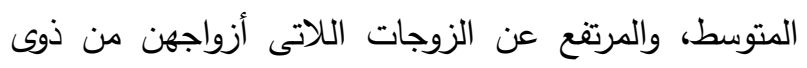

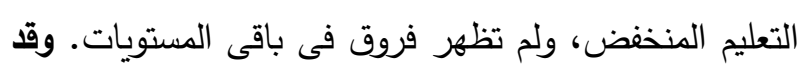

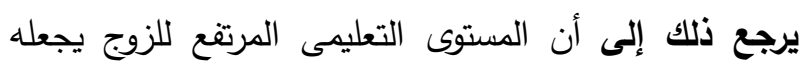
أكثر إدراكاً لدوره فى المسؤليات المنزلية، وأكثر مشاركةً

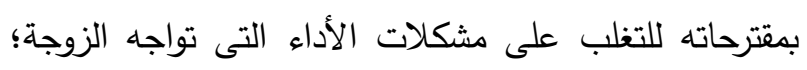

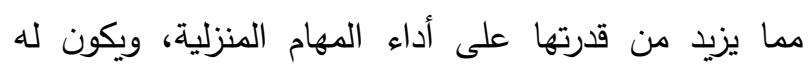

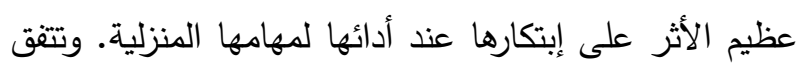

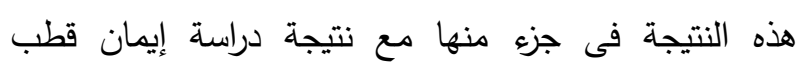

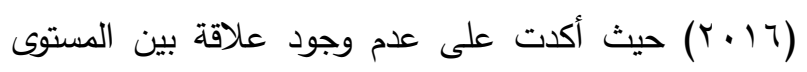

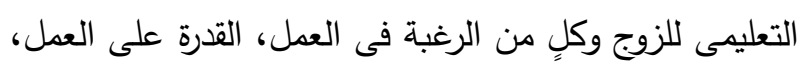

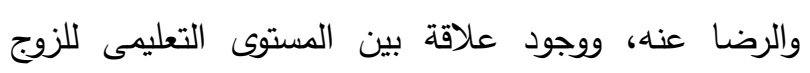

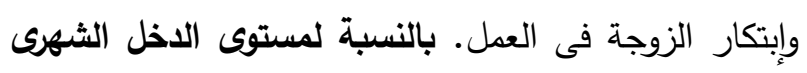

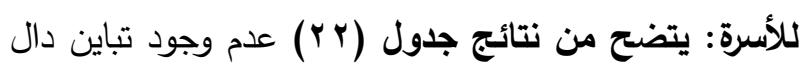

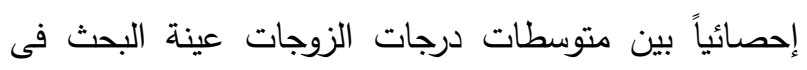

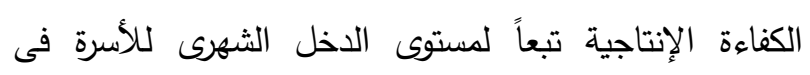

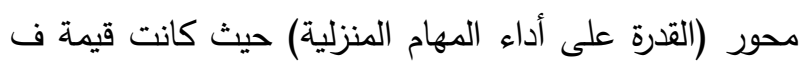

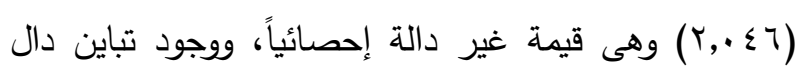

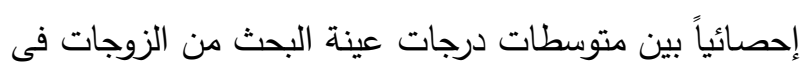

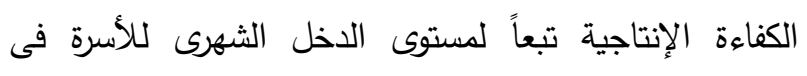

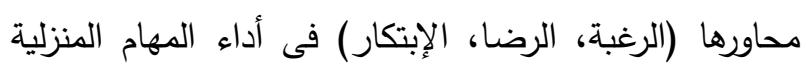

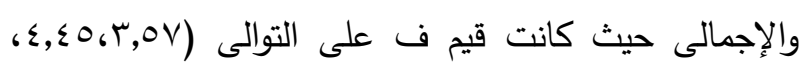

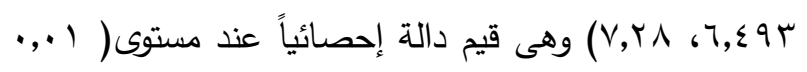

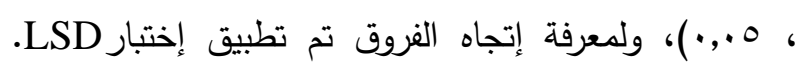

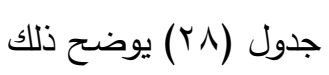

على رفع مستوى كفاءتها عند القيام بالمهام المختلفة فى

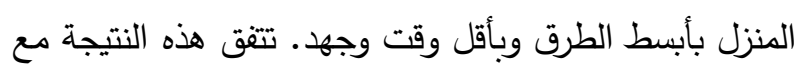

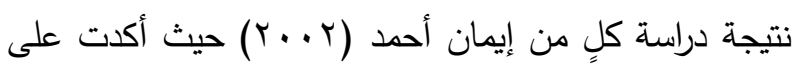
وجود علاقة إرتباطية موجبة بين تعليم الزوجة وإتقانها

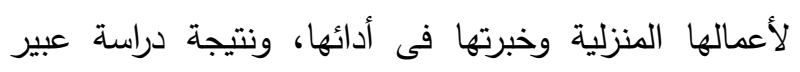

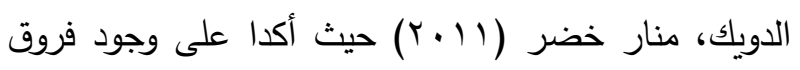

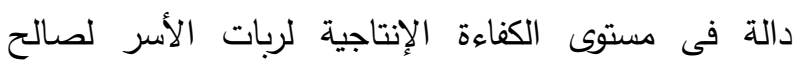

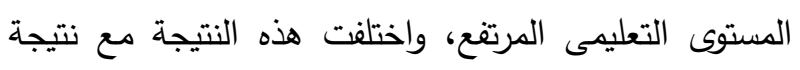

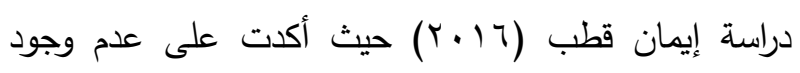
فروق دالة فى مستوى الكفاءة الإنتاجية لربات الأسر وفقاً

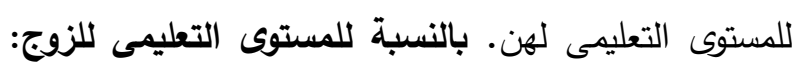
يتضح من نتائج جدول (Yr) عدم وجود تباين دال إحصائياً

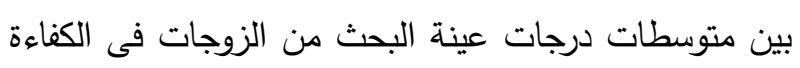

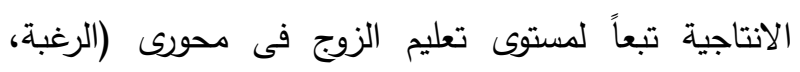

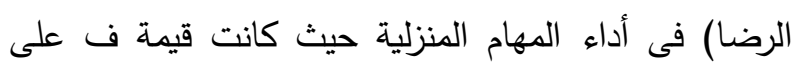

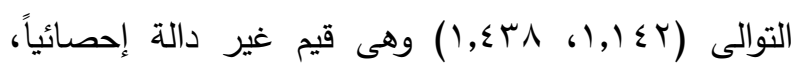

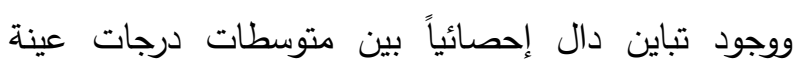

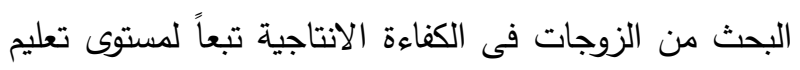

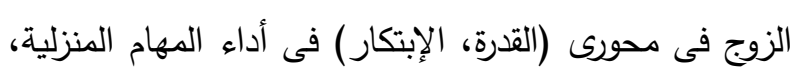

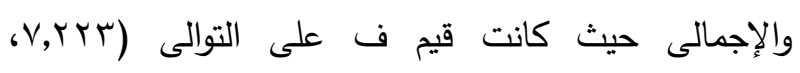

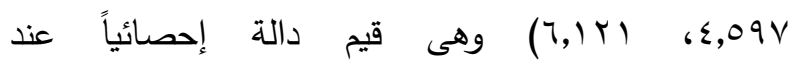

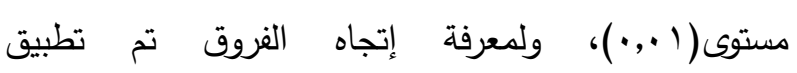
إختبار LSD. جدول (rVD) يوضح ذلك (بV)

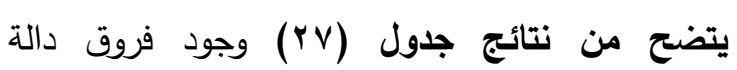

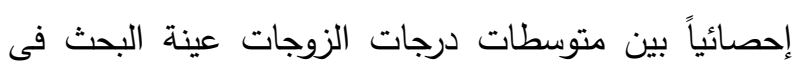

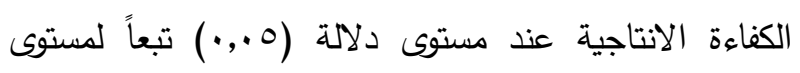

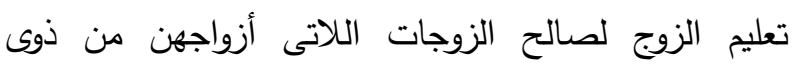

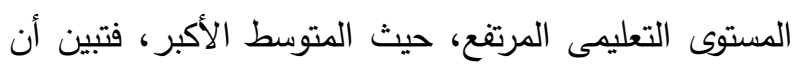

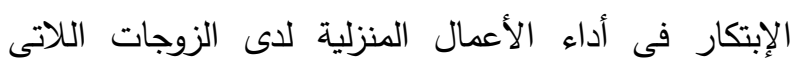



حنان حنا عزيز : الاغتراب الزواجى كما تدركه الزوجة وعلاقته بكلٍ من كفاءتها الإنتاجية فى أداء المهام المنزلية.....

جدول ^ץ. اختبار LSD لمعرفة دلالة الفروق بين متوسطات درجات الزوجات عينة البحث فى الكفاءة الإنتاجية تبعاً لمستوى الاخل

\begin{tabular}{|c|c|c|c|c|c|c|c|}
\hline \multicolumn{3}{|c|}{ الرضا على أداء المهام المنزلية } & \multicolumn{3}{|c|}{ الرغبة فى أداء المهام } & \multirow[t]{2}{*}{ ن } & \multirow{2}{*}{ متوسط الأخل الثهرى } \\
\hline$r r, T \Lambda=P$ & $r 1, \ldots=p$ & $r \cdot, q V=p$ & $r \mid, \wedge \Lambda=p$ & $r 1, .1=p$ & $19, \wedge \Lambda=p$ & & \\
\hline \multirow{4}{*}{-} & & - & \multirow{4}{*}{\multicolumn{3}{|c|}{ 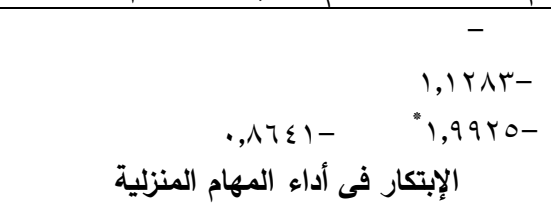 }} & $\wedge 7$ & منخفض \\
\hline & &.,$\cdot r \leq \wedge \Lambda-$ & & & & r & متوسط \\
\hline & "1,TVYT- & $" 1, \vee \backslash 11-$ & & & & 1.0 & مرتفع \\
\hline & الإجمالى & & & & & ن & متوسط الاخل الثهرى \\
\hline \multirow[t]{3}{*}{$\Lambda 7,10=p$} & $11, \cdot \tau=p$ & $V \wedge, V \mu=\rho$ & $r \cdot, 0 q=p$ & $19, \varepsilon=5$ & $i v, \wedge \theta=p$ & & للأسرة \\
\hline & & - & & & - & $\Lambda 4$ & منخفض \\
\hline & "a gri & 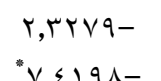 & & 1) grq- & $\begin{array}{l}1,0 \leqslant \wedge 1- \\
0 V<17-\end{array}$ & N & متوسط \\
\hline
\end{tabular}

الأكبر، مدة الزواج الأطول، حجم الأسرة الأصغر). عدم وجود تباين دال إحصائياً بين متوسطات درجاتهن فى محور (الرضا عن أداء المهام المنزلية) تبعاً للمستوى التعليمى للزوجات، ووجود تباين دال إحصائياً بين متوسطات درجاتهن فى باقى محاور الكفاءة الإنتاجية والإجمالى لصالح المستوى التعليمى الأعلى للزوجات. عدم وجود تباين دال إحصائياً بين متوسطات درجات عينة البحث من الزوجات فى محورى

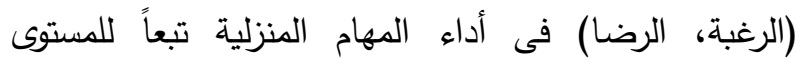
التعليمى لأزواجهن، ووجود تباين دال إحصائياً فى باقى لرئى

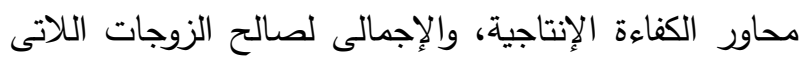
أزواجهن فى المستوى التعليمى الأعلى. عدم وجود تباين دال إحصائياً بين متوسطات درجات الزوجات عينة البحث فى البى

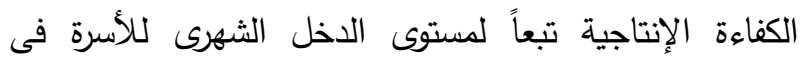
محور (القدرة على أداء المهام المنزلية)، ووجود تباين دال إحصائياً بين متوسطات درجاتهن فى باقى محاور الكفاءة الإنتاجية، والإجمالى لصالح الدخل الثهرى المرتفع. - وبذلك يكون الفرض الرابع قد تحقق جزئياً. الفرض الخامس: توجد فروق دالة إحصائياً بين متوسطات درجات عينة البحث من الأبناء المراهقين فى الرهاب الاجتماعى تبعاً لمتغيرات البحث (جنس الأبناء، مكان الاناء السكن) وللتحقق من صحة الفرض إحصائياً تم إستخدام
يتضح من نتائج جدول (Y^) وجود فروق دالة إحصائياً بين متوسطات درجات الزوجات عينة البحث فى الكفاءة الإنتاجية عند مستوى دلالة (0.,.) تبعاً لمستوى الدخل الثهرى للأسرة حيث المتوسط الأكبر فتبين أن (الرغبة، والابتكار) فى أداء المهام المنزلية لدى الزوجات من الأسر ذات الدخل المرتفع كانت أكثر أو أفضل من ذوات الدخل المنخفض، ولم تظهر فروق فى باقى المستويات، كما تبين أن الرضا عن أداء المهام المنزلية واجمالى الكفاءة الإنتاجية لدى الزوجات من الأسر ذات الدخل المرتفع كانت أكثر أو أفضل من ذوات الدخل المتوسط، والمنخفض، ولم تظهر فروق فى باقى المستويات. وقد ترجع هذه النتيجة إلى أنه كلما ارتفع الدخل الثهرى للأسرة كلما توافرت لدى الزوجة العديد من الأجهزة، والأدوات المنزلية الحديثة التى تُعينها على أداء المهام المنزلية بأقل وقت وجهد، مما يجعلها أكثر رغبةً ورضا عن العمل الذى تقوم به، كما قد يتوافر لديها وسائل حديثة تمدها بالمعلومات عن كيفية إبتكار أساليب جديدة لأداء مهامها بهاء المنزلية، الأمر الذى يؤثر على كفاءتها الإنتاجية. - نستخلص مما سبق: وجود تباين دال إحصائياً بين متوسطات درجات عينة البحث من الزوجات فى الكفاءة الإنتاجية فى أداء المهام المنزلية، ومحاورها، والإجمالى تبعاً (لعمر الزوجة، مدة الزواج، حجم الأسرة) لصالح (العمر 


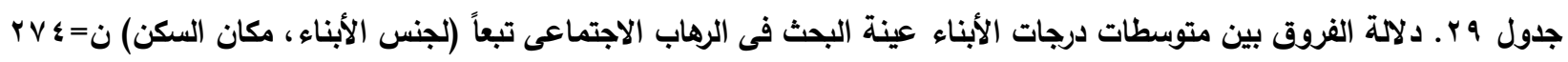

\begin{tabular}{|c|c|c|c|c|c|c|c|}
\hline مت ته & قيمة & الفرق بين & الإنحراف & المتوسط & & \multicolumn{2}{|c|}{ المتغيرات } \\
\hline \multirow{2}{*}{ دال عند مستوى } & \multirow{2}{*}{$\varepsilon, 111$} & & $0, \wedge 9 \leq$ & Yq,VY. & ITr & ذكور & جنس \\
\hline & & $r, \wedge)$ & $0, \Sigma Y T$ & $r 7,9.9$ & $1 \leq r$ & إناث & الابناء \\
\hline \multirow{2}{*}{ دال عند مستوى } & \multirow{2}{*}{$r, 001-$} & & 0,774 & $r 7,9 Y \wedge$ & lro & ريف & مكان السكن \\
\hline & & r, $\leqslant 00-$ & $0, V Y Y$ & rq,r^r & $1 \leq 9$ & حضر & \\
\hline
\end{tabular}

الأبناء المراهقين قاطنى الريف مستوى أقل من المتوسط

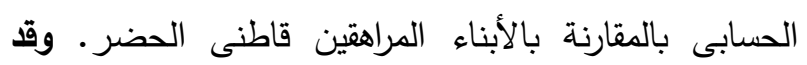

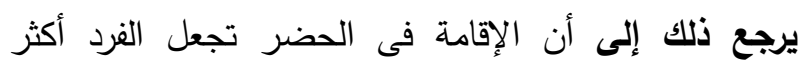
إحتكاكاً بغيره غير منغلق على نفسه؛ فالحضر به الكثير من إنى

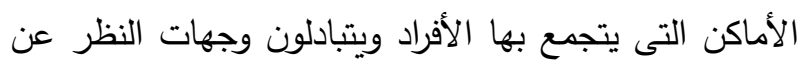
الريف، الأمر الذى يكون له أثره فى الحد من الرهاب

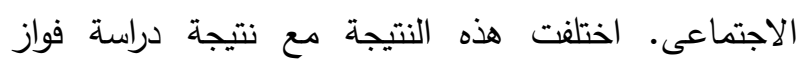
المومنى، عبد الكريم جرادات (1) (1) حيث أكدا على عدم وجود فروق تعزى لمكان السكن فى الرهاب الاجتماعى. - نستخلص مما سبق: وجود فروق دالة إحصائياً بين متوسطات درجات الأبناء المراهقين عينة البحث فى الرهاب

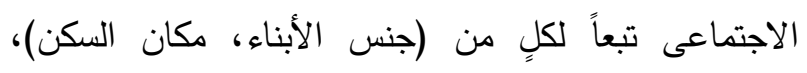
لصالح الأبناء الإناث، والأبناء قاطنى الريف. - وبذلك يكون الفرض الخامس قد تحقق كلياً.

الفرض السادس: يوجد تباين دال إحصائياً بين متوسطات درجات عينة البحث من الأبناء المراهقين فى ئى داين الرهاب الاجتماعى تبعاً لمتغيرات البحث (الترتيب بين

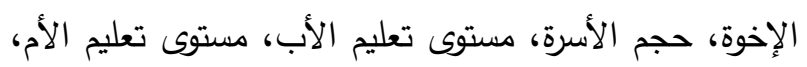

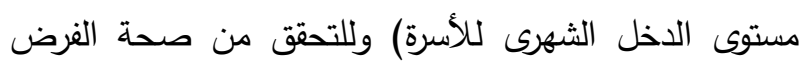

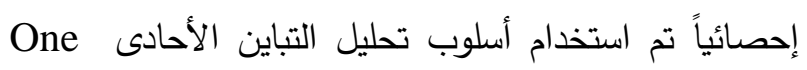
Way Anova الفروق إن وجدت وفقاً لمتغيرات البحث (السابقة الذكر). جدول ( • ب) يوضح ذلك
إختبار T test للوقوف على دلالة الفروق بين متوسطات درجات عينة البحث من الأبناء وفقاً (للمتغيرات سابقة الذكر ). جدول (9 ץ) يوضح ذلك

يتضع من نتائج جدول (Yq) بالنسبة لجنس الأبناء: وجود فروق دالة إحصائياً بين متوسطات درجات الأبناء عينة البحث فى الرهاب الاجتماعى تبعاً لجنس الأبناء، حيث

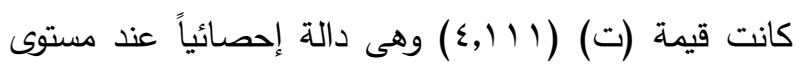
(1, (•) لصالح الإناث، حيث سجل الأبناء المراهقين من الإناث مستوى أقل من المتوسط الحسابى بالمقارنة من الإناء الأبناء المراهقين من الذكور. وقد يرجع ذلك إلى الحساسية الثديدة لأغلب الإناث والتى تجعلهن أكثر تأثراً من الذكور فى المواقف المختلفة، بالإضافة للبيئة النفسية والاجتماعية التى تتشأ فيها الإناث وتكون مليئة بمزيد من المخاوف والقلق عليها الأمر الذى قد يؤدى بها إلى الرهاب الاجتماعى فى فئه كثير من المواقف. تتقق هذه النتيجة مع نتيجة دراسة زينب

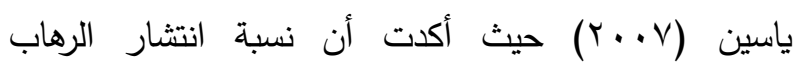
الاجتماعى لاى الإناث أعلى من الذكور ، وتختلف مع نتيجة

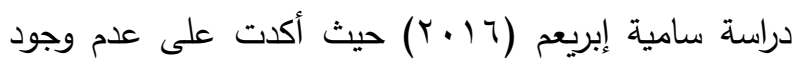
فروق تعزى للجنس فى الرهاب الاجتماعى. بالنسبة لمكان السكن يتضح من نتائج جدول (جq): وجود فروق دالة إحصائياً بين متوسطات درجات الأبناء المراهقين عينة البحث فى الرهاب الاجتماعى تبعاً لمكان السكن حيث كانت قيمة (ت) (-001, (r,01) وهى دالة إحصائياً عند مستوى (1 (.,.•) وذلك لصالح الأبناء المراهقين قاطنى الريف، حيث سجل إهل 
جدول · r. تحليل التباين أحادى الإتجاه للفروق بين متوسطات درجات الأبناء عينة البحث فى الرهاب الاجتماعى تبعاً (للترتيب بين

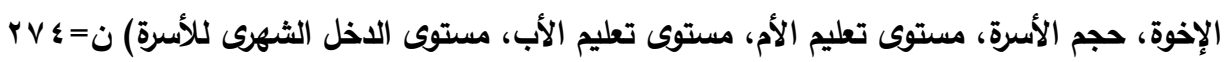

\begin{tabular}{|c|c|c|c|c|c|c|}
\hline مستوى الدلالة & قيمة ف & متوسط المربعات & درجات الحرية & مجموع المربعات & مصادر التباين & متغيرات البحث \\
\hline דا (Y, · غير دالة & $1,0 \leqslant 1$ & $\begin{array}{l}01,91 \\
r, V Y \leq\end{array}$ & $\begin{array}{l}r \\
r v i \\
r v r\end{array}$ & $\begin{array}{l}1 . r, 909 \\
91 r q, 1 r 1 \\
9 r \leqslant r, \cdot 1\end{array}$ & داخل المجموعات المجوعات & الترتيب بين الإخوة \\
\hline ד צ , ••غير دالة & I,YTr & $\begin{array}{l}\varepsilon, r, r \\
r, A, r\end{array}$ & $\begin{array}{l}r \\
r v i \\
r v r\end{array}$ & $\begin{array}{l}\wedge r, T \vee r \\
q 17 \cdot, \varepsilon \cdot \wedge \\
q r \leq r, \cdot \wedge\end{array}$ & داخل المجموعات المجوعات & حجم الأسرة \\
\hline دالة عند ا +,., & $\mathrm{V}, 90 \mathrm{r}$ & $\begin{array}{l}\text { Y0T,Y IT } \\
\text { Tr,YIT }\end{array}$ & $\begin{array}{l}r \\
r v i \\
r v r\end{array}$ & $\begin{array}{c}01 Y, \varepsilon r T \\
A V T \cdot, T \leqslant V \\
9 Y \leq T, \cdot 1\end{array}$ & داخل المجموعات المجوعات & مستوى تعليم الأم \\
\hline دالة عند ا +,, & 0,101 & $\begin{array}{l}179, Y 01 \\
r Y, \wedge 01\end{array}$ & $\begin{array}{l}\text { r } \\
r R \\
r V T\end{array}$ & $\begin{array}{l}r r \wedge, 0 \cdot 1 \\
\wedge q . \leq, 0 \vee q \\
q r \leq r, \cdot 1\end{array}$ & داخل المجموعات المجموعات & مستوى تعليم الأب \\
\hline دالة عند ا •,. & $\varepsilon, \wedge \ldots$ & $\begin{array}{l}\text { lo1, I ro } \\
r r, 9 \leq\end{array}$ & $\begin{array}{l}\text { r } \\
r R \\
r V t\end{array}$ & 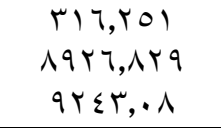 & داخل المجموعات المجوعات & الشهرى للأسرى الاخل \\
\hline
\end{tabular}

الرهاب الاجتماعى بين الأبناء الذين يأتون من أسر كبيرة الحجم أعلى من الأبناء الذين يأتون من أسر صغيرة الحجم. بالنسبة لمستوى تعليم الأم، مستوى تعليم الأب يتضح وجود الابناء لئن تباين دال إحصائياً بين متوسطات درجات الأبناء المراهقين عينة البحث فى الرهاب الاجتماعى تبعاً للمستوى التعليمى

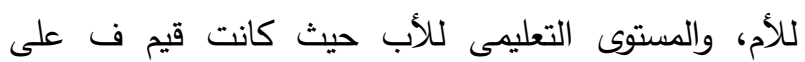
التوالى ( ( ),901)، (0,101) وهى قيم دالة إحصائياً عند مستوى (1 (,.•)، كما يتضح بالنسبة لمستوى الاخل الثهرى للأسرة وجود تباين دال إحصائياً بين متوسطات درجات الأبناء المراهقين عينة البحث فى الرهاب الاجتماعى تبعاً

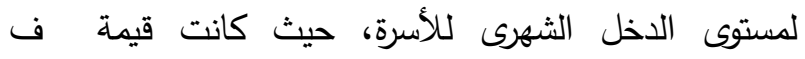

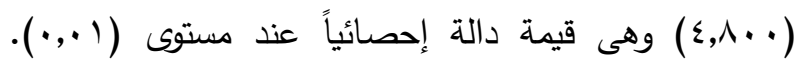
ولمعرفة إتجاه الفروق تم تطبيق إختبار LSD فى كلٍ من

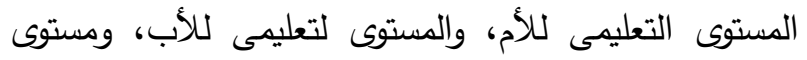
الاخل الشهرى للأسرة. جدول (اس) يوضح ذلك.
يتضح من نتائج جدول (·r) بالنسبة للترتيب بين الإخوة: عدم وجود تباين دال إحصائياً بين متوسطات درجات عينة البحث من الأبناء المراهقين فى الرهاب الاجتماعى تبعاً للترتيب بين الإخوة حيث كانت قيمة ف (1 (1,0) وهى غير دالة إحصائياً. وتتفق هذه النتيجة مع نتيجة دراسة فواز المومنى، عبد الكريم جرادات (1) (1) حيث أكدا على عدم وجود تباين فى مستوى الرهاب الاجتماعى بين الأبناء تعزى لمتغير الترتيب بين الإخوة. بالنسبة لحجم الأسرة يتضح عدم وجود تباين دال إحصائياً بين متوسطات درجات الأبناء المراهقين عينة البحث فى الرهاب الاجتماعى تبعاً لحجم الأسرة، حيث كانت قيمة ف (ITYM, (I) وهى غير دالة إحصائياً. وقد يرجع ذلك إلى أن الرهاب الاجتماعى ليس

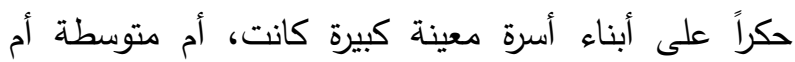
صغيرة الحجم، فبمقدار الترابط والإنسجام الأسرى، والتفاهم بين أفراد الأسرة؛ يكون له عظيم الأثر على الأبناء. وقد اختلفت هذه النتيجة مع نتيجة دراسة كلٍ من فواز المومنى، عبد الكريم جرادات (1) (1) حيث أكدا أن نسبة انتشار 
جدول اس. اختبار LSD لمعرفة دلالة الفروق بين متوسطات درجات الأبناء عينة البحث فى الرهاب الاجتماعى تبعاً لكلٍ من (المستوى

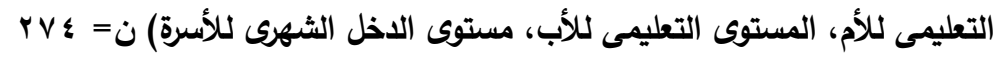

\begin{tabular}{|c|c|c|c|c|c|c|c|c|c|}
\hline \multicolumn{3}{|c|}{ مستوى تعليم الأم } & \multirow[t]{2}{*}{ ن } & \multirow{2}{*}{ المستويات } & \multicolumn{3}{|c|}{ مستوى تعليم الأب } & \multirow[t]{2}{*}{$\dot{0}$} & \multirow{2}{*}{ المستويات } \\
\hline$r \cdot, 1 \Lambda=p$ & $r V, Y 0=p$ & $r q, q \wedge=p$ & & & $r q, \leqslant \Lambda=p$ & $Y V, O_{0}=p$ & $r V, \cdot \varepsilon=p$ & & \\
\hline \multirow{8}{*}{-} & & & 19 & منخفض & & & - & vo & منخفض \\
\hline & & - T>01.- & 90 & متوسط & & & $\cdot, \leqslant \uparrow \ldots-$ & $V 4$ & متوسط \\
\hline & "r,oro- & "r.,.- & 9. & مرتفع & - & $" 1.9 \vee 9 \vee-$ & "r, & Tr & 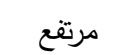 \\
\hline & & & & & \multicolumn{3}{|c|}{ مستوى الاخل الشهرى للأسرة } & ن & \\
\hline & & & & & $r q, 1 r=p$ & $\langle\wedge, \wedge l=5$ & r4,7q= & & \\
\hline & & & & & & & - & $\Lambda 4$ & منخفض \\
\hline & & & & & & & $* r,|r| r-$ & גז & متوسط \\
\hline & & & & & & - & $" r, \varepsilon r \vee \wedge-$ & 1.0 & 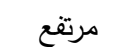 \\
\hline
\end{tabular}

البحث فى الرهاب الاجتماعى تبعاً للمستوى التعليمى للأب

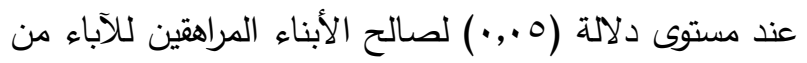
ذوى التعليم المنخفض، حيث وجد أن الأبناء المراهقين للآباء من ذوى التعليم المنخفض، والمتوسط كانوا أكثر شعوراً بالرهاب الاجتماعى من الأبناء المراهقين للآباء من ذوى دئ التعليم المرتفع، ولم تظهر فروق بين الأبناء المراهقين للآباء من ذوى التعليم المنخفض، والتعليم المتوسط. وقد ترجع هذه النتيجة إلى أن المستوى التعليمى المنخفض للأب يجعله

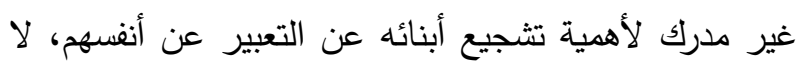

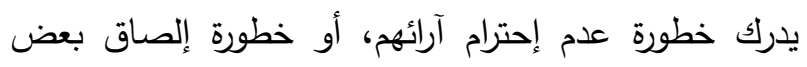

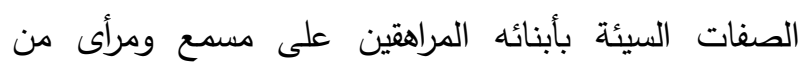
الآخرين، مما يُزيد من شعور أبنائه بالضعف، والرغبة فى لى تجنب المواقف الاجتماعية؛ لعدم قدرتهم على المواجهة الأمر الذى يُساهم فى نشأة الرهاب الاجتماعى لايهم. تتقق هذه النتيجة مع نتيجة دراسة كلٍ من فواز المومنى، عبد الكريم

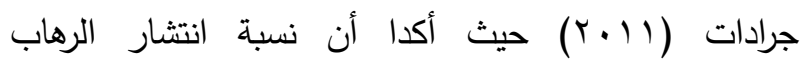
الاجتماعى لدى الطلبة الذين آبائهم فى مستوى تعليمى منخفض أعلى من الطلبة الذين آبائهم فى مستوى تعليمى

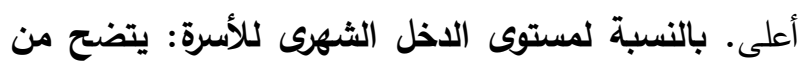

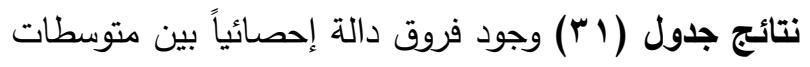

\section{يتضع من نتائج جدول (l) بالنسبة لمستوى تعليم}

الأم: وجود فروق دالة إحصائياً بين متوسطات درجات عينة البحث من الأبناء فى الرهاب الاجتماعى عند مستوى دلالة (0., (•) تبعاً لمستوى تعليم الأم لصالح الأبناء المراهقين للأمهات ذوات التعليم المنخفض، حيث وجد أن الأبناء المراهقين للأمهات ذوات التعليم المنخفض، والمتوسط كانوا أكثر شعوراً بالرهاب الاجتماعى عن الأبناء المراهقين للأمهات ذوات التعليم المرتفع، ولم تظهر فروق بين الأبناء المراهقين للأمهات ذوات التعليم المنخفض، والتعليم المتوسط. وقد ترجع هذه النتيجة إلى أن المستوى التعليمى المنخفض دولت

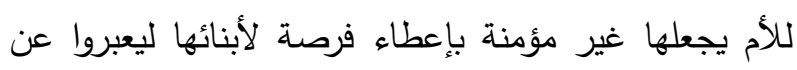

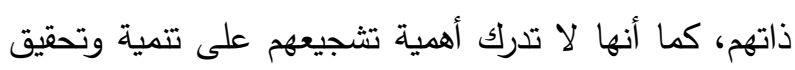
شخصيتهج، بالإضافة إلى الإفراط فى العقاب حال عدم تنفيذ

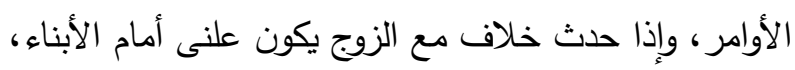
الأمر الذى يُساهم فى تكوين الرهاب الاجتماعى عند الأبناء. تتفق هذه النتيجة مع نتيجة (1995) Chapman et al حيث أكدوا على أن معدلات الرهاب الاجتماعى تكون أكثر انتشاراً

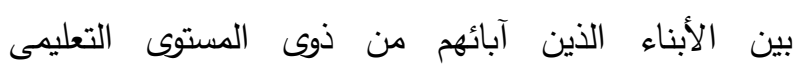
المنخفض. بالنسبة لمستوى تعليم الأب يتضح وجود فروق لين دالة إحصائياً بين متوسطات درجات الأبناء المراهقين عينة 
- - مبذلك يكون الفرض السادس قد تحقق جزئياً. توصيات البحث: في ضوء نتائج البحث تم التوصل إلى

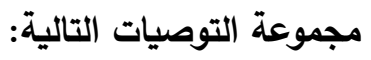

1- مساهمة وسائل الإعلام فى تقديم برامج حوارية تثقيفية وذلك بإستضافة أساتذة متخصصين فى مجال علم العال فل النفس، والإرشاد الأسرى؛ لتصصير الأزواج بماهية كلٍ من الاغتراب الزواجى، واضطراب الرهاب الاجتماعى الآى لإنى

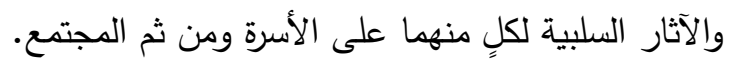
ץ- إعداد برامج إرشادية من قِبل الجهات المعنية بالمرأة (كالمجلس القومى للمرأة، ومكاتب التوجيه والإستشارات

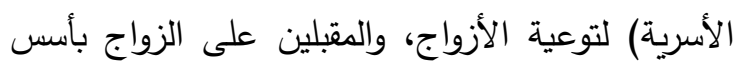

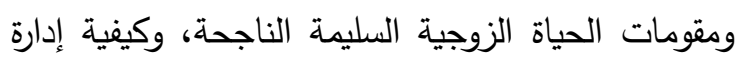
المشاكل ومواجهتها وعدم التهرب منها ؛ وذلك لأهمية التهاية

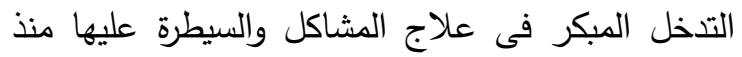
البداية قبل تفاقمها.

ץ- إطلاق قوافل إرشادية من قِبل الجمعيات الأهلية، والحكومية الخاصة بالمرأة تقوم من خلالها رائدات الجمعية، والمساعدات بتبصير الزوجات، والمقبلات على الزواج بسبل تحقيق الكفاءة الإنتاجية فى أداء

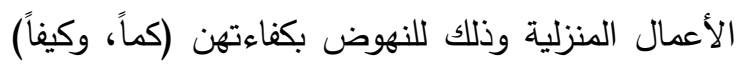
مما يكون له عظيم الأثر على الأسرة وبالتالى المجتمع.

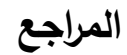

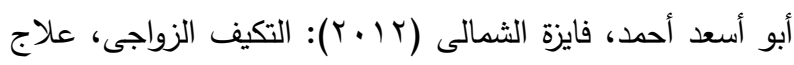
بـ مشكلة زواجية، مركز الأسرة للنشر والتوزيع، الكويت.

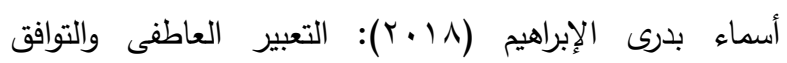

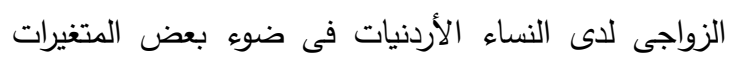

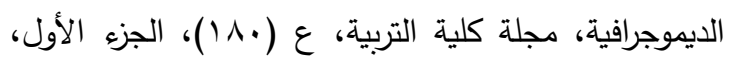

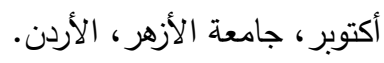

درجات عينة البحث من الأبناء المراهقين فى الرهاب

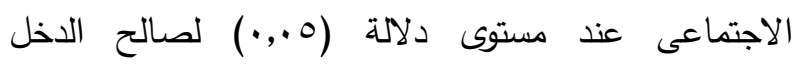

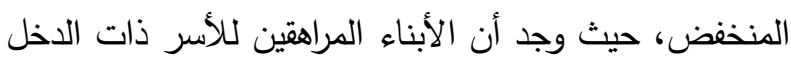
المنخفض كانوا أكثر شعوراً بالرهاب الاجتماعى من الأبناء

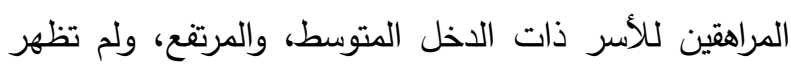

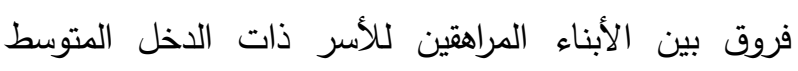

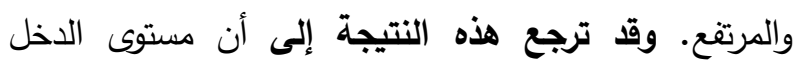

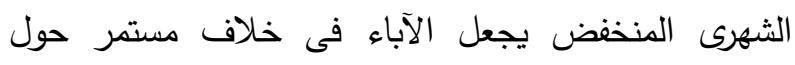

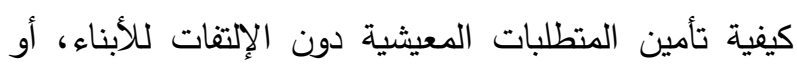
التقاعل معهم، عكس الآباء فى مستوى الدخل الثهرى

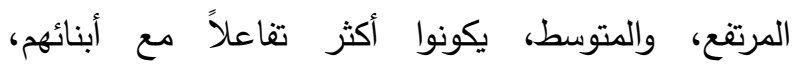

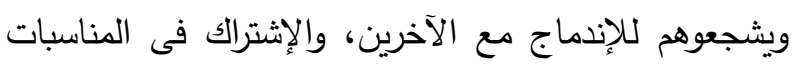

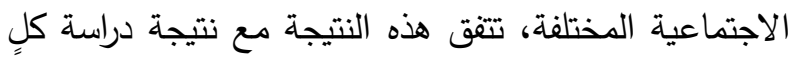
من Chapman et al (1995) حيث أكدوا على أن معدلات

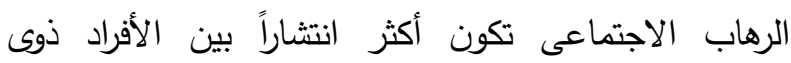

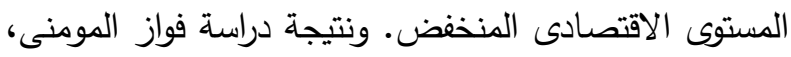

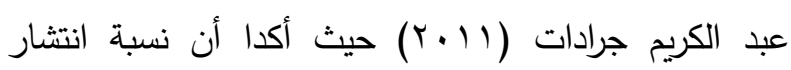
الرهاب الاجتماعى لدى الطلبة الذين يأتون من أسر دخلها

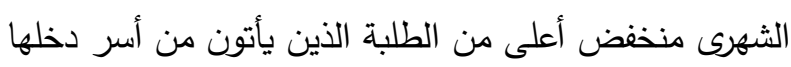

$$
\text { الثهرى متوسط أو مرتفع. }
$$

- - نستخلص مما سبق: عدم وجود تباين دال إحصائياً بين متوسطات درجات عينة البحث من الأبناء المراهقين فى الرهاب الاجتماعى تبعاً لكلٍ من (الترتيب بين الإخوة،

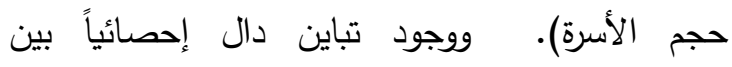
متوسطات درجات الأبناء المراهقين عينة البحث فى تئي

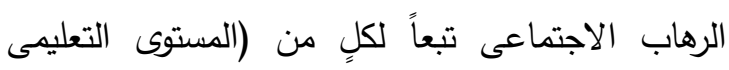

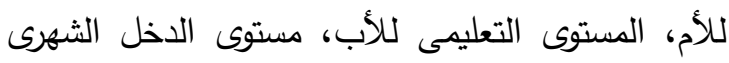

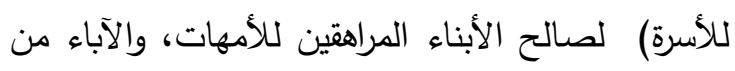
ذوى المستوى التعليمى المنخفض، الأبناء المراهقين

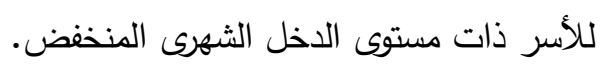




$$
\text { مجلة الإسكندرية للتبادل العلمى - (مجلد \& العدد () يناير - مارس IY.r }
$$

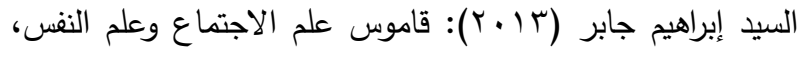
ط (1)، دار البداية ناشرون وموزعون، عمان، المملكة الإنة

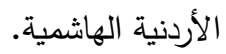

حاتم يونس محمود (· ( • (ب): الخلافات الزوجية وانعكاساتها على الأسرة، دراسة ميدانية فى مدينة الموصل، مجلة دراسات موصلية، ع (·r)، الموصل، العراق.

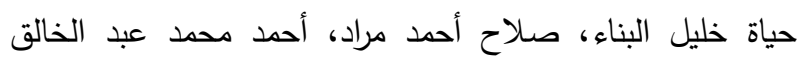

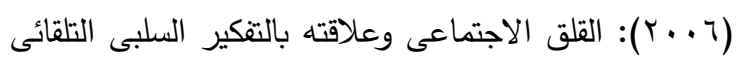

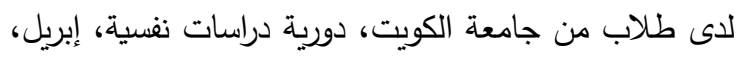

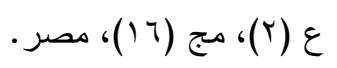

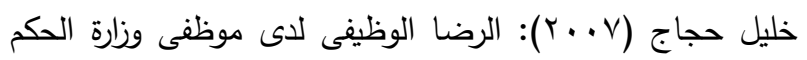

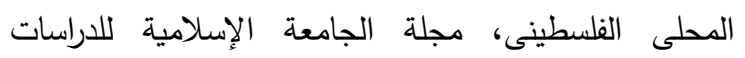

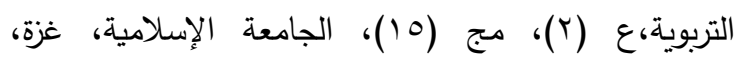
فلسطين. خولة السبتى (؟ . . Y): مشكلات المراهقة الاجتماعية، والنفسية، والدراسية، رسالة ماجستير غير منشورة، كلية الآداب، قسم الخدمة الاجتماعية، جامعة الملك سعود، السعودية.

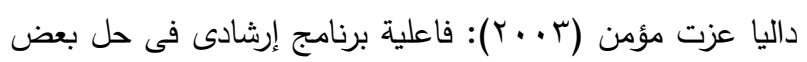
المشكلات الزواجية لدى عينة من المتزوجين حديثاً، رسالة دكتوراه، كلية الآداب، جامعة المنصورة، مصر • ربيع محمود نوفل (r . . r): أسلوب الأسرة فى إدارة الدخل المالى

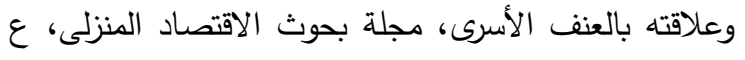

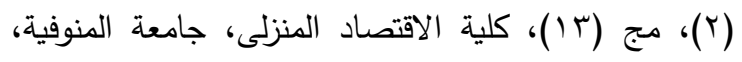
شبين الكوم، مصر .

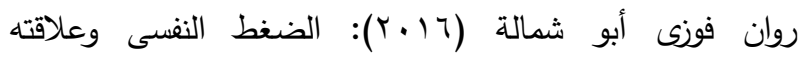
بالاغتراب الزواجى لاى عينة من الزوجات العاملات فى لونى

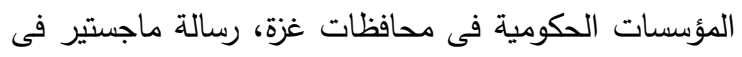
الصحة النفسية المجتمعية، كلية التربية، الجامعة الإسلامية،

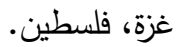

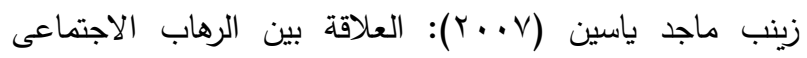
وتقدير الذات لدى عينة من طلاب الجامعة الأردنية، رسالة ماجستير ، كلية الدراسات العليا، الجامعة الأردنية، الأردن.

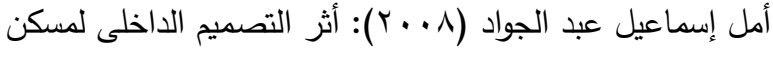

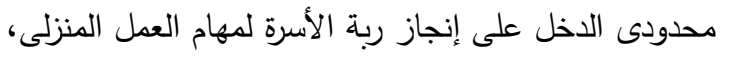
رسالة ماجستير، كلية الإقتصاد المنزلى، جامعة المنوفية،

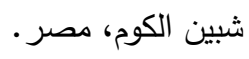

أنوار مجيد هادى (Y ( • ץ): أسباب الطلاق العاطفى لدى الأسر

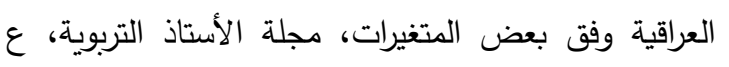
(Y (Y)، كلية التربية، جامعة بغداد، العراق.

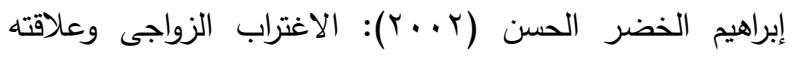

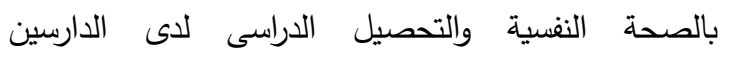
المتزوجين فى الجامعات السودانية بولاية الخرطوم، رسالة ماجستير، كلية التربية والدراسات الإنسانية، جامعة أفريقيا

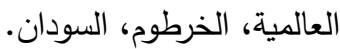
إيمان السيد محمد (T ( †): أساليب التفاوض فى الأسر حديثة التكوين من وجهة نظر الزوجات وعلاقتها بالكدر الزواجى، مجلة بحوث التربية النوعية، ع (1) (ع)، يناير ، كلية التربية

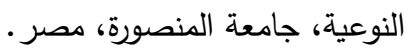

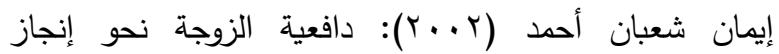
مسؤلياتها وأثر ذلك على كفاءتها الإدارية، رسالة دكتوراه غير منشورة، كلية الاقتصاد المنزلى، جامعة المنوفية،

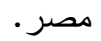

إيمان شعبان أحمد (9 . . ץ): إدارة موارد الأسرة للزوجة العاملة

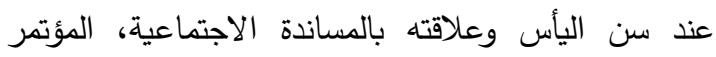

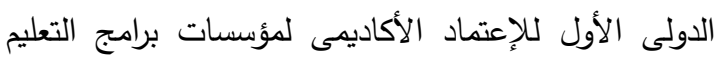

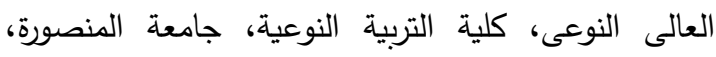

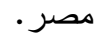
إيمان عبيد الرفاعى (9 ( ب): الصمت الزواجى وعلاقته بالرضا

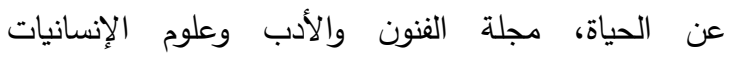
والإجتماع، ع (0؛) نوفمبر، كلية الإمارات للعلوم التربوية،

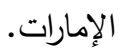

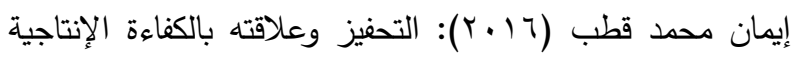

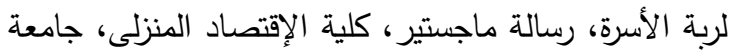

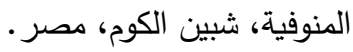


عايدة محمد نور (T/ (Y): اضطراب ضغوط ما بعد الصدمة وعلاقته بالرهاب الاجتماعى لدى النساء بمراكز الإيواء بدولة

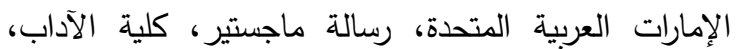
جامعة الخرطوم، السودان.

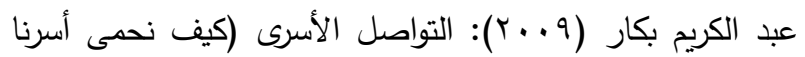

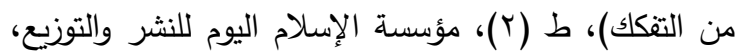

الرياض، المملكة العربية السعودية.

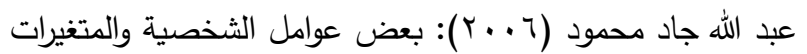

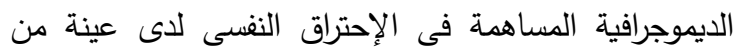

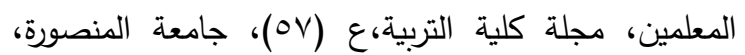

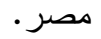

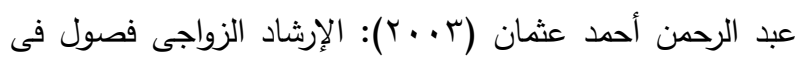
"الإختيار والسعادة والاغتراب الزواجى"، دار جامعة أفريقيا العالمية للطباعة، السودان.

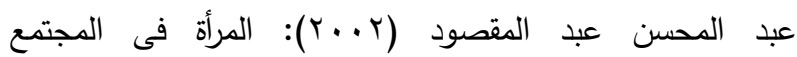
المعاصر ، دار العلم والثقافة، القاهرة.

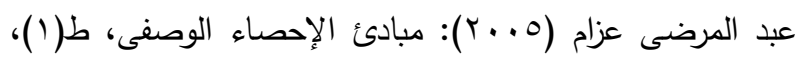

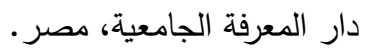

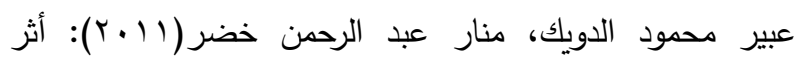
استخدام ربات الأسر لبعض الأجهزة المنزلية الحديثة على لهن

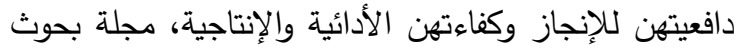

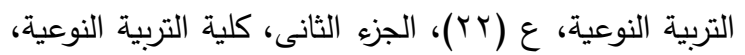

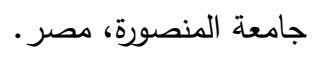

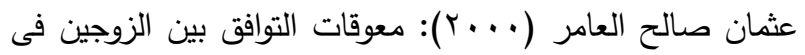
ظل التحديات الثقافية المعاصرة للأسرة المسلمة، مجلة كلية

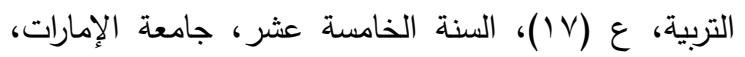
الإمارات.

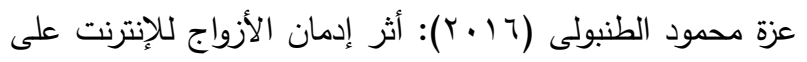
الاغتراب الزواجى لديهم من منظور الممارسة العامة للخدمة

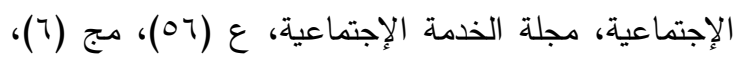
يونيو الجمعية العربية للأخصائيين الإجتماعيين، مصر.

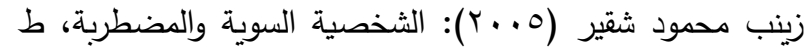

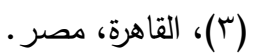

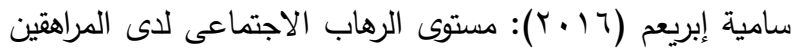

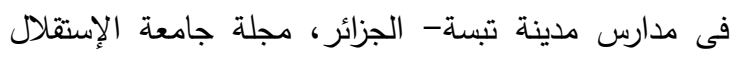

$$
\text { للأبحاث، ع(ب)، مج (1) (1)، الجزائر. }
$$

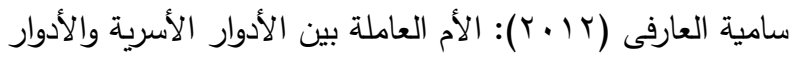

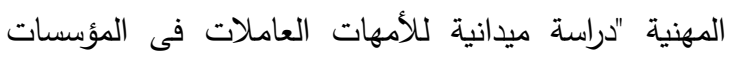
العمومية- البويرة"، رسالة ماجستير غير منشورة، معهد

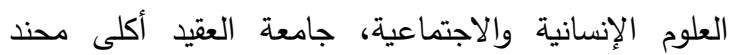

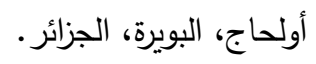

سلوى العضيدان (Y ( †): الطلاق الصامت، صحيفة الاقتصادية

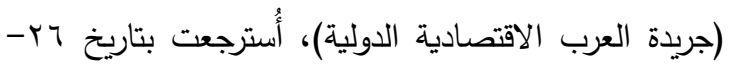

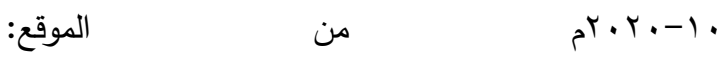
http://www.aleqt.com/2012/10/18/article_702721.h tml

سناء محمد سليمان (0 . . †): التوافق الزواجى واستقرار الأسرة من منظور إسلامى، نفسى، اجتماعى، ط (1)، عالم الكتب،

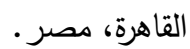
صفاء عادل مدبولى (ع . . ץ): ممارسة نموذج الحياة فى التخفيف

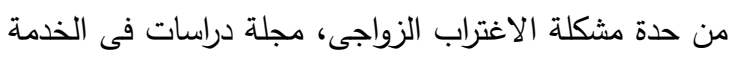

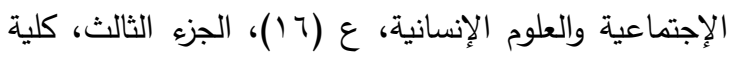
الخدمة الإجتماعية، جامعة حلوان، مصر . صلاح الدين محمد عبد الباقى (1 (. ب): إدارة الموارد البشرية،

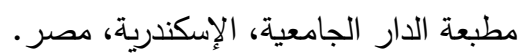
صلاح مراد، أحمد عبد الخالق ( (.....): الدافع للإنجاز وعلاقته ببعض المتغيرات الثخصية "دراسة تتبؤية"، مجلة علم النفس المعاصر والعلوم الإنسانية، كلية الآداب، جامعة المنيا.

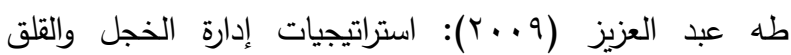
الاجتماعى، دار الفكر، عثمان.

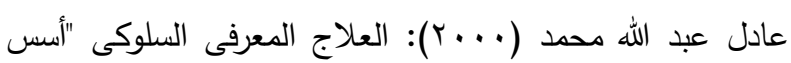
وتطبيقات"، دار الرشاد، القاهرة. 


$$
\text { مجلة الإسكندرية للتبادل العلمى - (مجلد بع العدد () يناير - مارس اY.r }
$$

محمد الطاهر طعبلى، سميرة عمامرة (乏) (ب): علاقة الإتصال

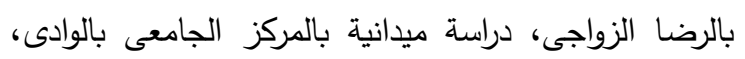

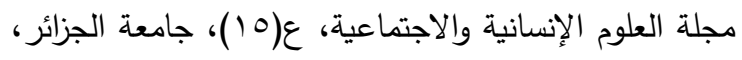
الجزائر

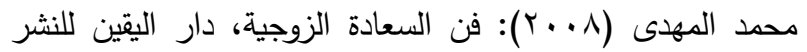

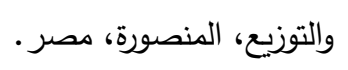

محمد خطاب (1) ب (1): الطلاق العاطفى بين التشخيص والعلاج،

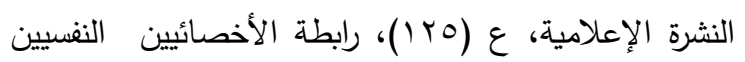

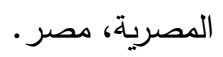

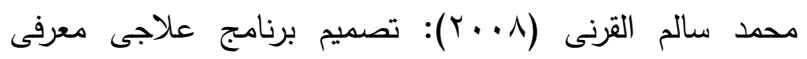
سلوكى لتخفيف مستوى الكدر الزواجى، مطابع جامعة الإمام

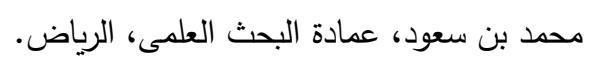

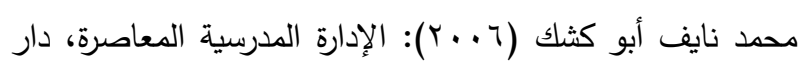

$$
\text { جرير للنشر والتوزيع، عمان، الأردن. }
$$

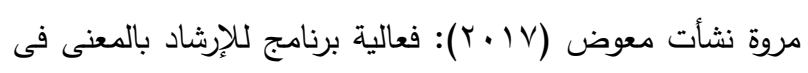

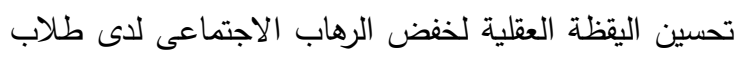

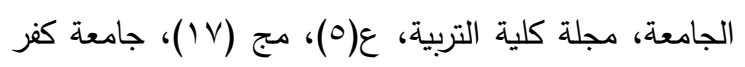

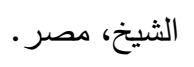

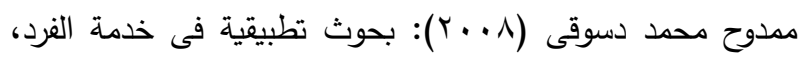

$$
\text { المكتب الجامعى الحديث، الإسكندرية. }
$$

منار خضر، رانية على (r (Y): الوعى بمتطلبات التصميم الداخلى للمطبخ وعلاقته بتطبيق أسس تبسيط العمل المنزلى،

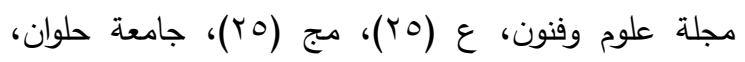

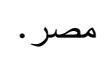

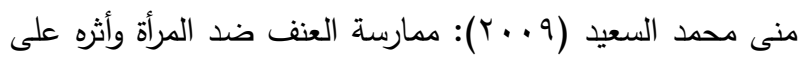
أداء أدوارها الأسرية، رسالة ماجستير غير منشورة، كلية

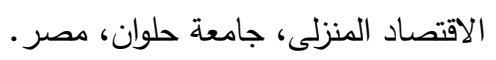

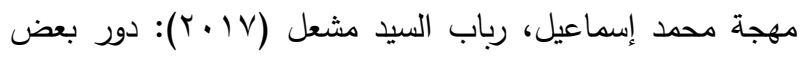

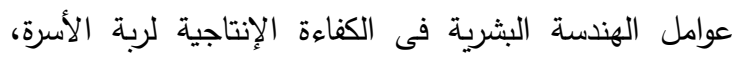
المؤتمر العلمى الدولى الخامس "التعليم وريادة الأعمال

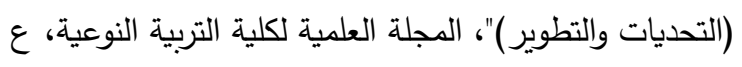
(·) (1)، مج (1)، كلية التربية النوعية، جامعة المنوفية، شبين
عماد على عبد الرازق، نهى عبد الله الراجح (T (ب): الاغتراب

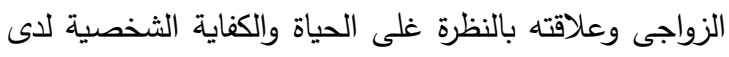

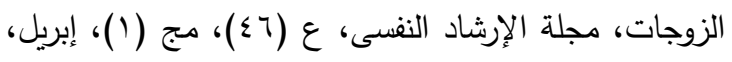

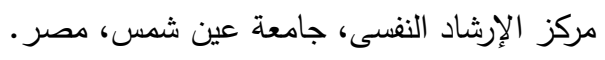
فاتتة حماد سعيد ديبه (r ( • ب): الإدراكات المتبادلة بين الزوجين

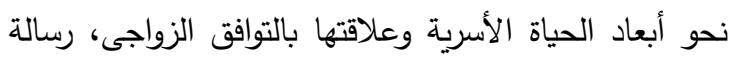

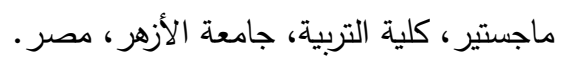

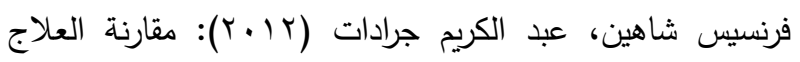
العقلانى الإنفعالى السلوكى بالتدريب على على المهارات

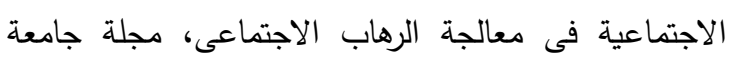

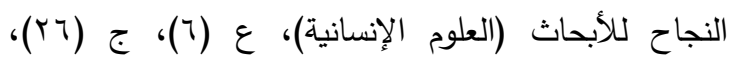
جامعة النجاح الوطنية، فلسطين. فطيمة ونوغى (ع ا • Y): أثر سوه التوافق الزواجى فى تكوين الميل إلى الأمراض النفسية لدى المرأة من خلال تطبيق اختبار (MMP12) ، رسالة دكتوراه، كلية العلوم الإنسانية والاجتماعية، جامعة محمد حيضر ، بسكرة، الجزائر.

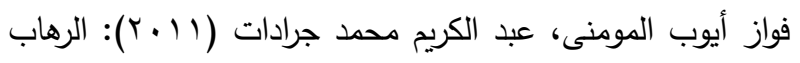

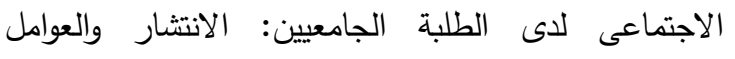

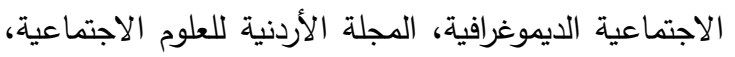

$$
\text { ع (1)، مج (ع)، عمان، الأردن. }
$$

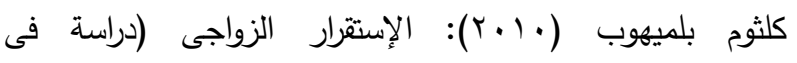

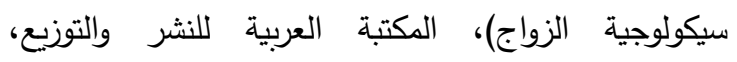

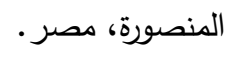

مارجريت رمزى ميخائيل (1 (. ب): الذكاء الوجدانى لدى حديثى الزواج وعلاقته بمهارات التفاوض، رسالة دكتوراه غيري منشورة، كلية الآداب، جامعة المنصورة، المنصورة، مصر .

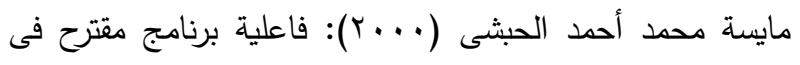
تنمية التحصيل الإبتكارى واكتساب الإتجاهات نحو مادة

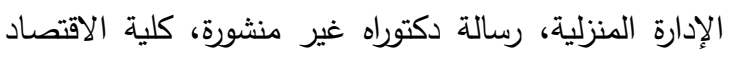

$$
\text { المنزلى، جامعة المنوفية، شبين الكوم، مصر . }
$$
محسن الخضيرى (.... (ب): الإدارة التتافسية للوقت- المنظومة المتكاملة لإمتلاك المزايا التتافسية الثاملة فى عصر العولمة العدان

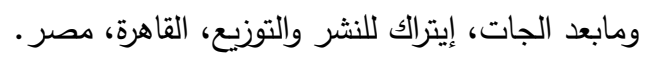




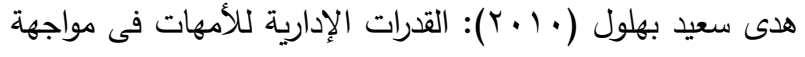

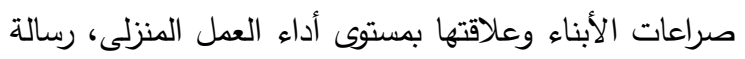

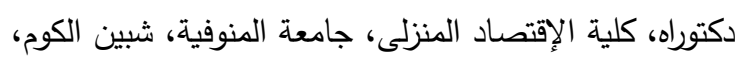

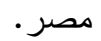

وفاء أحمد عبد الله الزهرانى (9 . . r): وعى ربات الأسر بمقومات الكفاءة الإدارية، الهاى للنشر والتوزيع، الكويت.

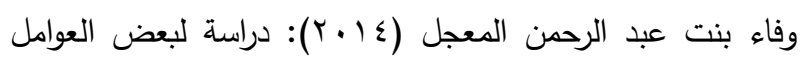

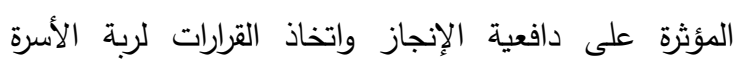

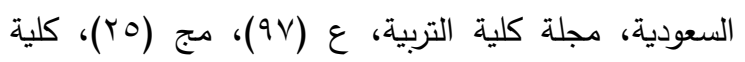

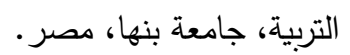

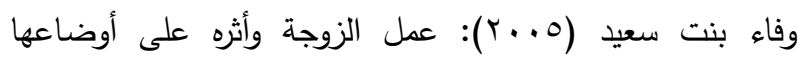

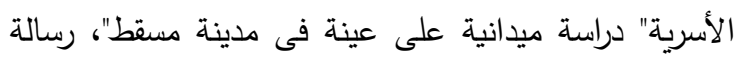

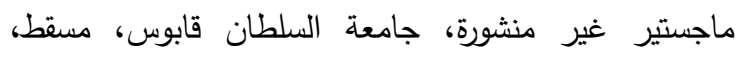

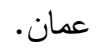

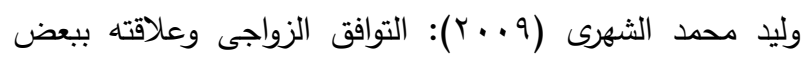

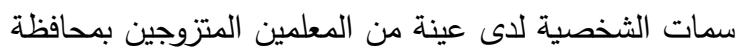

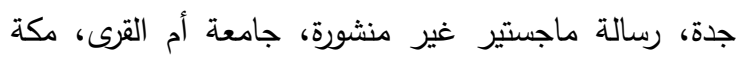

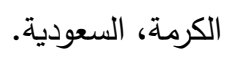

Ackerman, D. S., \& Gross,.B.L. (2005): My instructor made me do it: task characteristics of procrastination. Journal of marketing education, 27 (1),5-13.

Baker, A.(2005): The long-term effects of parental alienation on adult children: A qualitative research study, The American Journal of Family Therapy,33.

Bradbury,T. N., Fincham, F. D., \& Beach, S. R. H. (2000): Research on the nature and determinants of marital satisfaction: A decade in review. journal of marriage and family, 62, 964-980.

Chapman TF, Mannuzza S, Fyer AJ. (1995): Epidemiology and family studies of social phobia, In Heimberg RG, Liebowitz MR, Hope DA, Schneier FR, Social phobia diagnosis, Assessment, and Treatment, Guilfor, New York: 21-40.

Chiung, A,\& Shen, T.(2005): Factor in the martial of relationships in a changing society; A Taiwan/Case study- international social work, Durham University.

Conger, R.D., CONGER, K.J., Martin, M.J. (2010): Socioeconomic status, family processes, and individual development. Journal of marriage and family, 72, 685-704.

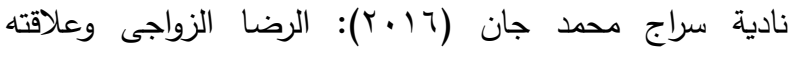
بالتواصل العاطفى وعدد سنوات الزواج وعدد الأبناء والمرحلة العمرية، ع (0)، مج (9) (المجلة التربوية الدولية المتخصصة، كلية التربية، جامعة أم القري، المملكة العربية

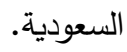
نازك عبد الصمد التركى (9 1 • ب): فاعلية برنامج إرشادى أسرى

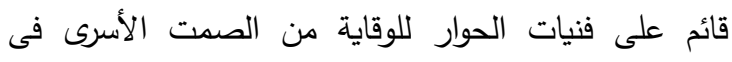

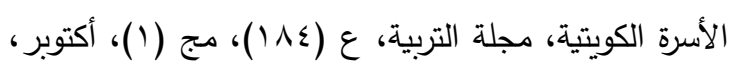
كلية العلوم الاجتماعية، جامعة الأزهر ، الكويت.

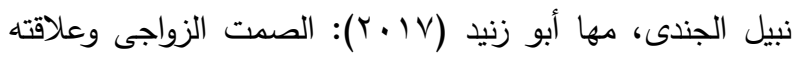

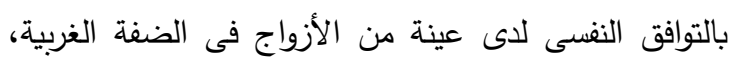

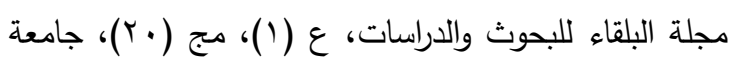

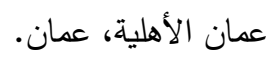

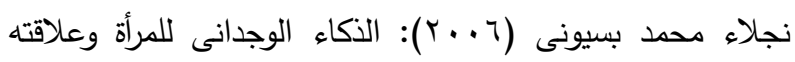

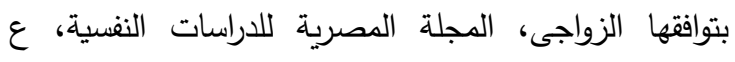

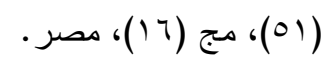
نعمة مصطفى رقبان، ربيع محمود نوفل (ا (. ب): العلاقة بين

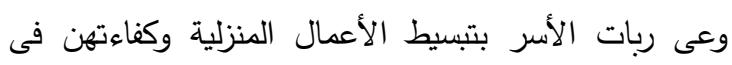

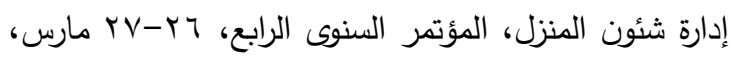

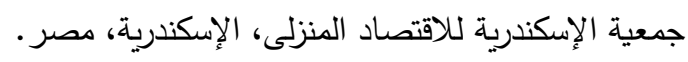

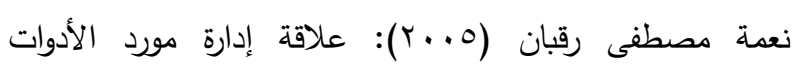

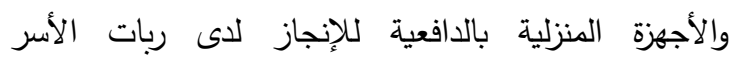

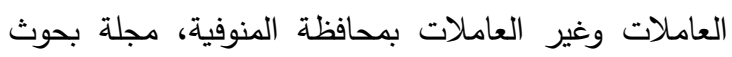

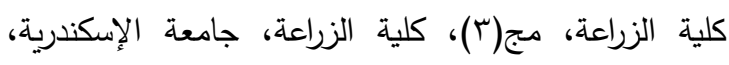
الإسكندرية، مصر.

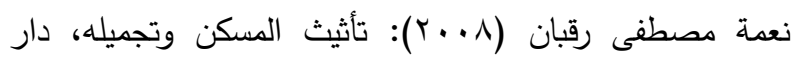

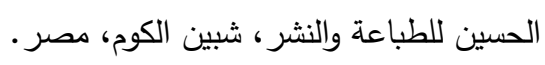

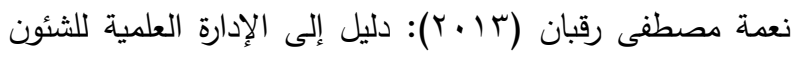

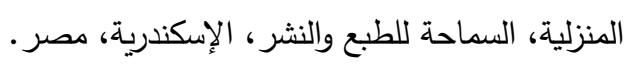

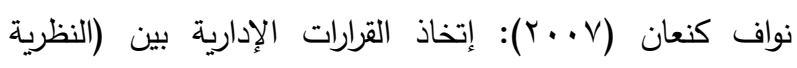
والتطبيق)، دار العلم والثقافة للنشر والتوزيع، عمان، الأردن.

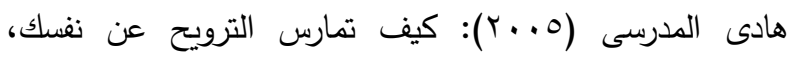
ط(1)، الدار العربية للعلوم ، المركز الثقافى العبى، لبنان. 


$$
\text { مجلة الإسكندرية للتبادل العلمى - (مجلد بـ العدد () يناير - مارس (Y.r }
$$

Pilling, S; Mayo-Wilson, E; Mavranezouli, I; Kew, K; Taylor, C; Clark, D. (2014): Guideline development, group, recognition, assessment and treatment of social anxiety disorder: Summary of NICE Guidance. Cite uses deprecated parameters, 73.

Rapee. R \& Hudson. J (2000): Origins of social phobia, Behavior Modification, Vole: 24,No: 1,P.P:102-129.

Rosenthal, J.(2009): The effect of internet use and treatment sought in individulas diagnosed with social phobia. Dissertation of Ph.D. Walden University.

Scott, J., \& Marshall, G. (2009): A dictionary of sociology. Oxford University Press, Oxford.
Cook, J., \& Crossman, A. (2004): Satifaction with performance appraisal systems: A study of role perceptions. Journal of managerial psychology, 19(5), 526-541.

Froyen, L.C. ; Skibbe , L. E.; Bowlers, R. P.; Blow, A. J. \& Gerde, H. K. (2013): Marital satisfaction, family emotional expressiveness, home learning environments, and children's emergent literacy. Journal of marriage and family, 75 (1), 42-55.

Miley, R (2015): The effect of martial proplems on job performance, P .h.D, University of Florida.

\title{
ABSTRACT \\ Marital Alienation as Perceived by The Wife and Its Relationship to Both Her Productive Efficiency in Performing Household Tasks and the Social Phobia of Her Children
}

\author{
Hanan Hanna Aziz
}

The current research aimed to reveal the relationship between marital alienation as perceived by the wife with its interlocutors (marital silence, poor emotional communication and familiarity, isolation and the inability to participate in marriage) and the overall and both of her productive efficiency in performing domestic tasks and their axes (the desire to perform household tasks, The ability to perform household tasks, satisfaction with performing household tasks, innovation in performing household tasks) and overall, and the social phobia of her children in adolescence. The data was completed through the application of research tools (prepared by the researcher) represented in (the initial data form, marital alienation measure, the measure of productive efficiency in performing household tasks, the social phobia scale for children) on an intentional and purposeful sample of (274) wives, (274) of their teenage children. They belong to different socio-economic levels, from the city of Mansoura, the center of Sinbillawin, the center and the city of Mit Ghamr and some of its villages (Oulaila, Meet Mehsen, Bashla, Tanamil) Among the conditions for selecting the sample was that the wives be (not divorced, widowed, or abandoned), and that their marriage period exceeded ten years, and they had a son / daughter in adolescence from (15-17) years, provided that the son / daughter is not her only one. This research followed the descriptive and analytical method, by conducting appropriate statistical analyzes using SPSS program to draw conclusions. The search resulted in a set of results, the most important of which were: The existence of an inverse correlational relationship statistically significant between marital alienation as perceived by the wives of the research sample with its axes, and the total, and their productive efficiency in their axes and the total, and the existence of a positive statistically significant correlation between marital alienation with its interlocutors and the total of the wives of the research sample and social phobia of their teenage children. There are no differences between their average scores in each of the marital alienation, its axes, the total, their productive efficiency, their axes, and the total according to the place of residence. And the existence of significant differences between their average scores in each of the marital alienation, its interlocutors, and the total, according to the wife's work in favor of non-working women, and the existence of differences in their productive efficiency, their axes, and the total in favor of female workers. There is also a statistically significant discrepancy between their average scores in marital alienation in its interlocutors, and the total according to (the wife's age, the length of marriage, the family size, the educational level of the wife) in favor of the younger age group, the shorter marriage period, the larger family size, and the wife's lower educational level. There is no statistically significant discrepancy between their average scores in marital alienation according to the husband's education level in (the axis of poor emotional communication and familiarity), and the presence of a statistically 
significant discrepancy between their average scores in productive efficiency in performing household tasks, their axes, and the total according to (the wife's age, the duration of marriage, Family size) in favor of (older age group, longer marriage duration, smaller family size). There is no statistically significant discrepancy between their average scores in the axis (satisfaction with performing household tasks) according to the educational level of the wives, and there is no statistically significant discrepancy between their scores on the two axes (desire and satisfaction) in performing household tasks according to the educational level of their husbands. On the other hand, it was found that there are statistically significant differences between the mean scores of adolescent children in the research sample in social phobia according to (the gender of the children, the place of residence), in favor of female children, and the children living in the countryside. Brothers, family size). And the existence of a statistically significant discrepancy between their averages of social phobia according to (the educational level of the mother, the educational level of the father, the level of the monthly income of the family) in favor of the teenage children of mothers, fathers with a low educational level, and a low monthly income level.

In light of the previous results, the researcher suggested a number of recommendations: Contribution of the mass media in providing educational dialogue programs, by hosting professors specializing in psychology and family counseling; To enlighten husbands about the essence of marital alienation, social phobia disorder and the negative effects of each of them. - Preparing counseling programs by bodies concerned with women (such as the National Council for Women and family guidance and counseling offices) to educate husbands and those who are about to marry on the basics and components of a healthy and successful marital life, and how to manage Problems. Launching guiding convoys by civil and governmental associations for women through which the pioneers of the association, and the female assistants, enlighten the wives, and those who want to marry, ways to achieve productive efficiency in the performance of household work in order to improve their efficiency (in terms of quantity and quality), which has a great impact on the family and thus society. 